듬 SCHOOL of GRADUATE STUDIES

EAST TENNESSEE STATE UNIVERSITY
East Tennessee State University Digital Commons@ East Tennessee State University

\title{
Intimate Violence: The Effects of Family, Threatened Egotism, and Reciprocity.
}

Jessica Lynne Holt

East Tennessee State University

Follow this and additional works at: https://dc.etsu.edu/etd

Part of the Criminology and Criminal Justice Commons

\section{Recommended Citation}

Holt, Jessica Lynne, "Intimate Violence: The Effects of Family, Threatened Egotism, and Reciprocity." (2005). Electronic Theses and Dissertations. Paper 994. https://dc.etsu.edu/etd/994

This Thesis - Open Access is brought to you for free and open access by the Student Works at Digital Commons @ East Tennessee State University. It has been accepted for inclusion in Electronic Theses and Dissertations by an authorized administrator of Digital Commons @ East Tennessee State

University. For more information, please contact digilib@etsu.edu. 
Intimate Violence: The Effects of Family, Threatened Egotism, and Reciprocity

\author{
A thesis \\ presented to \\ the faculty of the Department of Criminal Justice and Criminology \\ East Tennessee State University
}

In partial fulfillment

of the requirements for the degree

Master of Arts in Criminal Justice and Criminology

by

Jessica Lynne Holt

May 2005

\author{
Wayne Gillespie, PhD., Chair \\ Marian Whitson, $\mathrm{PhD}$. \\ John Whitehead, $\mathrm{PhD}$
}

Keywords: Intimate Violence, Threatened Egotism, Intergenerational Transmission of Violence, Reciprocity 


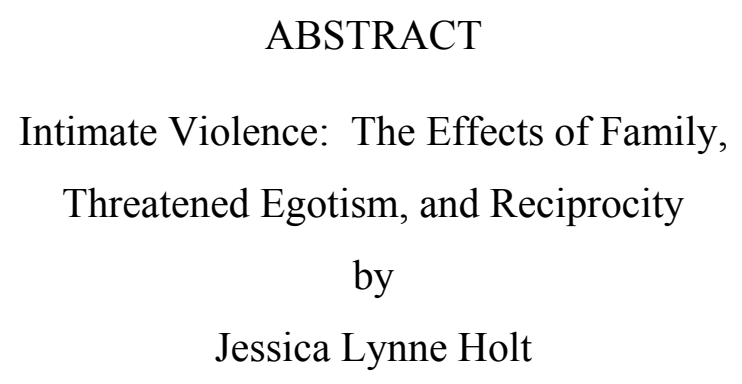

This study was undertaken in an attempt to investigate the impact of family, threatened egotism, and reciprocity on a person's use of intimate violence. Threatened egotism proposes that aggression is the result of high but unstable self-esteem, which is conceptualized as high selfesteem coupled with high narcissism. Self-report questionnaires were administered to randomly selected cluster samples of 423 college students, 147 males and 276 females. The mean age is approximately 22 with 93\% indicating they are White and 7\% non-White. While no support was found for threatened egotism, violence witnessed in the family of origin and reciprocity were found to significantly impact intimate violence. Analyses conducted separately for males and females indicate that these factors operate differently based on gender. 


\section{ACKNOWLEDGEMENTS}

I would like to thank my parents and sister for the continued and unfaltering support that they have given me throughout my life. Without their belief in my ability and their assertion that I could do anything that I wanted, I probably would not have had the courage to undertake a project of this magnitude.

Through my experience as both a graduate student and graduate assistant, I have met so many interesting people. I would especially like to thank Beverly Chadley for being such a wonderful officemate and caring friend. Thank you for always listening to me and helping me to keep things in perspective.

I would also like to thank all of my friends outside of the department. Thank you for your understanding when it must have seemed that I was AWOL with no time for anything but school. I would especially like to thank Karl Turner. You have always believed in me and my ability even when I did not. You have patiently listened when I needed to vent and been a great sounding board. You have been so understanding and supportive and I cannot thank you enough.

Thank you, Dr. Gillespie, for all of your hard work in chairing my committee. You have always given me so much encouragement. Thank you for always taking the time to meet with me and help me with this process.

Thank you, also, to the other members of my committee, Dr. Whitehead and Dr. Whitson. Thanks for all of your work and input that have made this possible. I would also like to thank Dr. Whitson for her support. I have enjoyed working with you as your graduate assistant. You have taught me so much over the past two years and I cannot thank you enough. 


\section{CONTENTS}

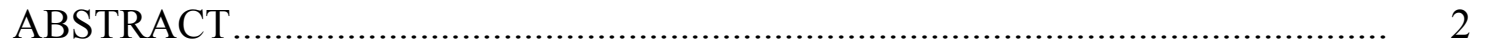

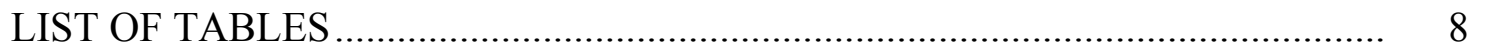

\section{Chapter}

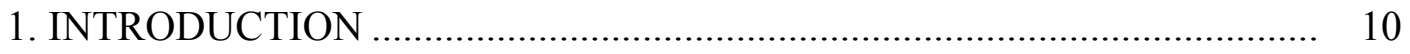

Variations of Intimate Violence........................................................... 10

Measuring Violence ……………………........................................... 13

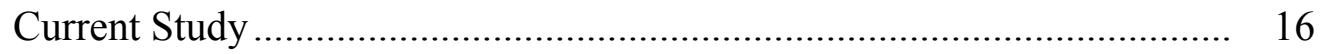

Theoretical Perspective ........................................................................ $\quad 18$

Factors Affecting Intimate Violence ...................................................... 19

Intergenerational Transmission of Violence ..................................... 19

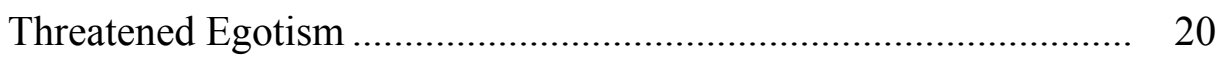

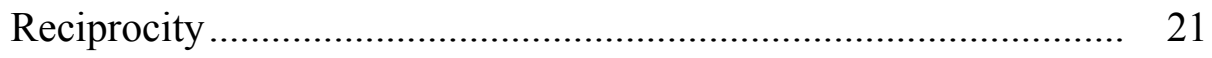

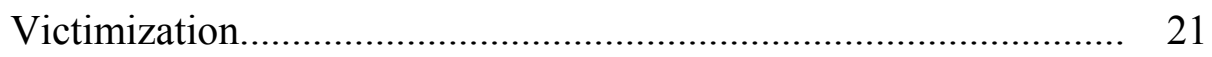

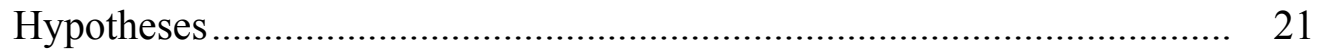

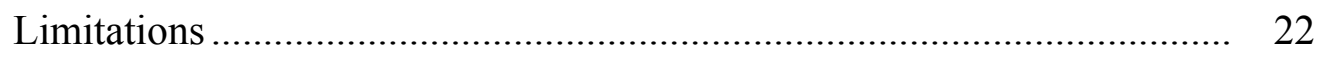

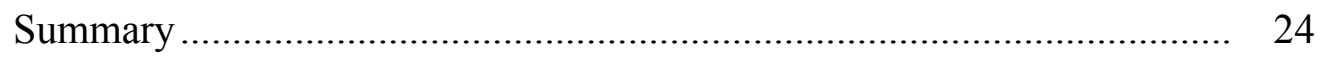

2. LITERATURE REVIEW ............................................................... 25

Theoretical Perspective ...................................................................... 25

Factors Affecting Intimate Violence...................................................... 26 
Factor One - Intergenerational Transmission of Violence .............. 26

Factor Two-Threatened Egotism........................................... 37

Factor Three-The Gendered Nature of Violence......................... 43

Factor Four-Reciprocity ............................................... 50

Victimization............................................................................ 52

Summary ............................................................................. 55

3. METHODOLOGY …................................................................. 56

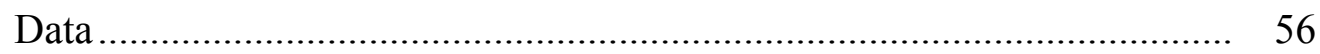

Population ......................................................................... 56

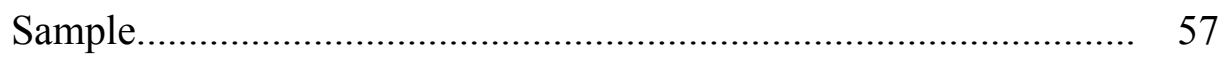

Participants...................................................................... 58

Data Collection .............................................................. 59

Data Collection Instrument ....................................................... 60

Measures .................................................................................. 61

Demographics ................................................................ 61

Conflict Tactics Scale (CTS) ............................................... 61

Rosenberg's Self-Esteem Scale _............................................. 62

Narcissistic Personality Inventory (NPI) ................................. 63

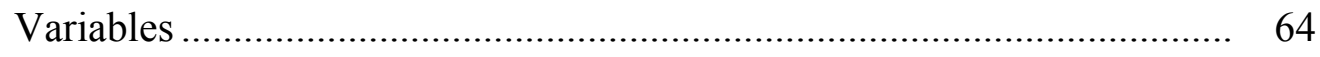

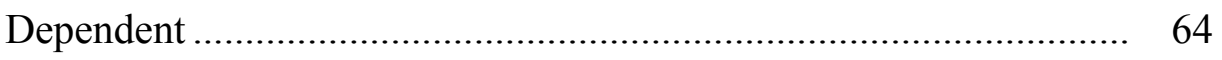

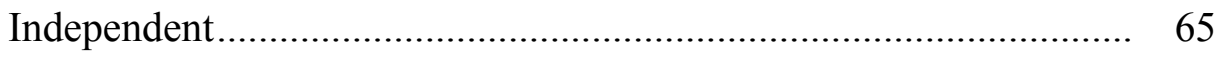

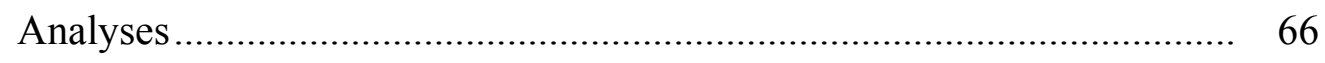

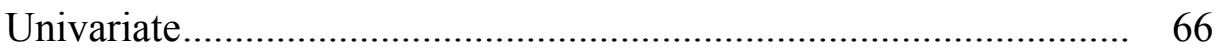




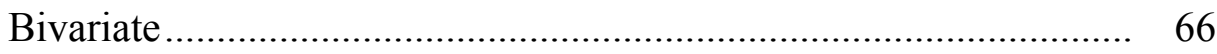

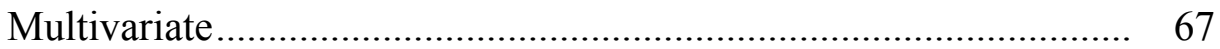

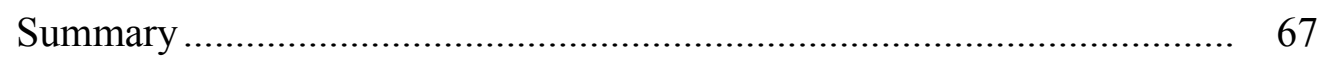

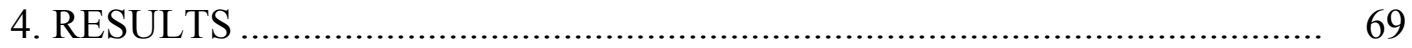

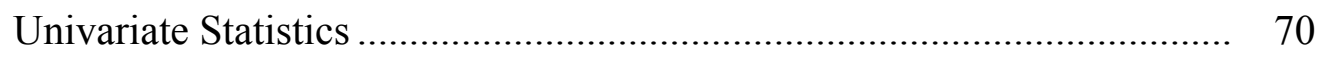

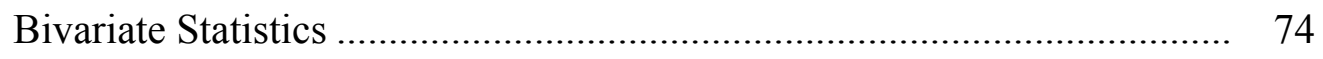

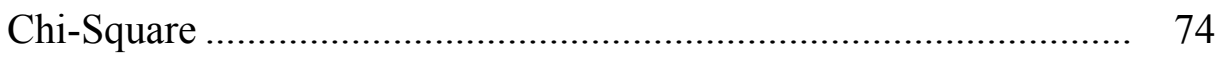

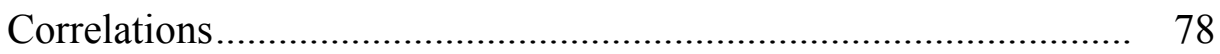

Mean Comparisons …………………....................................... 81

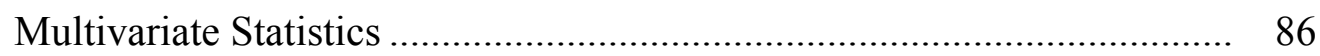

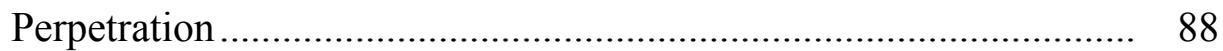

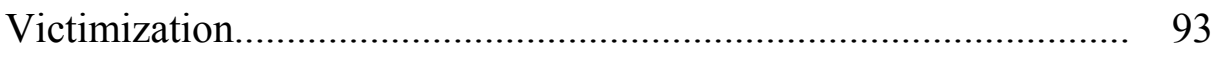

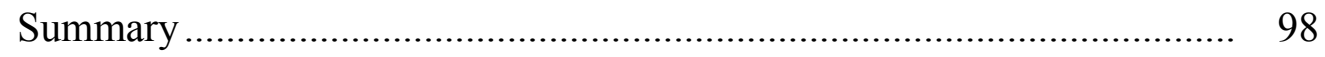

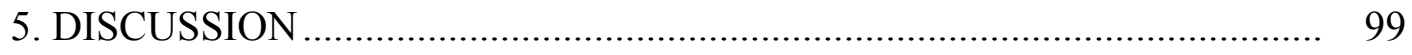

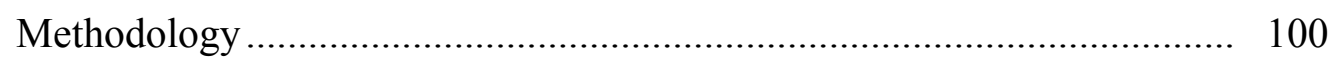

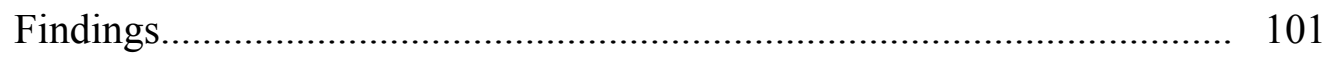

Prevalence of Intimate Violence ....................................................... 101

Gendered Nature of Intimate Violence .............................................. 101

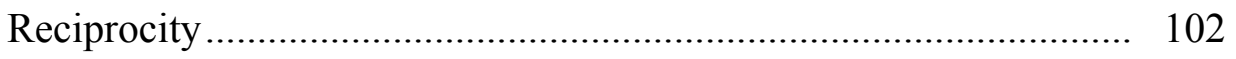

Interparental Violence.................................................................. 103

Threatened Egotism …………………………............................... 104

Predicting Perpetration and Victimization............................................... 105

Predicting Perpetration.................................................................. 106 
Predicting Female Perpetration.......................................................... 106

Predicting Male Perpetration ........................................................ 108

Predicting Victimization ............................................................... 108

Predicting Female Victimization ...................................................... 109

Predicting Male Victimization ........................................................ 109

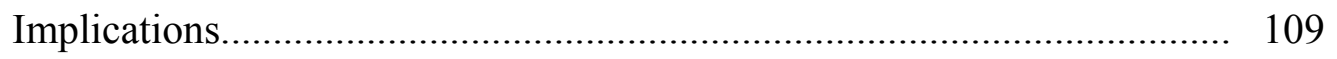

Victimization vs. Perpetration ....................................................... 109

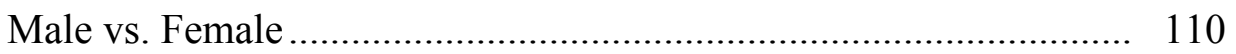

Factors Affecting Intimate Violence................................................ 110

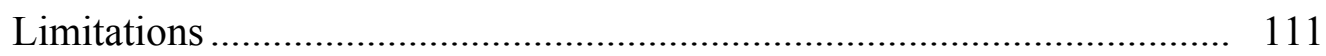

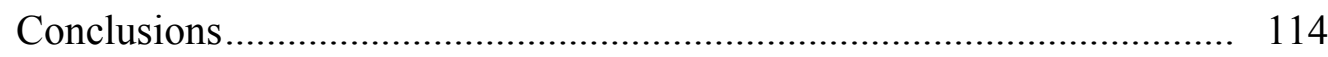

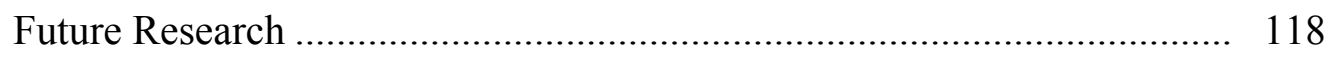

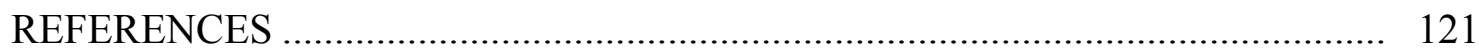

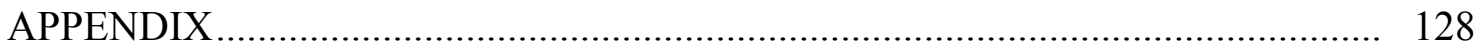

Appendix: Data Collection Instrument ………………….............................. 128

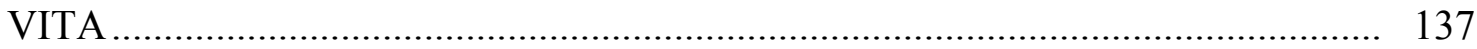




\section{LIST OF TABLES}

Table

Page

1. Frequencies ................................................................................... 71

2. Descriptive Statistics............................................................................. 74

3. Perpetration Cross-Tabs ...................................................................... 75

4. Perpetration Chi-Square Tests for Independence ..................................... 76

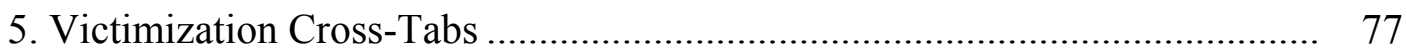

6. Victimization Chi-Square Tests for Independence .................................. 78

7. Pearson Correlation Matrix ............................................................................. 79

8. Perpetration t-Tests ....................................................................... 82

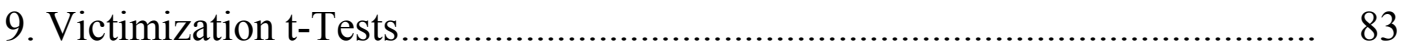

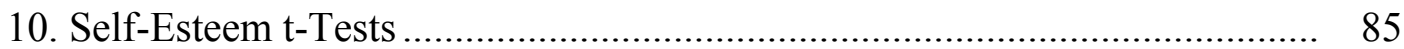

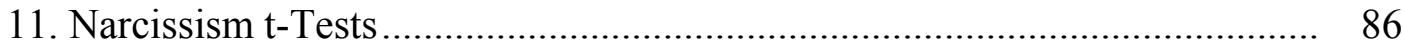

12. Summary of Regression Analysis for Variables Predicting Perpetration of

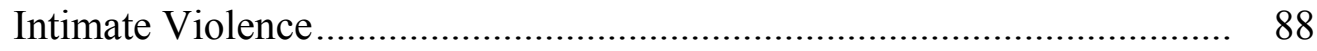

13. Summary of Regression Analysis for Variables Predicting Female

Perpetration of Intimate Violence

90

14. Summary of Regression Analysis for Variables Predicting Male

Perpetration of Intimate Violence

92

15. Summary of Regression Analysis for Variables Predicting

Victimization of Intimate Violence

16. Summary of Regression Analysis for Variables Predicting Female

Victimization of Intimate Violence 
17. Summary of Regression Analysis for Variables Predicting Male

Victimization of Intimate Violence 


\section{CHAPTER 1}

\section{INTRODUCTION}

The problem of violence in American society garners much public attention and myriad theories purporting to identify its causes. Violence has been defined as behavior that is intended to hurt another person (Roark, 1987). Violence is especially harsh when it comes from the hands of a loved one. When someone who is loved and trusted inflicts harm, it becomes difficult to reconcile these two events. In stranger-to-stranger violence, those involved often do not see each other frequently, if ever, after the incident. However, in intimate violence, there are often ties holding the people together. The abused may feel that they have too much invested in the relationship to leave. Even if they do leave, couples often socialize in small circles of friends and they are bound to come in contact with each other again sometime through proximity.

Violence in intimate relationships is a serious problem in our society and deserves public attention. It has been suggested that domestic violence is the most underreported crime in America (Carlson, 1987). The so-called culprits of this epidemic of violence come from many different arenas such as cultural influences, social influences, biology, and personal traits. No one theory can explain all occurrences of violence in society, nor is it feasible to believe that there exists a theory that will fit every person and situation. However, it could be possible to identify different individual factors that increase a person's propensity towards violence. This study was undertaken to assess some factors that are purported to be salient in identifying individuals who are at an increased risk of expressing violence in intimate relationships.

\section{$\underline{\text { Variations of Intimate Violence }}$}

Domestic violence is a problem that has come under increased scrutiny in recent years. According to Tennessee code, domestic violence is violence that involves adults or minors who 
are current or former spouses, live or have lived together, dating or have dated, been involved in a sexual relationship, related by blood or adoption, currently or formerly related by marriage, or an adult or minor child of a person in one of the aforementioned categories (T.C.A. §36-3-601, 2004). In research literature of domestic violence, the term most often is used to identify violence between a husband and a wife. In a national sample of over 2,000 married couples, 325 indicated that they had had at least one violent incident in the past year (Straus, 1980). In spousal abuse, the couple typically has children together and is economically bound together, making the situation more volatile and harder to leave (Carlson, 1987). Many factors have been identified that contribute to domestic violence. Of course, conflicts in general are a major contributor to violence in relationships. For married couples, there are some specific factors that are particularly salient to incidences of violence. Children and the stresses and responsibilities that come with raising them can be an aggravating factor along with disagreements revolving around money, sex, housekeeping, and social activities (Carlson, 1987).

Often times, however, violence does not just start out of the blue after a couple is married. Premarital violence, which is often termed courtship or dating violence, is an important aspect of domestic violence as dating relationships are often seen as a type of rehearsal for later marital relationships (Bird, Stith, \& Schladale, 1991). As dating is especially prevalent on college campuses and many young people enter into their first serious relationships during their college years, dating violence has been called the campus equivalent of domestic violence (Roark, 1987). Dating violence has been defined as aggressive acts in dating relationships including verbal aggression, such as threatening communication or verbal abuse, and physical aggression, such as pushing, slapping, or being struck with a weapon (Lewis \& Fremouw, 2001; Roark). Behaviors that would be viewed as criminal assault in any other situation are often 
viewed more leniently when they occur in an intimate relationship or, at the very least, not viewed as criminal. The idea is that closer relationships are more private and insulated from outside interference. If a couple has a problem, they do not advertise it to everyone; they typically want to resolve it without having to bring in a third party. It has been noted that there is a positive relationship between the amount of violence that is tolerated and the closeness of a relationship. As a relationship gets closer, the level of violence that is tolerated also increases (Roark).

The observations that dating relationships are more insulated from public scrutiny and, therefore, seem to be more susceptible to violence is also true of marital relationships. Intimate relationships, whether marital or premarital, tend to be characterized by many of the same distinctions. While individuals in marital relationships may be compelled to remain in a relationship for reasons that are not present in dating relationships, the occurrence of conflict is similar. In both marital and dating relationships, couples experience conflicts and must find someway in order to resolve them. The conflict resolution styles that work during their dating relationships will be the ones to which they turn first in their marital relationships. In this way, marital and premarital violence are interwoven as conflict resolution styles that are honed and ingrained through continued use and tolerance.

While dating violence and marital violence are closely related, there are some distinct differences between them. While stress is a universal factor that influences violence in relationships, the stressors that tend to operate in dating relationships are different from those in marital relationships. In marital relationships, the couple lives together, often has children, has shared financial dependence and responsibilities, and often has a fuzzy division of household chores and responsibilities. While there are some dating relationships in which the couple 
experiences these same stressors, the majority do not. Yet, research indicates that marital violence and dating violence are closely related (Carlson, 1987; Lewis \& Fremouw, 2001; Roark, 1987). There are some common factors that are more individual than situational that are believed to be contributors to violence in interpersonal relationships, both marital and premarital. These factors include a family background of violence, alcohol use/abuse, and a general climate in society that, even if it does not condone violence, does not condemn it either. Factors that have been found to influence violence in dating relationships in particular are jealousy, insecurity, and instability of the relationship. These factors are specific to dating relationships because a marriage, while all marriages obviously are not lasting unions, is legally binding. Alternate relationships are not as accessible to those couples who are married as they are to those who are merely dating. It is believed that stress resulting from this insecurity and instability compensates for the absence of other stressors that are inherent to marital relationships (Carlson, 1987).

\section{Measuring Violence}

While violence is measured in many different ways, the majority of research into dating violence has been undertaken on college campuses, often on only one campus. White and Koss (1991) conducted research into the incidence of relationship violence in a national sample of college students. The design that White and Koss employed was similar to that which is typical of investigations into dating violence. The sample in this study was 4,707 college students enrolled in 32 colleges and universities across the continental United States. Institutions were selected based on certain criteria and, once they were chosen, a random sample of classes was obtained in which to conduct the anonymous surveys. The surveys included demographic information such as age, ethnicity, gender, family income, marital status, and religious affiliation. The surveys also included the Conflict Tactics Scale (Straus, 1979) which the 
participants responded to twice, once for receipt and once for expression of each act (White \& Koss).

For the results, White and Koss (1991) analyzed responses for both symbolic aggression and physical aggression. The participants were also differentiated on the basis of the number of reported incidents: never, once, and more than once. For each act of courtship aggression, both symbolic and physical, there were no significant differences found between males and females for either inflicting or sustaining. The findings for prevalence rates of physical aggression in this national sample were comparable to those in other studies using smaller samples. White and Koss found that about $37 \%$ of males and $35 \%$ of females reported inflicting some form of physical aggression against a partner, while $39 \%$ of the males and $32 \%$ of the females reported being the recipient of some form of physical aggression from a partner. The results of this study also lend support to the theory of a bidirectional nature of violence. For both males and females, there was a significant correlation of about the same strength between inflicting and sustaining physical aggression (White \& Koss).

Consistent with the findings of White and Koss (1991), reviews of existing literature on dating violence identify prevalence rates ranging from $21 \%$ to $45 \%$, with an average of $30 \%$ (Lewis \& Fremouw, 2001). The majority of studies investigating dating violence employ selfreport questionnaires with college students as the target populations (e.g. Follingstad, Bradley, Laughlin, \& Burke, 1999; Hendy et al., 2003; Jenkins \& Aube, 2002; Lewis, Travea, \& Fremouw, 2002; Makepeace, 1986). The reasons for this are probably partly convenience, as most research is undertaken on college campuses, and also because, as aforementioned, college is probably when people date the most and become involved in more serious relationships. The standard for measuring interpersonal violence, whether the relationship of interest is dating, 
marital, or familial, is the Conflict Tactics Scale (CTS) developed by Maury Straus (1979). The CTS has been used in hundreds of studies focusing on interpersonal violence and is the most widely used and accepted measure of interpersonal violence (Archer, 1999; Straus \& Gelles, 1990; Swan \& Snow, 2002).

Even while the Conflict Tactics Scale is the most widely used measure in the study of intimate violence, its use is not without controversy. One controversy that revolves around its use is the argument of quality versus quantity (Archer, 2000b). As noted before, the vast majority of studies use the Conflict Tactics Scale, which is a quantitative measure of interpersonal violence. Studies using the Conflict Tactics Scale have consistently found that women report perpetrating as much or more physical aggression than males (e.g. Archer, 2000a; Babcock, Miller, \& Siard, 2003; Flynn, 1990; Frieze, 2000; Hendy, et al., 2003; Jenkins \& Aube, 2002; Lewis \& Fremouw, 2001; Marshall \& Rose, 1990; Straus, 1999). While studies consistently reaffirm this finding, many studies do not take into consideration the motives behind the behavior or injuries sustained. While women, of course, are capable of inflicting substantial injury, men are typically bigger and more powerful than women. It has been noted that women sustain more injuries than do men, regardless of who initiated the incident (Babcock et al.; Dasgupta, 2002; Fiebert \& Gonzalez, 1997; Murphy, Stevens, McGrath, Wexler, \& Reardon, 1998). For this reason, some people feel that any study of intimate violence should focus on the context of the incident, meaning the motivations of the parties involved, injuries sustained, and the situation in which the event occurred. These ideas tend to present violence perpetrated by females as inconsequential, or less important, than violence by men. 


\section{$\underline{\text { Current Study }}$}

The current study focuses on intimate violence. This is not differentiating between those individuals who are dating and those who are married. As the sample is one of college students, the majority might be single instead of married but those who are married were analyzed with those who are single and dating. The reason for this is that the incidence rates for violence in married and unmarried couples are very similar (Carlson, 1987). While it was noted earlier that some of the stressors that precipitate violence in married couples are different than those at work in dating relationships, this research was undertaken operating under the assumption that the individual characteristics that influence a person's use of violence in any intimate situation are similar. As aforementioned, research indicates that some individual characteristics that lead to violence in both dating and marital relationships are violent family background, general societal approval of violence, and alcohol use (Carlson, 1987). Nor did the current study differentiate between individuals involved in opposite sex or same sex relationships. One influence that may be present in homosexual relationships that is not present in heterosexual relationships is the stigma present in society regarding homosexual relationships and the ensuing stress. However, the focus of this research was individual, not situational, characteristics that are related to the use of violence in intimate relationships.

As noted earlier, intimate violence can refer to verbal aggression or abuse and/or physical aggression or abuse (Lewis \& Fremouw, 2001; Roark, 1987). The focus of this research was the use of physical aggression in intimate relationships, not verbal aggression. Therefore, for purposes of this research, intimate violence refers to physical aggression or abuse. The Conflict Tactics Scale (Straus, 1979) was the measure used in the current research to ascertain an individual's use of intimate violence in the past year and the use of violence in the family of 
origin. Based on the CTS, physical violence begins with throwing something at a person and escalates to include such actions as slapping, choking, hitting, kicking, threatening with a gun or knife, using a gun or knife, and hitting a person with something (Straus \& Gelles, 1990). These items were the measure of physical aggression used for analyses in the current research.

This study is important because much of the research on intimate violence focuses on violence occurring after a couple is married. While this study did not differentiate between those who are married and those who are single, there was an assumption that participants were probably single and dating. Instead of being reactive and trying to correct the problem when a couple is married, with more information about factors influencing a person's propensity to violence, society could be more proactive and deal with violence before there is a legally binding relationship and children. If it would be possible to curtail intimate violence in dating relationships, this could result in decreased violence in marital relationships. This, in turn, could result in fewer children being exposed to violence in the home which could diminish their likelihood to engage in violent relationships themselves as they enter into adulthood. While it has been widely noted that the problem of violence is cyclical, meaning that violent families often have children who have violent families of their own, the solution could also be cyclical. As people become less tolerant of violence, both in the home and otherwise, it is reasonable to assume that fewer children will be exposed to the violence that could influence them in later life by predisposing them to become involved in relationships that are violent in nature. Instead, the children may be less inclined to become involved in intimate violence and less accepting of violence in general. The use of violence becomes a conflict resolution tactic. If violence becomes a person's primary conflict resolution tactic, that violence will not be contained to intimate relationships and will infiltrate others areas of their life. 


\section{Theoretical Perspective}

The theories that led the current study of violence in intimate relationships were derived from theories based on symbolic interaction and self-esteem. Akers' (1994) theory of differential association asserts that deviance is learned and reinforced through the same process that leads to conforming behavior. The difference lies in the direction, content, and outcome of the behaviors (Akers). This theory, as well as the self-esteem theory, is derived from the paradigm of symbolic interaction. Symbolic interaction theorizes that individuals derive meaning of symbols (i.e., events and people) from their interactions with the world. Symbols do not have an inherent meaning, but are defined and responded to in different manners based upon the individual and the interactions that they have had. For example, if a person has had more experiences that are deviant and are supportive of deviance, that person will more likely define these behaviors as acceptable and normal. This is the premise of differential association. If one has more definitions that are supportive of deviant behavior, the motives and drives of that person will be supportive of engagement in deviant behaviors. This is related to the current study by the investigation of the intergenerational transmission of violence and reciprocity of intimate violence. If violence between one's parents is witnessed in the family of origin, the behavior of intimate violence is defined based on these experiences. A person who has grown up witnessing such violence is more likely to define it as normal and acceptable. Likewise, if a person is subjected to violence in an intimate relationship, that person is more likely to respond in kind due to this behavior being defined as normal for this relationship and with this person.

Self-esteem relates to a person's image of him/herself. Some researchers have defined self-esteem as being a relatively stable, global view of oneself while others have defined selfesteem as being more fluid and changing over time and situation. The current study operates 
under the assumption that self-esteem is stable over time. This view identifies self-esteem as being more of a personality trait that is constant with a stable baseline. If a person has high selfesteem today, self-esteem should remain high tomorrow, irrelevant of situations that may occur. While there may be minor fluctuations dependent on the context of the evaluation, generally a person's global self-esteem will be stable over time and situation.

\section{$\underline{\text { Factors Affecting Intimate Violence }}$}

\section{Intergenerational Transmission of Violence}

One factor that has been found to be related to a person's use of violence in intimate relationships is the violence witnessed in the family of origin (e.g. Carr \& VanDeusen, 2002; Foshee, Bauman, \& Linder, 1999; Gwartney-Gibbs, Stockard, \& Bohmer, 1987; Hendy et al., 2003; Lavoie et al., 2002; Marshall \& Rose, 1990; O’Keefe, 1998). From this came the intergenerational transmission of violence. A person who witnesses interparental violence will come to view that behavior as, in the least, acceptable if not normal. Children learn about love and relationships mostly through observation of their parents' relationship. Intergenerational transmission of violence suggests that violence is something that can be passed on from one generation to the next (Hendy et al.; Lewis \& Fremouw, 2001). It, therefore, follows that children who grow up in homes in which violence is used will learn to use violence in their own relationships, developing into a cycle of violence (Hendy et al.). In order to curtail such behavior and help future generations, it is important to understand and address domestic violence and its precursors in an attempt to help not only those who are directly involved in the situation but the many people who can be indirectly impacted. 


\section{Threatened Egotism}

Besides the aforementioned intergenerational transmission of violence, another factor that relates to individual characteristics of a person that may be indicative of a predisposition to violence is threatened egotism (Baumeister, Smart, \& Boden, 1996; Baumeister, Bushman, \& Campbell, 2000). The theory of threatened egotism goes against years of contradictory and inconsistent literature that low self-esteem was the source of violence and aggression. The theory of threatened egotism proposes that violence and aggression are actually the result of high but unstable self-esteem (Baumeister et al., 2000). If a person with high, but stable, self-esteem is confronted with an ego threat, the result is not likely to be an aggressive reaction because of the security and stability of the self-image. One threat is not going to have such a detrimental impact. However, if a person with high, but unstable, self-esteem is confronted with an ego threat, this person is more likely to vehemently deny the source and fight to preserve the tenuous positive ideal image of self. Likewise, the qualities that identify a person as having low self-esteem seem counterintuitive to a person acting violently and/or aggressively. A person with low self-esteem is likely to avoid risk and potential loss, submit to others' influence, lack confidence, be uncertain and confused about themselves, be shy and modest, and have a tendency towards anxiety and depression (Baumeister et al., 2000). Just on the surface, none of these characteristics would seem to place a person at an increased risk of perpetrating violence or being overly aggressive; on the contrary, most of the characteristics would seem to make a person more likely to be victimized by violence or aggression than perpetrating violence. Threatened egotism, however, postulates that when a person with high, but unstable, self-esteem is presented with an ego threat, the reaction will likely take the form of violence or aggression towards the source of that ego threat. 


\section{Reciprocity}

In terms of intimate violence, it has been widely reported that a significant predictor of perpetration of violence is receipt of violence. In light of this, there appears to be a reciprocal nature to intimate violence. What has been done to people in their relationships could be a leading factor in what they in turn do in that relationship. Simply put, the reciprocity factor means that violence begets violence. The use of violence seems to set an overall tone that develops into an environment that is conducive to physically aggressive behavior.

\section{$\underline{\text { Victimization }}$}

Another aspect of intimate violence addressed in the current study was victimization. While the overall focus was on the perpetration of physical violence, it is difficult to talk about one and not the other, especially when the aforementioned factor of reciprocity is considered. If acting aggressively is related to receipt of aggression, then the roles of perpetrator and victim are also intertwined and both must be addressed. Factors related to being a perpetrator were examined for a relationship with being a victim. However, the focus of the study remained on perpetration.

\section{Hypotheses}

There were seven hypotheses investigated in the current study. The first hypothesis was that females would report using violence as much or more than males. This hypothesis goes against societal ideals of how intimate violence occurs. However, as reviewed in Chapter 2, there is ample literature to support this hypothesis. Hypothesis two was the figurative other side of the coin. This hypothesis proposed that there would be no significant differences based on gender for reported victimization of intimate violence. While this hypothesis is also contradictory to what is generally expected, it is also supported by a wide body of literature. Hypothesis three claimed an 
individual's use of violence would be significantly related to that person's receipt of violence. This hypothesis is more straightforward than the previous two and also has empirical support. The next two hypotheses were related to the intergenerational transmission of violence. Hypothesis four was that an individual's use of violence would be significantly related to the reported use of violence in the family of origin. Hypothesis five was that an individual's victimization would also be significantly related to the reported use of violence in the family of origin. These two hypotheses relate to the intergenerational transmission of violence because people can learn to be victims just as they can learn to be aggressors. The sixth hypothesis was related to threatened egotism. This means that those individuals scoring high on self-esteem and narcissism will report using more physical violence. Finally, hypothesis seven suggested that those individuals who perpetrate physical violence in intimate relationships would also report having witnessed violence in the family of origin, being the recipient of more intimate violence, and will have higher self-esteem and narcissism when demographic variables such as age, gender, and race are controlled.

\section{$\underline{\text { Limitations }}$}

With all this being said, the current study does suffer from some shortcomings. The sample came from the population of students at a mid-sized southeastern public university. Therefore, whether the results can truly be generalized to the population at large is debatable. Also, while an attempt was made to obtain a sample using randomly selected clusters, some biases were introduced into the sample due to some selected classes' inability to accommodate the request for participant recruitment during class time. Surveys were administered during the final three weeks prior to exams of the fall semester of 2004. This is a difficult time to administer 
surveys because classes typically fall behind during the semester. The response rate for classes may have been higher had the surveys been administered earlier in the semester.

Another possible limitation of the current research is the measure that was employed to ascertain participants' exposure to intimate violence, both in their own relationships and in their family of origin. The Conflict Tactics Scale was used to measure both intimate violence in the participant's life and the family of origin. As previously noted, the CTS has been employed as a measure of interpersonal violence in more than 100 studies and is the most widely accepted measure of interpersonal violence (Straus, 1999). However, as will be addressed later in Chapter 3, there are some researchers who oppose the CTS. These oppositions are often centered on the aforementioned quality versus quantity argument. Some researchers contend that the CTS is an inaccurate measure of interpersonal violence because it only measures the quantity of violent interactions as opposed to investigating the different situations in which violence occurs. In Chapter 3, concerns regarding the Conflict Tactics Scale will be more fully addressed.

Another limitation of the current research is related to the previous limitation regarding the Conflict Tactics Scale. The current research is a quantitative investigation into the use of aggression in the intimate relationships of college students. This view focuses on only one aspect of the problem. There are numerous contextual and qualitative factors that can influence the use of violence in interpersonal relationships. This study, however, focused on individual characteristics influencing the use of violence.

Finally, as with all self-report surveys, a limitation of this study is the honesty, memory, and candidness of the participants involved. Self-report surveys are a very common method of conducting research but they are also marked by very distinct limitations. The research is based strictly on the reports of the participants and not on direct observation. The researcher has to trust 
the responses of the participants and their understanding of the questions. As this research does not involve couples, there is no way to validate a participant's honesty by comparing responses for the couple. This limitation, however, is not unique to this research and should not discredit the results.

\section{Summary}

In conclusion, this study sought to identify some characteristics of an individual that are related to a person's involvement in the use of aggression in intimate relationships. Specifically, this study investigated the impact of witnessing violence in the family of origin, the receipt of intimate violence, and high, unstable self-esteem on the use of physical aggression in intimate relationships. This research primarily focused on the use of aggression but it also looked at some factors dealing with victimization by intimate violence. In Chapter 2, literature will be reviewed that supports the aforementioned hypotheses. Chapter 3 presents and supports the methodology employed in conducting this research. In Chapter 4, the results of statistical analyses to test the specified hypotheses will be presented. And finally, Chapter 5 includes discussion of these findings and the implications of these findings for future research. 


\section{CHAPTER 2}

\section{LITERATURE REVIEW}

Violence is an area of research that is of interest to many. Due to this overwhelming interest and intrigue, the extent of research that has been undertaken in order to decipher factors that influence a person's proclivity for violence is extensive. The range of studies includes those focusing on youth violence, fatal violence, stranger violence, intimate violence, and so on. For purposes of the current research, the literature that will be reviewed will consist of those studies that selectively focus on intimate violence. In particular, the studies of interest are those that are similar in focus to the current research. First, studies will be reviewed that focus on the theoretical perspectives that the current research is operating under. These theories are derived from the perspective of symbolic interaction and include the intergenerational transmission of violence, which is closely related to differential association and social learning theory, and threatened egotism, which focuses on an individual's self-esteem. Secondly, articles will be reviewed that focus on the quantity of violence and gender of participants. These articles will involve both perpetration and victimization and findings based on gender. Finally, articles will be reviewed that address the relationship between the reciprocity of intimate violence and intimate violence victimization.

\section{Theoretical Perspective}

The current study is an investigation of intimate violence from the perspective of symbolic interactionism. Symbolic interactionism theorizes that people give meaning to situations and events based upon how they define their interactions. This theory focuses on individual perception. It is this individual perception that is paramount. If an individual perceives another's actions to be acceptable and normal, that person is likely to adopt reactions that are 
similar. A person's behavior is defined by the meanings that are attached to the situations that are experienced and the behaviors of others.

Symbolic interactionism does not purport that a person's behavior is predetermined by events in their life or their biological make-up or social influences. Instead, symbolic interactionism views events that have happened in a person's life as being influential on behavior but not deterministic (Sandstrom, Martin, \& Fine, 2003). This goes along with the current study's view of the intergenerational transmission of violence. If a person is reared in a home in which violence is readily used as a means of conflict resolution, this behavior is more likely to be defined as normal. Subsequently if a similar situation presents itself, that person may be more inclined to act in the ways that have been observed. The perception is more likely to be that this behavior is acceptable because of previous interactions that have been favorable towards the behavior.

\section{Factors Affecting Intimate Violence}

Factor One-Intergenerational Transmission of Violence

Theories attempting to explain some aspect of violent perpetration abound. One theory that attempts to explain aberrant behavior is the theory of differential association by Akers (1994). Differential association identifies deviant behavior as being learned in the exact same manner as conforming behavior is learned. The difference lies in the motives and direction of the behavior. Through their interactions with others, people acquire definitions for behaviors and actions. If a person has more definitions that are favorable to behavior which is aberrant, the likelihood of engaging in such behavior increases. However, if more definitions are acquired that are favorable to law abiding behavior, the person is more likely to engage in behavior that coincides with these definitions. 
Differential association is similar to social learning theory that purports events in a child's life are of great importance. If a child lives in a home where parents engage in violence towards each other, the child is more likely to attach definitions to such behavior that are favorable. It has long been held that exposure to violence in the home is strongly related to a child's later aggressive tendencies, not only in intimate relationships but in general (Carlson, 2002). When children observe their parents acting aggressively towards each other, they learn that the way to resolve conflict is aggression and that violence is acceptable. Research has found that a large percentage of both wives and husbands who are batterers witnessed interparental violence in their families of origin (Flynn, 1990).

The theory of an intergenerational transmission of violence was born out of social learning theory, differential association, and research indicating that witnesses to interparental violence are likely to use aggression in their own intimate relationships. This theory implies that children who are exposed to violence in their family of origin are more likely to engage in violence in their families of procreation (Lewis \& Fremouw, 2001; O'Keefe, 1998). The theory posits that children learn to act violently towards others and to be more tolerant of violence inflicted towards themselves through the observation of their parental models' use of violence in their relationship. This is closely linked to social learning theory by the implication that children learn through the observation of their parents' interactions. The relationship that a child's parents have with each other will often be the model for the child's later love relationships. Through the observation of their parents' relationship, children learn how relationships are supposed to be. Perception is reality. With that being said, if a child perceives that the only relationship that has been seen up close (i.e., the parents') is what it means to be in love, it is likely that the child's later relationships will closely model those that have been observed. 
Many researchers have undertaken studies in an attempt to test for the existence of such a theory. Lavoie et al. (2002) conducted a longitudinal study in order to investigate the influence of family dysfunction on the perpetration of dating violence by adolescent boys. The sample used in this study was 717 adolescent boys in an area near Montreal, Canada. The participants' use of physical violence was ascertained by administering a scale adapted from the Conflict Tactics Scale, while psychological abuse was also measured by implementing measures drawn from several different sources. Other variables that were measured included witnessing interparental conflict, monitoring by parents, harsh parental practices, antisocial behavior, and familial adversity. Overall, the results indicated that family dysfunction did have a significant impact on adolescent boys' perpetration of dating violence. Upon conducting multiple regression, Lavoie et al. found that some factors in particular that were significantly positively associated with dating violence perpetration were harsh parenting practices, low monitoring, and child abuse. While the results of this did find support for the idea that dysfunctional families can contribute to a child's later propensity for violence, there was a lack of support for the intergenerational transmission of violence as witnessing interparental conflict did not have a significant impact on the boys' perpetration of dating violence. However, this could be due in large part to the manner in which the researchers chose to measure interparental conflict. Lavoie et al. included a one-item measure asking the respondents how often their parents argued in front of them during the past 12 months. This measure may not have captured the true magnitude of conflicts occurring in the families of the participants resulting in inaccurate results.

Some researchers, such as Foshee et al. (1999), have investigated not only the influence of social learning but also social control on the perpetration of dating violence. Unlike social learning theory, social control theory identifies deviance as normal and conformity as aberrant. 
Therefore, conformity needs to be explained, not deviance. Hirschi (1969) proposes that human nature leans towards those behaviors that are viewed as aberrant such as greed, aggression, and basically hedonism. Under this ideology, those who do not act on these natural tendencies must have some reason or stake in society that keeps them from following their instincts. Social control seeks to explain conformity through attachment and bonds while viewing deviant behavior as an inherent aspect of human nature (Hirschi). The participants for the study conducted by Foshee et al. were 1,965 eighth- and ninth-grade students in public schools in North Carolina. The researchers measured variables relating to perpetration of dating violence, social control, and social learning.

Results supported the intergenerational transmission of violence. The researchers found that witnessing interparental violence and being hit by an adult were both positively associated with perpetrating dating violence for males and females (Foshee et al., 1999). For females, factors that were found to be associated with an increased aggressive response to conflict were witnessing interparental violence, being hit by an adult, and being hit by a mother. Likewise, males who witnessed interparental violence and reported being hit by an adult also reported a more aggressive response style to conflict. Foshee et al. also measured the participants' acceptance of dating violence. Results indicated that females who witnessed interparental violence and reported being hit by a mother and males who reported being hit by an adult were more accepting of dating violence (Foshee et al.). While these results are indicative of an intergenerational transmission of violence, there are some limitations. The participants were all in the eighth- or ninth-grade. Because of this young sample, the extent of experience in dating relationships is limited. Also, the questions investigating violence sustained by the children were 
limited by the young age of the sample. If abuse was disclosed during the surveys, researchers would have been obligated by law to disclose this information to the proper authorities.

While witnessing interparental violence could be a factor that increases a person's propensity for violence, it is not an absolute guarantee. This is similar to child survivors of sexual abuse. While many abusers report being abused themselves as children, there are many more survivors of abuse who do not become abusers. O'Keefe (1998) undertook research to investigate what factors could mediate the intergenerational transmission of violence. The sample for this study consisted of 1,012 students in public high schools in Los Angeles. A final sample of 232 males and females with a mean age of 16.9 years was obtained by selecting those participants who reported witnessing the most interparental conflict, at or above the $75^{\text {th }}$ percentile for the sample. The modified version of the physical aggression subscale of the Conflict Tactics Scale was used to measure inflicted and sustained dating violence, interparental violence and experiencing child abuse. For the dating violence scales, the participants were asked if they had ever inflicted or sustained the acts in a dating relationship, and, for the interparental violence and child abuse scales, the participants were instructed to think back to the worst year of their childhood. Other variables of interest were acceptance of dating violence, exposure to community and school violence, self-esteem, success in school, drug and alcohol use, and socioeconomic status (O'Keefe).

While the entire sample witnessed excessive interparental violence, the focus of this study was on factors that differentiate those who engaged in and experienced dating violence and those who did not. In the remaining sub-sample of 232 participants who witnessed high levels of interparental violence, $49 \%$ indicated that they had perpetrated violence on a dating partner and $55 \%$ reported that they had been the recipient of violence in a dating relationship (O'Keefe, 
1998). For males, lower socioeconomic status, exposure to community and school violence, acceptance of dating violence, and lower self-esteem were related to the perpetration of dating violence. For females, exposure to community and school violence, poor school performance, and experiencing child abuse were related to inflicting violence on a dating partner. O'Keefe also found that for those experiencing dating violence, males who were of a lower socioeconomic status and more accepting of dating violence and females who performed poorer in school and experienced child abuse were more likely to experience dating violence. While this study brings to light several important factors, the findings cannot be viewed as a causal relationship due to the cross-sectional nature of the study. Also, the final sample was fairly small as the criterion for selection was very specific.

Males and females are socialized differently in society and different factors may affect them differently, especially in regards to intimate violence. For this reason, Lewis et al. (2002) chose to conduct surveys using only undergraduate females as the respondents in an attempt to investigate factors differentiating those who are victims and those who are perpetrators. The participants were 300 undergraduate females who self-selected into the study. The criterion for selection was that the women had to have been involved in a relationship of at least three month duration in the previous 18 months. The Conflict Tactics Scale was used to ascertain the use and receipt of violence in dating relationships as well as mother-to-father and father-to-mother violence that the participant witnessed. Based on answers on the CTS for perpetration and receipt of physical violence, the participants were divided into four groups: victim-only, perpetratoronly, bi-directional aggression (participant indicated being both a perpetrator and victim), and controls (those who did not report any experience with dating violence). Other variables of 
interest were self-esteem, alcohol use, love attitudes, and, in an attempt to ascertain truthfulness on self-report, social desirability (Lewis et al.).

The breakdown for participants into the four groups was as follows: $69 \%$ identified as controls, $16 \%$ were in the bi-directional aggression group, $8 \%$ were victims only, and $7 \%$ identified as the sole perpetrator (Lewis et al., 2002). When these percentages are viewed in light of the participants who reported some experience with dating violence, $53 \%$ were involved in bidirectional aggression, $21 \%$ were perpetrators only, and $22 \%$ were victim only. This brings to light the finding that almost three quarters of the females who reported experiencing dating violence indicated that they were perpetrators at some point in time. Consistent with social learning theory, Lewis et al. found that females who reported being involved in bi-directional aggression were more likely to report witnessing their father be physically violent towards their mother. In social learning theory, the idea is that the children will identify with and relate to their parents and subsequently model their behavior. It is further hypothesized that children will identify more closely with their same sex parent. As a result, theoretically, the same sex parent would be a more influential model than the opposite sex parent. This aspect was not supported by the research. It was hypothesized that, because this sample was female only, participants reporting mother-to-father aggression would report more perpetration of physical aggression. There was no significant difference found for participants who reported witnessing mother-tofather violence (Lewis et al.). However, this study does suffer from some limitations. The sample is not very diverse as the entire sample was Caucasian. Also, the sample was of students who self-selected into the study to receive extra credit in college courses. This could have an influence on the results as certain people may be more likely to select into such studies. 
While some researchers have chosen to focus on females' use of aggression, others, such as Carr and VanDeusen (2002), have focused on males' use of aggression. While self-reported rates of violence by males and females may be similar, it has long been noted that the results of the violence are disparate (Murphy et al., 1998). For this reason, some feel that aggression by males towards females deserves more attention due to the increased risk of injury when males aggress against females. Carr and VanDeusen conducted research to investigate the relationship of family of origin violence and dating violence. The participants were 99 undergraduate males from a large Midwestern university. The participants completed the physical violence subscale of the Conflict Tactics Scale to ascertain their use of violence in dating relationships along with scales investigating their sexual experiences, attitudes towards women, sexual beliefs, attitudes towards violence against women, and acceptance of rape myths (Carr \& VanDeusen).

Results for the sample indicated that approximately one quarter of the participants witnessed interparental violence while about $20 \%$ of the sample admitted to inflicting some form of violence on a dating partner (Carr \& VanDeusen, 2002). Of all of the variables that were included in analysis, the only significant predictor of perpetrating physical violence in a dating relationship was witnessing interparental violence. These findings support social learning theory and the intergenerational transmission of violence. This research, however, has some serious limitations. For starters, the sample size was very small. Also, the method of recruitment could impact the validity of results. Part of the sample was obtained by a convenience sample of college men in classes while another portion was obtained by exclusively surveying males who belonged to a fraternity. The surveys were analyzed together; however, it is reasonable to assume that males who are fraternity members may be different from nonmembers. 
While the majority of studies reviewed to this point have focused solely on physical aggression, verbal aggression is also of interest. Gwartney-Gibbs et al. (1987) conducted research focusing on both verbal and physical aggression. Gwartney-Gibbs et al. studied abuse, violence, and sexual aggression. Abuse was limited to verbal aggression such as threats and swearing, violence was classified as physical violence such as hit, pushed, grabbed, punched, etc., and sexual aggression was obtaining sex by the use of actual physical coercion, getting someone drunk or stoned, or lying. The participants in the research were 289 undergraduates at a public university on the West Coast who were randomly mailed questionnaires that were anonymously mailed back to the researchers. The researchers were interested in six dependent variables: sustained and inflicted abuse, violence, and sexual aggression. Independent variables relate to the participants' parents', peers', and their personal experiences with aggression in their relationships (Gwartney-Gibbs et al.).

The findings of the study show support for the intergenerational transmission of violence. For males with parents who were abusive towards each other, $69 \%$ reported inflicting abuse and $32 \%$ inflicted violence; however, the percentages jump markedly to $87 \%$ inflicting abuse and $54 \%$ inflicting violence when the males reported having parents who were both abusive and violent (Gwartney-Gibbs et al., 1987). While parental influences were a significant predictor of inflicting courtship aggression for males, the relationship did not remain significant for females. The relationship was repeated for sustaining courtship aggression. Males who witnessed more severe parental aggression reported sustaining more courtship aggression; however, peer influences seem to have a more substantial influence on females' sustenance of courtship aggression. The reciprocal nature of dating violence was also highlighted in the study by the finding that the greatest effect was that of the participants' personal experience. Gwartney-Gibbs 
et al. found that if a participant reported sustaining courtship aggression, that person was more likely to also report inflicting courtship aggression and vice versa. This study, like many before, is limited by a small sample size and limited generalizability. Also, the researchers do not disclose over what time period the participants answered the questions regarding parental aggression or their own experiences with courtship aggression.

Like the previous study, many researchers interested in social learning theory are not only interested in studying parents as models but also the influence of peers. Hendy et al. (2003) studied six models of violent romantic relationships in college students. These six models were violence from mother-to-father, father-to-mother, mother to participant, father to participant, past partner to participant, and present partner to participant. The participants of the study were 608 students from the University of Pennsylvania who completed self-report, anonymous questionnaires either in class or outside of class. A modified version of the Conflict Tactics Scale was used to measure the participants' experience with violence. Only the items of the physical violence subscale were presented and, instead of the standard six-point Likert scale ranging from never to more than 20 times, participant responses were scored on a more subjective three-point scale of never, once or twice, and many times. Participants answered this scale for seven combinations: participant to present partner and vice versa, mother to father and vice versa, mother to participant, father to participant, and past partner to participant (Hendy et al.).

Again, results show support for intergeneration transmission of violence. For prevalence rates, $26 \%$ of females and $16 \%$ of males reported inflicting violence on their present partner at least once or twice, and $23 \%$ of females and $22 \%$ of males reported violent victimization from the present partner at least once or twice (Hendy et al., 2003). While the difference in sustaining violence based on gender was not statistically significant, the difference in inflicting was 
significant with more females reporting inflicting violence than males. For both genders, participants with a greater number of violent models were more likely to report personal experiences with dating violence. Hendy et al. found that when males reported sustaining violence from mothers, past partners, and present partners, they were more likely to inflict violence with $39 \%$ of the variance explained. For females, those who reported witnessing their mothers being violent towards their father and receiving violence from their present partner also reported inflicting more violence on their present partner with $51 \%$ of the variance explained. For receiving violence from the present partner, males reported more if their mothers were violent to them and if past partners had been violent, with $32 \%$ of the variance explained, while females reported more if their mothers had been violent to both them and their father with $18 \%$ of the variance explained (Hendy et al.). While the sample size of this study was better than those of previous studies, it is still limited by the diversity of participants. Again, the researchers do not indicate what time period the participants answered the questions based on.

Based on the theory of an intergenerational transmission of violence, the current research proposed that significant relationships would emerge between participants' own experience with dating violence and violence witnessed in their family of origin. It was hypothesized that participants who witnessed greater physical violence in their family of origin would also report inflicting more violence in their intimate relationships. Additionally, it was hypothesized that those participants reporting that they witnessed more violence in their family of origin would also report higher rates of victimization in their own intimate relationships. These hypotheses are firmly grounded in literature that supports an intergenerational transmission of violence and that individuals learn violence through the observation of important models in their lives. 


\section{Factor Two-Threatened Egotism}

The theoretical premise of threatened egotism is derived from some theories surrounding self-esteem. Before proceeding, the very concept of self-esteem needs some attention. While self-esteem can be defined in many different ways, two main concepts seem to be paramount: self-love and self-confidence (Salmivalli, 2001). Healthy self-esteem is a positive, yet realistic, view of self, and also involves the feeling of being a worthwhile individual (Salmivalli). A question that is often raised is whether aggression is related to high or low self-esteem. For decades, research has asserted that aggression and violence were the result of low self-esteem (Baumeister et al., 2000). However, many studies are now asserting the theory that aggression is more closely linked to high, yet unstable self-esteem (Baumeister et al., 2000; Baumeister et al., 1996; Bushman \& Baumeister, 1998; Papps \& O’Carroll, 1998).

There are many self-esteem scales available to ascertain a person's self-esteem. The question that remains lies with the interpretation of the scores. This is also the question that is the focus of threatened egotism. If a person scores high on a self-esteem scale, does this necessarily mean that he/she has high self-esteem, or could this be the way that the person desires to be viewed, and, therefore, be a protective feature for an unstable self image? Self-esteem measures are typically very straightforward and, therefore, are subject to false scores due to social desirability (Salmivalli, 2001). Therefore, it is important to take high scores with a grain of salt and determine some way in which to differentiate those with truly high self-esteem from those with artificially high self-esteem.

Baumeister et al. (1996) and Baumeister et al. (2000) propose that the idea that aggression is the result of low self-esteem is inconsistent with characteristics of low self-esteem as well as going against some common sense ideas regarding low self-esteem. If aggression 
comes as the result of a threat to a person's favorable self image, it makes sense that a person who is already suffering from low self-esteem will not react as vehemently as someone with high self-esteem. The reasoning is that people with low self-esteem do not have as much to lose if their self view is threatened. They already think the worst of themselves so chances are that this new negative feedback will not drastically impact their current self view (Baumeister et al., 1996). On the other hand, if people who hold highly favorable, inflated, and grandiose ideals of their self receive negative feedback, this will be perceived as a threat and they will lash out against the source in an attempt to preserve their self view (Baumeister et al., 1996). Also, characteristics of those with low self-esteem are counterintuitive to acting aggressively. Some of these characteristics are uncertainty, ready submission to others' influence, lacking in confidence, avoids risk and potential loss, and confusion about themselves (Baumeister et al., 2000). Just taking these characteristics at face value, they seem to point in the direction opposite of acting aggressively.

Because the theory is that inflated and grandiose self views lend themselves towards more aggression, the idea must be operationally defined in order to differentiate those who have truly high self-esteem and those who have unrealistic high self-esteem. The most often used method for this is implementation of measures of narcissistic traits. People with narcissistic characteristics have been said to “...care passionately about being superior to others, even if they are not yet convinced that they have achieved this superiority" (Bushman \& Baumeister, 1998, pg. 220). Narcissism is characterized by grandiose views of superiority, low empathy, inflated sense of entitlement, fantasies of personal greatness, and an egocentric dependence on social relations that are positive and consistently reinforcing (Baumeister et al., 2000; Ruiz, Smith, \& Rhodewalt, 2001). Bushman and Baumeister proposed that it is not high self-esteem per se that is 
related to aggression but high self-esteem coupled with narcissism, which represents an unstable view of self. It is when people with these two traits are presented with a threat to their favorable self-view that threatened egotism comes into play as these people strive to protect their selfesteem from the source of the threat.

According to research for both males and females, narcissism seems to be closely associated with hostility which could logically lead into aggression and violence (Hart \& Joubert, 1996; Ruiz et al., 2001). While hostility and aggression are not identical concepts, they are closely related and these findings lend support to the theory of threatened egotism. Using a sample of undergraduate males and females, Hart and Joubert found a positive relationship for males who scored higher on narcissism and their scores on measures of total hostility, assault, suspiciousness, and negativism. Females scoring higher on narcissism were also found to score higher on total hostility, negativism, assault, and verbal hostility (Hart \& Joubert). When both male and female scores were combined for analysis, higher narcissism scores were found to be associated with higher scores on total hostility, negativism, assault, verbal hostility, and suspiciousness (Hart \& Joubert). While this study cannot be interpreted as cause and effect, nor is it a direct evaluation of threatened egotism, it does provide a starting point and support for the idea of using narcissism as a measure related to aggression and violence.

Researchers such as Washburn, McMahon, King, Reinecke, and Silver (2004) have taken the research a step further and sought to investigate specifically aggression, narcissism, and selfesteem. The participants were 233 students in the fifth through eighth grades of public schools located in low-income, densely populated areas in Chicago. The Narcissistic Personality Inventory (NPI), which was developed by Raskin and Hall (1979) and is a highly regarded measure of narcissism, was administered along with teacher, peer, and self evaluations of 
aggression, self-esteem, impulsivity, empathy, beliefs about aggression, and exposure to violence (Washburn et al.). Results from the study supported the idea that narcissism is associated with aggression. For participants in the study, scores on the NPI were positively associated with a participant's self-report of aggression. Washburn et al. found an interaction between self-esteem and narcissism on teacher's report of aggression. The students scoring higher on adaptive narcissism and self-esteem were scored lower on aggression by their teachers. However, not all of the teachers answered questions relating to the student's aggression so these findings must be viewed in light of these facts. Also, the sample is a relatively homogenous one as the sample was almost 90\% African-American and mainly low-income adolescents (Washburn et al.).

Research has also been undertaken on college campuses in an attempt to investigate the relationship of narcissism and anger. Witte, Callahan, and Perez-Lopez (2002) administered anonymous surveys to 130 undergraduate males that consisted of the NPI and a scale that presented different scenarios that participants were told to score as to how angry they would feel if they were subjected to these circumstances. Witte et al. tested each of the factors of the NPI to ascertain which specific aspects of narcissism were most related to feelings of anger. Results indicated that the subscales of authority and entitlement were positively associated with anger scores. Conversely, exhibitionism and self-sufficiency were negatively correlated to anger while superiority, exploitativeness, and vanity were not significantly correlated in any way (Witte et al.). This study is limited in that the sample consists strictly of males and the sample was relatively small.

The theory of threatened egotism does not propose that all people with high self-esteem will behave aggressively when presented with an ego threat. In theory, it is those individuals who have an unrealistic and unstable high self image who will be more likely to react aggressively. 
Bushman and Baumeister (1998) put this theory to the test in a study involving undergraduate males and females who completed both a measure of self-esteem and the NPI prior to being placed into a laboratory experiment. Participants were exposed to an evaluation that was either negative or positive in nature then given the chance to aggress against the evaluator. Results indicated that negative evaluations resulted in more aggression by all participants but was strongest for those scoring higher on the measure of narcissism. Interestingly, Bushman and Baumeister found that those individuals scoring higher on narcissism reported more aggression than those scoring lower on narcissism towards those evaluators who rated them favorably as well as negatively. Bushman and Baumeister conducted a second study that replicated their finding that narcissists responded more aggressively to negative criticism but they did not aggress towards positive evaluators nor did they aggress against third parties when they received a negative evaluation.

Kirkpatrick, Waugh, Valencia, and Webster (2002) sought to replicate the findings of Bushman and Baumeister (1998) in an attempt to further the understanding of narcissism as it relates to aggression. For their study, 74 undergraduate males and females completed measures of self-esteem and the NPI before continuing to the laboratory experiment in which the researchers found partial support for the findings of Bushman and Baumeister. Kirkpatrick et al. found that those who scored higher on narcissism were more likely to act aggressively. However, that finding in this study was not as limited as it was in Bushman and Baumeister's study. Kirkpatrick et al. found that those scoring higher on narcissism were more likely to act aggressively regardless of the quality of the feedback. This finding suggests that the quality of the feedback may not be as important as just the possibility of that feedback being negative or the fact that someone is standing in judgment of the narcissistic individual. 
The idea of threatened egotism and the pursuit of some reason for aggression are not limited to the United States. Papps and O'Carroll (1998) conducted research in the United Kingdom in order to investigate anger and aggression in light of extremes of self-esteem and aggression. The sample was 338 students from two higher education centers with measures including self-esteem, narcissism, provocation, and trait anger expression. The participants were classified into four groups based on self-esteem and narcissism: high self-esteem/high narcissism, high self-esteem/low narcissism, low self-esteem/high narcissism, and low selfesteem/low narcissism. The findings of Papps and O'Carroll indicated that those individuals in the high self-esteem/high narcissism group were more likely to experience both provoked and unprovoked anger as well as the expression of anger towards other people or objects. In addition, the strength of that expression was reported to be higher for the high self-esteem/high narcissism group. The high self-esteem/low narcissism group controlled their anger significantly more than did the high self-esteem/high narcissism group. Interestingly, the researchers found that individuals in the low self-esteem/high narcissism group also reported moderate levels of anger. This group was lower than the high self-esteem/high narcissism but higher than the high selfesteem/low narcissism group (Papps \& O’Carroll). This would seem to indicate that narcissism might be a better predictor of anger than would be self-esteem by itself.

The current research proposed that threatened egotism would emerge as a significant factor in the perpetration of dating violence. To operationalize this theory, the current research mirrored previous research which sought to conceptualize this by the measurement of selfesteem in conjunction with measurement of narcissistic traits. Specifically, it was hypothesized that those individuals scoring high on both self-esteem and narcissism would also report greater perpetration of intimate violence. 


\section{Factor Three-The Gendered Nature of Violence}

When people in today's society think about interpersonal violence that takes place between married or dating couples, many people automatically assume that in the majority of cases, the male would be the perpetrator and the female would be the victim. However, when one looks to the research on the subject, the picture that emerges is very different. In fact, Straus (1999) reports that when examining studies relating to domestic violence that use self-reports, more than 100 have found that women report perpetrating violence against their partners as much as men. This is astounding because it basically goes against everything that society teaches about how women are supposed to act. Women are supposed to be nurturing and passive, not violent and assertive. In a survey given to college students that informed them of these findings that women report being as, if not more, physically aggressive towards men as vice versa, it was found that more than half of the students, both males and females, reported that they were unaware of these research findings (Fiebert, 1996). Interestingly, about one third of both males and females were unwilling to accept these findings as accurate. There are, however, controversies surrounding these findings which may be the basis for those students' disbelief.

The majority of information that is available on intimate violence is based on the Conflict Tactics Scale (Straus, 1979), which is a self-report quantitative measure of intimate violence perpetration and victimization (Archer, 2000a). Those who oppose the use of strictly quantitative measures of intimate violence often do so on the grounds of no consideration being taken for motives, who initiated the incident, or consequences, possible or actual, of the behavior (Dasgupta, 2002; Frieze, 2000; Saunders, 2002; Worcester, 2002). Some researchers propose that increased aggressive behavior by females in intimate relationships could be the result of society's pointed focus on male perpetrated intimate violence (Flynn, 1990). In light of attention 
given to the problem of battered women, men who act aggressively or violently towards women are viewed as cowardly and brutish while women who do the same are viewed as liberated and empowered (Bethke \& DeJoy, 1993; Hendy et al., 2003). Focus on women's use of aggression in intimate relationships should not take the focus off the very real and serious problem of battered women. However, the goal should be to improve everyone's quality of life, both males and females, by focusing on all violence in intimate relationships. Researchers have consistently found that intimate violence is largely reciprocal in nature (Harned, 2002; Jenkins \& Aube, 2002; Marshall \& Rose, 1990; White \& Koss, 1991); therefore, if one partner refused to resort to using aggressive tactics, this might decrease the chances of that person becoming a victim of violence in return.

Violence perpetrated by women tends to be viewed more leniently and as more inconsequential as the same by men. Bethke and DeJoy (1993) found that male and female college students, in fact, did not have significantly different experiences with dating violence, but acceptance of the use of violence differed depending on the circumstances. Participants were presented with different scenarios of dating violence and asked to score them on different variables. Results indicated that males who perpetrated dating aggression, both emotional and physical, were seen as inflicting much more harm than females who perpetrated the same. Findings supported a differential view based on the perpetrators' gender. Bethke and DeJoy found that if a male slapped his partner, he was viewed much more harshly than a female who did the same; and, violence in general was viewed more criminally if the perpetrator was a male than if she was a female. Victimization of males was trivialized as was perpetration by females (Bethke \& DeJoy). These findings support the need for research into the quantity of violence. 
Violence by females should not be trivialized because they are typically smaller and less able to inflict serious harm.

Due to research findings that females engage in physical aggression against partners as much, if not more, than males, researchers have been interested to learn what motivates females to act in such ways. Fiebert and Gonzalez (1997) chose to undertake research addressing this question by investigating the use of aggression by women and why they engaged in this behavior. The participants in this study were 978 undergraduate females who completed anonymous surveys that asked about the participants' initiation of physically aggressive acts towards a partner in the past five years. The study did not use the Conflict Tactics Scale but instead just asked general questions about different aggressive behaviors and how often the participant had initiated them towards a partner. If the participants responded that they had engaged in the physically aggressive behavior, they were then presented with five surface reasons for the act and told to select all that applied. The reasons included a desire to gain their partner's attention, partner's verbal abuse, disbelief that their actions would hurt their partner, etc. The participants were then asked to reflect on deeper reasons for their behavior and instructed to respond to 10 additional reasons, checking all that applied. These responses indicated such things as women being in charge in domestic situations and having a right to strike their partners if they break the rules, men have been trained not to hit women so they are not fearful of retaliation, mother was sometimes physically aggressive towards father or stepfather, feelings of empowerment, men are readily able to protect themselves, etc. (Fiebert \& Gonzalez).

The prevalence rate for physical aggression in the women's dating relationships was found to be similar to those reported elsewhere at 29\% (Fiebert \& Gonzalez, 1997). Results 
indicate that younger women, aged 20 to 30 , were more frequently initiating aggression against their partners than those women over 31 . When the women selected the surface reasons for engaging in the aggressive behaviors, no one reason was selected significantly more than others. Fewer participants responded to the deeper reasons, resulting in an inability to meaningfully analyze the responses. However, the reason with the greatest percentage of responses, besides other, was the belief that men can readily protect themselves followed by the reason that men have been trained not to hit women and, therefore, there is no fear of retaliation (Fiebert \& Gonzalez). This study is limited to the number of motivations listed. The surface motivations had only five to choose from. On the deeper reasons, it is sometimes too difficult for people to interpret their own deeper reasons for engaging in behavior, especially behavior that is aberrant. That may be one reason why relatively few women answered these questions.

Most research investigating the use of physical aggression in dating relationships has been limited to using individual participants, not couples. When relying on self-report individual responses, the researcher has no way to validate the response. However, with couple data, the researcher can calculate correspondence rates to determine if the couples are reporting the same behavior patterns. Jenkins and Aube (2002) surveyed 85 heterosexual couples on a college campus, with the requirement that the couple had to have been together at least three months. Dating aggression was measured using the physical and symbolic aggression subscales of the Conflict Tactics Scale, both toward the partner and received from the partner. Participants indicated how often the acts occurred and how severe the act was on a three-point scale. The participants also answered questions relating to gender constructs and adherence to traditional male norms. 
Jenkins and Aube (2002) found results that coincide with other research findings that males and females engage in acts of aggression at similar rates. For all measures of perpetration of aggression, there were no gender differences reported for either frequency or severity. The finding that there were no gender differences for severity is surprising based on the idea that aggression by males should be viewed more seriously due to increased risk and potential for injury. In terms of victimization, however, males reported significantly more victimization by females than vice versa for all forms of aggression except severity of symbolic aggression. Forty-one percent of males reported being the victim of at least one act of physical aggression while $21 \%$ of females reported the same. Logically, Jenkins and Aube found that males who held to more traditional male norms engaged in more male aggression while less traditional views by females coincided with greater severity of aggression by females. The results of this study emphasize the need for attention on all aggression, not just male perpetrated. There was no difference in the severity of aggression perpetrated by males or females. This demonstrates a need to change society's way of thinking of women as weak and not a threat. This study was limited by a relatively small sample. However, the fact that the participants were separated from their partner during the questionnaire was a good move. If the surveys had been completed together, one partner may have attempted to influence or intimidate the other into falsifying answers.

While some research focuses on attributes of perpetrators of intimate violence, others focus on the attributes and risk markers of victimization. Harned (2002) conducted such research in an attempt to determine which factors were the most salient for intimate victimization. The participants in this study were 1,150 college students who completed anonymous surveys online. Of these 1,150 participants, 874 were retained for analysis due to the selection criteria of having 
dated while enrolled in the university from which the sample was drawn. The sample was largely heterosexual (94\%), with $4 \%$ identifying as homosexual and the remaining $2 \%$ bisexual. Along with physical violence perpetration and victimization measured based on the physical violence subscale of the Conflict Tactics Scale, the participants' psychological victimization and perpetration and sexual victimization and perpetration were also assessed using various scales. In addition to these experiences, individual victim attributes were obtained based on various demographic variables such as race, age, sexual orientation, etc., as well as situational factors, such as substance use and the number of casual and serious dating partners (Harned).

In this research, Harned (2002) attempted to determine which factors were the most predictive of dating violence victimization: bidirectional aggression, victim attributes, or situational factors. In this sample, $22 \%$ of women and $21 \%$ of men had been the recipient of physical aggression from a dating partner. Based on analyses for all three types of dating violence, bidirectional aggression was the best predictor followed by situational factors. The data were further analyzed to determine if different factors affected males and females to the same degree. When these results were analyzed for physical aggression, Harned found that perpetrating physical aggression against a partner, general substance use, and substance use with dating partners were predictive of an increased risk of physically violent victimization for females. While the perpetration of physical aggression against a partner remained significant for males, the other two variables were not and, additionally, the perpetration of psychological aggression against a partner was indicative of greater risk for physical aggression victimization. This study, however, is limited due to the factors that were included in the victim attributes section. The only victimization that was significantly predicted by victim attributes was, interestingly, male sexual victimization. However, there were only five victim attributes 
measured for analysis. These were age, sexual orientation, race, Greek membership, and patriarchal beliefs (Harned). These variables do not take into account other important aspects of an individual that could influence risk of victimization.

Probably the biggest argument against a quantitative focus on intimate violence is based on the absence of important factors such as motivations and effects of the violence. In an attempt to reconcile the need for quantitative and qualitative investigations into intimate violence, Follingstad, Wright, Lloyd, and Sebastian (1991) conducted a quantitative study of dating violence that also addressed the motivations and effects of violence by males and females. The participants in the study were 495 college students who completed self-report surveys measuring feelings of anger, social desirability, a scale investigating the participants' perceived justification for using force against an intimate partner, the Conflict Tactics Scale, and motivations and effects of dating violence perpetrated against them and that which they perpetrated against others in addition to demographic variables. The motivations were presented in a list of 13 possible motivations and participants were instructed to select all that applied, then to go back and select the one that was the strongest. The participants selected motivations that influenced themselves as perpetrators and victims also selected those motives that they perceived to have affected their perpetrator. The motivations included such things as inability to express themselves verbally, to feel power, self-defense, in retaliation for emotional hurt or being hit first, punishment, to show love, etc. For effects, the participants were presented with 17 possible effects and were told to select all that applied then to select the most prominent effect, both as a victim and the perceived effect as a perpetrator. The list of effects included fear, anger, depression, thought it was funny, sexually arousing, helplessness, shame, love, afraid of not being loved, etc. (Follingstad et al.). 
In this study, the prevalence of dating violence was similar to that found in other studies. Follingstad et al. (1991) found that $23 \%$ of their sample indicated that they had been the victim of physical aggression in a dating relationship. Of those victims, $29 \%$ were male while $71 \%$ were female, which was found to be statistically significant. A smaller percentage, $17 \%$, admitted to perpetrating dating violence against a partner. Interestingly, Follingstad et al. found that the percentages for each gender are almost identical to those for victimization. Thirty percent of those perpetrating violence were males and $70 \%$ were females. Again, this difference was significant, indicating that females report being the victim and the perpetrator at almost twice the rate of males (Follingstad et al.).

Factor Four-Reciprocity

The aforementioned reciprocal nature of intimate violence has been the focus of much research. Marshall and Rose (1990) are among those researchers with a study investigating the impact of family of origin violence, stress, and reciprocity on premarital violence. The participants in this study were 579 undergraduate students of whom 454 met the criteria for not being married, cohabiting, or divorced. Marshall and Rose chose to eliminate those participants who reported that they were married, cohabiting, or divorced in order to focus on strictly premarital relationships. The measures included in this study were the physical violence subscale of the Conflict Tactics Scale, which was scored on a 5-point Likert type scale ranging from never to very often, and a life experiences survey that indicates what stressors, both positive and negative, have been present in the respondents' life. Participants completed the CTS section four times for their own relationships and three times for their family of origin violence. For their own relationships, the participants responded to the CTS based on receipt and expression of acts in the past two years and in the past in an adult romantic relationship. For family of origin, the 
participants rated the same items for their mother to their father, father to their mother, and receiving the behavior from a parent or guardian during childhood (Marshall \& Rose).

The violence scores were dichotomized and those who expressed or received one or more violent acts were separated from those who reported no experience. For this sample, $76.3 \%$ of the females and $72.5 \%$ of the males reported having expressed a violent behavior while $61.8 \%$ of the females and $62.7 \%$ of the males reported having been the recipient of violence (Marshall \& Rose, 1990). In general, females consistently reported expressing behaviors more than being the recipient of the behaviors. For females, the expression of recent violence was highly correlated with the receipt of recent violence; however, the same pattern was not significant for males. There was a strong correlation found for males between the recent receipt of violence and the past receipt of violence, indicating that males who have experienced abuse in dating relationships tend to continue to do so. For females' recent expression of violence, Marshall and Rose found that the most powerful predictor was their receipt of violence; and, for receipt of recent violence, the most powerful predictor was the expression of violence.

These findings lend support to the reciprocity argument. However, the same did not hold true for males. Both being abused as a child and positive stress contributed to males' recent expression of violence, while the equation for recent receipt of violence was not significant (Marshall \& Rose, 1990). Overall, however, the equations for females had considerably more explanatory power than did those for males. For these types of studies, the subjective measure of violence may not be the most accurate. What may be rare to one person may be often to another and vice versa. Therefore, the analyses must be viewed in light of this caveat. Also, the findings in this study cannot absolutely confirm a reciprocal relationship because participants may have 
been reporting on more than one relationship and the person to whom they were expressing the violence may not be the same one from whom they received violence (Marshall \& Rose).

\section{$\underline{\text { Victimization }}$}

Just as it is important to identify those individuals who may have a propensity to engaging in violent behaviors, it is also very important to identify those who may be at an increased risk for violent victimization. Makepeace (1986) conducted research to identify gender differences in terms of dating violence victimization. The participants in this study were 2,338 students at seven colleges. The participants completed anonymous and voluntary surveys that consisted of two parts. The first part included, in addition to demographic information, questions relating to the participants personal beliefs and dating experiences. In part two, scales similar to the Conflict Tactics Scale were used to assess experience with dating violence along with first and worst incident details, effects of the behavior, and motivations for the behavior (Makepeace).

The findings of this study are similar to others with the finding that $16.7 \%$ of participants reported having experience with courtship violence (Makepeace, 1986). Females reported significantly more experience with relationship violence than did males; but, while the mean number of acts did not significantly vary, males appeared to have been engaged in violence with more partners than females had. Each violent act that was measured was analyzed separately by gender to determine if any patterns existed for receipt and/or expression by gender. Most of the acts are considered low level violence, including throwing an object, hitting, shoving, biting, punching, kicking, with relatively few measures of high level violence such as struck with an object, beat up, or threatened or assaulted with a knife or gun. Makepeace found that for inflicting violence, there were only two acts that females engaged in significantly less than males: pushing/shoving and threatening with a knife or gun. On the other hand, there were only 
three acts that females reported sustaining more than males: being beaten up, being struck with an object, and other. Females reported sustaining significantly fewer acts for six of the remaining eight acts. Interestingly, nearly twice as many females perceived themselves to be victims while three times as many males reported being the aggressor (Makepeace). This is interesting because it appears that both males and females in this study are subscribing to a patriarchal view in that females cannot truly be aggressors and males cannot truly be victims. However, this study was undertaken nearly two decades ago and views may have changed since that time. As attention has been focused on domestic violence in the past decade, some of the stereotypes concerning it may be undergoing changes that would account for different perceptions now.

In the study that was previously reviewed by Follingstad et al. (1991), the researchers sought to investigate the victims' perception of the aggressors' motivation as well as the actual reported motivation of the aggressors. In terms of perceived motivations, female victims perceived their abusive partners as wanting to control them and retaliating for their hitting him first while males perceived their abusive partners as attempting to show how angry they were and retaliating for being emotionally hurt or mistreated. When comparing these perceived motives with actual reported motives of perpetrators, the victims were surprisingly accurate. Female perpetrators were more likely to report retaliation for emotional hurt and showing anger while males were more likely to indicate they acted in retaliation for being hit first. In contrast to the perception of female victims, female perpetrators more often cited the motivation of gaining control over their partner than did their male counterparts. Self-defense was chosen by perpetrators as a motivation equally for males and females which goes against conventional wisdom that females mainly use violence as a form of self-defense (Follingstad et al.). 
In addition to motivations, Follingstad et al. (1991) also sought to assess the effects of the aggression in terms of both the perception of the aggressor and the actual effect felt by the victim. In terms of perceived effects by perpetrators, females were more likely to indicate that their victims would feel that they had a right to be violent against them and that their victims would feel guilt, while males were more likely to indicate that their victims would likely suffer from fear and anxiety, sadness and depression, along with a need to get away to protect themselves. For actual effects, the male perpetrators were accurate in their perception of fear, anxiety, and a need to get away to self-protect along with females indicating being emotionally hurt. Although there were no effects that males victims indicated significantly more than females, the two most often cited effects were anger and emotional hurt which did not coincide with female perpetrators perceptions (Follingstad et al.).

These results are important because it appears that females view their own acts of aggression as insignificant and less damaging than the same actions by males. While the females did report being victimized twice as often as males, they also reported being perpetrators twice as often. When one considers the apparent bidirectional nature of aggression, these findings are very meaningful. According to these findings, it appears that women feel justified in their use of force and that their male victims see it that way also, which is not accurate. The females reported that their male victims would feel that they had a right to do what they did and that they would feel guilty. These two effects were not among the ones most reported by male victims. These findings are consistent with those reported by Archer (2000a) that females do not fear retaliation for dating violence nor do they perceive that they are at risk of formal sanctions. From this, it appears that if females think their violence is justified, they are the only ones. Instead of feeling 
guilty, the males reported feeling angry and emotionally hurt, which, in turn, can lead to increased aggressiveness by males towards females. And, thus, the cycle begins.

\section{$\underline{\text { Summary }}$}

The literature that has been reviewed in this chapter is merely the tip of the iceberg when analyzing the body of literature that exists in the study of violence and victimization. While the previous studies are merely a subsection of the whole, the hypotheses that have been set forth for the current study are strongly supported by the literature in this review. To reiterate, it was hypothesized that females and males would report similar rates of both expressing and receiving intimate violence; a person's use of violence would be strongly related to that person's receipt of violence; those with higher self-esteem and narcissism would perpetrate more violence; and those persons who witnessed violence in their family of origin would report using more violence in their intimate relationships. In the next chapter, the methodology of the current study will be put forth and compared to the methodology of previous studies. 


\section{CHAPTER 3}

\section{METHODOLOGY}

The current study identified factors that are related to a person's use of physical violence in intimate relationships. Factors that were under consideration for having an impact on the incidence of a person's use of violence included: violence witnessed in the family of origin, threatened egotism, and reciprocity. Therefore, it was hypothesized that participants who witnessed violence in their family of origin would report using more violence in their intimate relationships; participants who were found to have high self-esteem and high narcissism would report using more violence in intimate relationships; and participants who reported higher levels of perpetrating physical violence would also report receiving more violence in intimate relationships.

In addition, analyses were undertaken to determine if any gender differences were manifested in the expression or receipt of physical violence in intimate relationships. The current study hypothesized that there would be little to no differences emerge for gender for either perpetration or victimization. It was also hypothesized that a person's use of physical violence would be highly correlated with that person's reported receipt of intimate violence. Finally, an attempt was made to explain the variation in the incidence of physical violence in intimate relationships by examining violence in the family of origin, threatened egotism, and reciprocity while controlling for several demographic variables.

\section{$\underline{\text { Data }}$}

\section{$\underline{\text { Population }}$}

The population for the current study was college students enrolled at East Tennessee State University in Johnson City, Tennessee. East Tennessee State University is a public, state 
university with an enrollment of approximately 11,000 located in Johnson City, Tennessee. Johnson City is in northeast Tennessee and, according to the 2000 census, had a population of 55,469 . The area is predominantly rural and the racial composition is mostly White, with $90 \%$ of residents in 2000 reporting that they were Caucasian, and only 6.4\% African-American. For gender, $48 \%$ of residents in 2000 were males and $52 \%$ females.

$\underline{\text { Sample }}$

A random probability sample of 42 classes offered in the fall semester of 2004 was obtained from the administration of East Tennessee State University. Due to the random nature of the sample, classes from numerous disciplines and levels of study were included. This was done in an attempt to get a more representative sample of students than would have been obtained had a strictly convenience sample been obtained.

After the selection of these 42 classes, an attempt was made to contact the professors via e-mail. This e-mail stated that the class had been randomly selected for the study, and that the researcher was seeking permission to come to the class in order to recruit participants. The professors were told the purpose of the study and that the surveys would take approximately 20 minutes to complete. The professors were to respond to the e-mail to set up a day and time for the researcher to come to the class to administer the surveys. Of the 42 classes that were selected, 14 permitted the researcher to come to class in order to recruit participants, for a response rate of approximately $33 \%$ from the professors. As the target sample for the study was 500 and the possible sample for the 42 classes was over 1500, follow-up e-mails were not sent to those professors who did not respond to the initial request. 


\section{$\underline{\text { Participants }}$}

The participants in this study were those students enrolled in the randomly selected classes that permitted the researcher to recruit subjects during class time. The researcher went to the class on the agreed upon day and time. The study was explained to the students in attendance, and they were instructed that their participation was voluntary. The survey was approved without a consent form; therefore, students were informed that they were consenting to participate in the study by their completion of the survey. The reason that this study was approved without a consent form was to protect the confidentiality and anonymity of the participants. Some of the questions included on the survey were very sensitive in nature. If participants had been required to sign a consent form, they may have felt more inhibited in their responses. Any potential breach in the confidentiality of the questionnaires would have constituted the greatest risk. There were 423 participants out of 708 students enrolled in the selected classes. A response rate of approximately $60 \%$ was calculated based on the total number of participants (i.e. 423 ) versus the total enrolled in the surveyed classes (i.e. 708).

The average age of the participants was 22.31 years old, with a mode and median of 21 and a standard deviation of 5.07. As is typical of college samples, the participants were fairly young with $90 \%$ twenty-six or younger. Seniors made up $35 \%$ of the sample, which was the most represented class. Almost $28 \%$ of the participants were juniors followed by approximately $19.5 \%$ sophomores and 15\% freshman. Almost 2.5\% identified themselves as either graduate students or some other classification that was not listed. The participants were overwhelmingly Caucasian (92.4\%). Almost 4\% identified as African-American; approximately 1\% Asian; 2\% Hispanic; and less than $1 \%$ identified with a race that was not listed as an option. There were also 276 females (65\%) and 147 males (35\%). 
These demographics were in line with those of the university at large. In $2000,41 \%$ of students enrolled at East Tennessee State University were males and 59\% were females. In addition, in $2000,90 \%$ of students reported that they were Caucasian and $4 \%$ reported that they were African-American. These are not very different from those found for the sample for the current study. Therefore, at least for these demographic characteristics, the participants in the study appear to be representative of the population of East Tennessee State University.

The vast majority of participants were single and had never been married (i.e., $80 \%$ ), while $15 \%$ reported that they were currently married. Of those participants who did not indicate that they were currently married, almost half (i.e., 49\%) were involved in dating relationships, either serious or casual, and $29 \%$ indicated that they were currently single and not dating anyone at the present time. Less than $10 \%$ of the participants were engaged. The average length of the participants' current relationship was 3.25 years with a standard deviation of 3.6 years and both a median and mode of two years. As for current living arrangements, only about one fifth (21\%) lived on campus. The majority of participants (i.e., 54\%) lived off-campus, not with their parents, while almost one quarter (i.e., 24\%) lived with their parents. The participants were also asked whether they considered themselves to be religious. Eighty-one percent indicated that they were religious while approximately $18 \%$ were not.

\section{$\underline{\text { Data Collection }}$}

Data for the current study are cross-sectional in nature, meaning that the data were collected at one point in time. The surveys were administered in the final three weeks of classes before final exams in the fall semester of 2004. Data were collected via confidential, anonymous self-report surveys handed out to students enrolled in the selected classes in attendance on the day that professors allowed the researcher to recruit participants. Whether participants were 
offered extra-credit for their participation was at the discretion of the professor. The students received no other inducement for their participation.

The desired method of collection was to administer surveys during class time. There was one class that could not accommodate this due to time constraints, so the students were given self-addressed envelopes attached to the surveys and were instructed to mail them to the

researcher via campus mail. Three other classes had surveys handed out by the researcher during one class period and they were returned in sealed envelopes to the professors at the start of the next class period. After the second class period, the researcher collected the surveys from the professors.

\section{$\underline{\text { Data Collection Instrument }}$}

The apparatus for the current study was a self-report survey questionnaire (see Appendix). The surveys took approximately 20 minutes to complete. Each survey started with a cover page that introduced the study and stated the purpose. Also, contact information was included for the researcher. Resources were also included for those participants who might have adverse effects or were in need of intervention for intimate violence or substance use.

The body of the survey consisted of seven sections, the first six of which were for males and females and the final section which was for females only for use in another study. Section one consisted of demographic information such as age, gender, relationship status and length, marital status, religiosity, etc. Measures of violence in the participants' relationships made up section two. The participant's motivation for engaging in intimate violence was section three. Section four consisted of measures of interparental violence witnessed by the participant. Section five was composed of questions relating to the participants' substance use. And finally, section six included measures of the participants' self-esteem and narcissism. 


\section{$\underline{\text { Measures }}$}

\section{$\underline{\text { Demographics }}$}

For this study, demographics were assessed via straightforward questions. Some of the variables measured were categorical in nature while others were continuous. Participants were asked to indicate their age, gender, classification, marital status, etc. Age and current relationship length are both continuous. Most of the other demographics, such as gender, marital status, and current relationship, were categorical.

\section{Conflict Tactics Scale (CTS)}

Straus (1979) developed the Conflict Tactics Scale in order to measure interfamilial violence. The Conflict Tactics Scale is the most often used measure of physical aggression in married couples and dating relationships (Archer, 1999). The scale consists of a list of 19 actions that a person might take when in conflict with another. The participants were asked to read each action and indicate how often they employed that tactic when in conflict with their partner and also, how many times their partner used that tactic toward them during the previous 12 months. The response categories were a Likert-type scale ranging from 0 (never) to more than 20 times (6). The same list was presented a second time and participants were asked to indicate how often their mother and father had used the tactics toward each other either during the previous 12 months if they still lived at home or in the last year that they lived with their parents.

Using exploratory factor analysis, three factors emerge from the Conflict Tactics Scale. These findings are consistent with those of other researchers (Archer, 1999; Archer, 2000a; Straus, 1979; Straus \& Gelles, 1990). These three factors correspond to reasoning, verbal or symbolic aggression, and physical aggression. While the Conflict Tactics Scale was administered in its entirety for the current study, the physical aggression subscale was the only part retained 
for analyses. The tactics that make up the physical aggression subscale range represent both low level and severe violence. The acts included are: threw something at someone, pushed/grabbed/shoved, slapped, kicked/hit/bit, hit/tried to hit with something, beat up, choked, threatened with a knife or gun, and used a knife or fired a gun (Straus \& Gelles). Responses for each item were summed to obtain an overall score of physical violence.

Analyses to assess the reliability of the physical aggression subscale of the CTS based on Cronbach's alpha coefficient have been found to range from .42 to .96 (Straus \& Gelles, 1990). In the current study, the CTS was administered twice: once for the participants' relationship and again for the relationship of the participants' mother and father. Cronbach's alpha was conducted to determine the reliability of the scale in the current study. In the current study, the scale was found to be reliable in all four instances. For self to partner, alpha was .88; partner to self, .92; mother to father, .90 ; and father to mother, .93 . These findings were consistent with previous studies using the CTS (Straus, 1979; Straus \& Gelles).

\section{$\underline{\text { Rosenberg's Self-Esteem Scale }}$}

For the current research, self-esteem was measured via a scale developed by Rosenberg (1965). This scale is the most widely used measure of self-esteem in use today (WhitesideMansell \& Corwyn, 2003). In general, self-esteem refers to a person's overall perceptual assessment of his/her personal worth (Papps \& O'Carroll, 1998). The scale consists of 10 straight-forward items. These items included such statements as "On the whole, I am satisfied with myself"; "I am able to do things as well as most other people"; and "I take a positive attitude toward myself". There were five statements that were straightforward like these. In addition, there were five items that were presented in reverse fashion in order to control for participants marking one answer for all items. These reverse items included such statements as "I 
certainly feel useless at times"; "I feel I do not have much to be proud of"; and "I wish that I could have more respect for myself".

The response category was a four-point Likert-type scale. The responses ranged from strongly agree (1) to strongly disagree (4). The responses that were straightforward were reverse coded, and responses were added together to obtain an overall score of self-esteem. Based on the scoring and the reverse coding of the straightforward items, higher scores correspond to higher self-esteem while lower scores indicate lower self-esteem.

Based on Cronbach's alpha, Rosenberg's (1965) self-esteem scale has been found to have high reliability. Previous studies have found the reliability coefficient to range from .81-.83 (Whiteside-Mansell \& Corwyn, 2003). For the current study, the reliability coefficient was found to be .90 . This reliability was sufficient and consistent with previous findings. Narcissistic Personality Inventory (NPI)

Raskin and Hall (1979) developed the Narcissistic Personality Inventory as a measure of narcissistic traits in non-clinical individuals. While some traits of narcissism are maladaptive, all of them are not. Some aspects of narcissism such as self-sufficiency and leadership have been found to be adaptive in nature and to be indicative of mental health. The NPI consists of 47 forced-choice statements that are answered based on true/false responses. The statements are based on characteristics that are deemed to be indicative of narcissism in individuals.

Based on exploratory factor analysis of the complete NPI completed by Emmons (1987) and Raskin and Terry (1988), several factors emerge. Two of these factors are entitlement and exploitativeness (Emmons; Raskin \& Terry). Among the seven factors that emerge, research indicates that the two aforementioned traits of exploitativeness and entitlement are more maladaptive and less conducive to healthy functioning (Raskin \& Terry; Soyer, Rovenpor, 
Kopelman, Mullins, \& Watson, 2001; Watson \& Biderman, 1993). Based on these findings, the current study included only those eight items which loaded on the exploitativeness and entitlement factor in the survey for analysis. The items for these factors were selected based on research by Emmons.

Instead of the standard dichotomous response category, the current research employed a four-point Likert-scale ranging from strongly agree (1) to strongly disagree (4). The statements included "I expect a great deal from other people"; "I insist on getting the respect that is due to me"; and "I find it easy to manipulate people". After the responses were reverse coded, they were added together to get an overall score of narcissism. Higher overall scores indicate higher narcissism while lower scores indicate lower narcissism.

Again, Cronbach's alpha was computed to determine the reliability of the scale. For the eight items composing the entitlement/exploitativeness factor, alpha was .68 for the current study. This was exactly the same as the alpha coefficient obtained by Emmons (1987) and was sufficient for this study.

\section{$\underline{\text { Variables }}$}

\section{$\underline{\text { Dependent }}$}

The current study investigated intimate violence while examining two dependent variables. The first of these variables was intimate violence perpetrated by the participant against their partner. The second variable was intimate violence received by the participant from their partner. These variables were based on the physical aggression subscale of the Conflict Tactics Scale. Both of these variables were continuous and measured at the interval-ratio level. 


\section{$\underline{\text { Independent }}$}

There were several independent variables of interest in the current study. The first category of independent variables was demographics. These included gender, race, and age. Gender was a dichotomous, nominal variable. For purposes of this study, gender was dummycoded in order for meaningful analysis to be undertaken. Race was collapsed into a dichotomous, nominal variable of White and non-White. This variable was also dummy-coded for analysis. Age was a continuous variable measured at the interval-ratio level.

In addition to being the dependent variables of interest, the participants' reported perpetration and receipt of violence also served to be independent variables. These two variables were used as independent variables in an attempt to determine whether there was a reciprocal quality to the violence that the participants experienced. Again, these variables were based on the physical aggression subscale of the CTS. These variables were both continuous and measured at the interval-ratio level of measurement.

The study also examined concepts derived from theories of social learning and differential association. Violence witnessed in the family of origin was another independent variable of interest. This variable was assessed based on the physical violence subscale of the CTS for mother and father conflict. The totals for both mother-to-father and father-to-mother were added together. The total scale for interparental violence was used for analyses, with higher scores corresponding to more violence in the family of origin. The scale was continuous and measured at the interval/ratio level. In addition, the variable was collapsed into yes and no, indicating whether or not any violence had been witnessed, in order to perform bivariate analyses. 
In addition to a total score for interparental conflict, separate scores for mother to father violence and father to mother violence were also retained. These scores were used to investigate whether violence by one parent had more impact than that by the other. Again, higher scores indicated more violence used while lower scores indicated less violence was used.

Finally, threatened egotism was examined by assessing the values of self-esteem and narcissism. Scores on the self-esteem and narcissism scales were multiplied in order to develop an interaction term representative of threatened egotism. Higher scores indicated higher selfesteem and higher narcissism.

\section{$\underline{\text { Analyses }}$}

\section{$\underline{\text { Univariate }}$}

Univariate analyses were undertaken on all independent and dependent variables of interest. Demographics were examined for composition of the sample. Descriptive statistics were analyzed for gender and racial composition as well as relationship status and classification. In addition measures of central tendency were examined for age and relationship length in an attempt to assess the normalcy of the distribution.

\section{Bivariate}

Bivariate analyses were conducted to examine relationships that occurred between variables. A t-test for mean differences was used to determine whether there were any gender differences for perpetration or receipt of intimate violence. In addition, a t-test was also used to determine whether those participants who witnessed violence in their family of origin reported differences in the perpetration or receipt of intimate violence. Finally, t-tests were also run for both self-esteem and narcissism to determine if any differences emerged in the mean scores of both scales. 
Correlations were conducted to determine whether relationships existed between variables. For all interval level variables, a correlation matrix was generated to examine these relationships. This included all scales and the demographic variable of age.

Cross tabs were constructed and chi-square tests of independence were undertaken to determine whether variables were independent of each other. These tests were conducted with the use of dichotomous nominal variables. These variables were based on the receipt and expression of intimate violence, race, gender, and whether or not violence had been witnessed in the family of origin.

$\underline{\text { Multivariate }}$

Ordinary least squares regression was conducted in an attempt to examine the reported perpetration of intimate violence as a function of the receipt of violence, witnessed family of origin violence, and ego threat while controlling for gender, race, and age. Multiple regression models were included to determine the influence of certain variables added in a stepwise manner on the dependent variables. Separate regressions were also conducted for males and females because variables may affect them differently.

\section{$\underline{\text { Summary }}$}

As stated before, this study was an investigation into factors that were purported to affect the use of aggression in intimate relationships. While there are many possible factors that could contribute to the use of aggression in relationships, this study focused on a limited number. These factors were based on theories derived from differential association, social learning, and self-esteem. Based on these theories, family of origin violence and receipt of violence along with high self-esteem and narcissism were assessed in relation to perpetration of physical aggression in intimate relationships. 
The methodology of the current study was consistent with those that have been employed in previous research. All of the scales in the current study were reliable based on analysis of Cronbach's alpha. The obtained alphas in this study ranged from .68 to .93 . The demographics of the sample were consistent with those of the student population of East Tennessee State University, which allows for more inferences to be generalized to the population, at least, of East Tennessee State University. These characteristics coupled with the large randomly selected sample lend credence to the current study and results, which will be discussed in the following chapter. 


\section{CHAPTER 4}

\section{RESULTS}

Several different analytical strategies were undertaken in order to determine what, if any, relationships exist between the variables of interest. Univariate statistics were conducted in order to get an idea of the composition of the sample. Measures of dispersion were conducted in order to determine if the variables were normally distributed or skewed in some direction. These statistics are descriptive in nature as they only describe the sample and are not inferential. Bivariate statistics were also run to test for relationships between variables and also to compare means of different groups. Chi-square tests and correlations test for significant relationships between two variables. These statistics are not casual in nature, therefore, the existence of relationships can be inferred but cause and effect cannot be determined. Independent samples ttests were conducted to determine if the means scores of variables are the same for different groups. Finally, multivariate statistics were conducted in order to determine which variables retain their significance when other variables are examined simultaneously. Equations were developed in order to predict the dependent variable of interest. In addition, each variable can be examined to determine the strength and direction of the impact.

In order to perform analyses for the variables under investigation, some were collapsed categorically. While race was measured based on five categories, for analysis, race was recoded into the variable white with the categories White and non-White. There were too few participants indicating races other than White to conduct meaningful analysis. While family of origin violence includes both the scales of mother to father violence and father to mother violence, the individual scales were also retained in order to analyze relationships more fully. In addition, while scales were retained for analysis, the variables of self perpetration, partner perpetration, 
and family of origin violence were dichotomized into yes and no in order to conduct mean comparisons and categorical comparisons.

\section{$\underline{\text { Univariate Statistics }}$}

For the current study, frequencies were conducted for the categorical variables of interest. The majority of these variables are demographics. Frequencies were run for academic classification, gender, current relationship status, marital status, race, self perpetration of violence, and self victimization (see Table 1). There were 423 participants in this study. Of these, $35 \%$ (147) were male and $65 \%$ (276) were female. In terms of race, $93 \%$ of the participants indicated that they were White with 7\% reporting that they were non-White. For classification, the sample was made up of $15 \%$ (64) freshman, 20\% (83) sophomores, $28 \%$ (118) juniors, 35\% (148) seniors, .5\% (2) graduate students, and 2\% (8) other. Eighty percent (340) of the participants indicated that they had never been married, 15\% (63) indicated they were currently married, $4 \%$ (17) were divorced, .5\% (2) were separated, and .2\% (1) indicated they were widowed. Besides the $15 \%$ of participants who were married, for current relationship status, $29 \%$ (121) indicated that they were not currently dating, 16\% (66) were casually dating, 33\% (139) were seriously dating, and 8\% (33) indicated that they were currently engaged.

In order to establish prevalence rates for this sample, frequencies were conducted for the dichotomized variables of self perpetration and self victimization. For those participants in this sample who reported on their violent perpetration, $80 \%$ (316) reported no perpetration of violence while $20 \%$ (78) reported that they had perpetrated violence against a partner in the past year. For self-reported victimization, $79 \%$ (300) had not and 22\% (82) had been the victim of violence during the past year. For an overall prevalence rate of violence in intimate relationships, 
$24 \%$ of the current sample indicated that they had been involved in violent interactions in the past year, either as perpetrator or victim.

Table 1

Frequencies

\begin{tabular}{|c|c|c|}
\hline Variable & Frequency & Percent \\
\hline \multicolumn{3}{|l|}{ Gender } \\
\hline Female & 276 & 65.2 \\
\hline Male & 147 & 34.8 \\
\hline \multicolumn{3}{|l|}{ Race } \\
\hline White & 391 & 92.4 \\
\hline Non-White & 29 & 6.9 \\
\hline \multicolumn{3}{|l|}{ Classification } \\
\hline Freshman & 64 & 15.1 \\
\hline Sophomore & 83 & 19.6 \\
\hline Junior & 118 & 27.9 \\
\hline Senior & 148 & 35.0 \\
\hline Graduate & 2 & .5 \\
\hline Other & 8 & 1.9 \\
\hline \multicolumn{3}{|l|}{ Current Relationship } \\
\hline Single, Not Dating & 121 & 28.6 \\
\hline Casually Dating & 66 & 15.6 \\
\hline Seriously Dating & 139 & 32.9 \\
\hline Engaged & 33 & 7.8 \\
\hline Married & 63 & 14.9 \\
\hline \multicolumn{3}{|l|}{ Marital Status } \\
\hline Single, Never Married & 340 & 80.4 \\
\hline Married & 63 & 14.9 \\
\hline Divorced & 17 & 4.0 \\
\hline Separated & 2 & .5 \\
\hline Widowed & 1 & .2 \\
\hline \multicolumn{3}{|l|}{ Any Intimate Violence } \\
\hline Yes & 100 & 23.6 \\
\hline No & 281 & 66.4 \\
\hline \multicolumn{3}{|l|}{ Perpetration } \\
\hline Yes & 78 & 18.4 \\
\hline No & 316 & 74.7 \\
\hline
\end{tabular}


Table 1 (continued)

\begin{tabular}{ccc}
\hline Variable & Frequency & Percent \\
\hline Victimization & & \\
Yes & 82 & 19.4 \\
No & 300 & 70.9 \\
\hline
\end{tabular}

Descriptive statistics were generated for all of the interval level variables, which included: age, self-esteem, narcissism, ego threat, family of origin violence, mother violence, father violence, perpetration, and victimization (see Table 2). For each of these variables, the mean, median, mode, minimum, maximum, and standard deviation were obtained. The youngest participant in the study reported being 17 years old with the oldest 58 . The mean age was 22.31 years with a standard deviation of 5.068, and a median and mode of 21 . This means that age was slightly positively skewed with more participants reporting being younger, which is to be expected with a college sample. The self-esteem scale had a minimum of 13 and a maximum of 40. Lower scores indicate lower self-esteem with higher scores indicating higher self-esteem. The mean score on the self-esteem scale was 32 with a standard deviation of 5.42 and a median of 32 and a mode of 40 . This distribution is slightly negatively skewed indicated by the most frequently cited score being higher than the mean and median. On the narcissism scale, the minimum was 8 with a maximum of 29. Again, lower scores indicate lower narcissism and higher scores indicate higher narcissism. The mean narcissism score was 18.29 with a standard deviation of 3.50 and a median of 18 and mode of 19 . These scores indicate that the distribution is fairly normally distributed. The measure of ego threat was obtained by multiplying the participants' scores on the self-esteem scale and narcissism scale to create an interaction term. The interaction term was created in this way so that those with high self-esteem and high narcissism would have the highest scores for ego threat. For the measure of ego threat, the minimum score was 144 with a maximum of 1000 . The mean was 585.50 with a standard 
deviation of 149.08 and a median of 570 and mode of 540. This distribution is somewhat positively skewed as evidenced by the mode being less than the median and mean.

Descriptive statistics were also obtained for each of the scales measuring physical violence (see Table 2). For the participants' report of their own perpetration, the minimum was 0 , indicating they did not perpetrate violence against their partner, with a maximum of 31 . The mean score was 1.19 with a standard deviation of 3.94 and both a median and mode of 0 . This indicates that the distribution is positively skewed, which is to be expected because the majority of participants did not express violence against their partners. A similar pattern was observed for all measures of violence which is expected as violence is a low baseline phenomenon. The minimum score for partner perpetration was 0 with a maximum of 53 . The mean score for victimization was 1.59 with a standard deviation of 5.40 and both a median and mode of 0 . As for perpetration, the minimum was 0 with a maximum of 68 . The mean score for interparental violence was 2.42 with a standard deviation of 9.06 and, again, both a median and mode of 0 . The scales which were added together to obtain the total score of interparental violence were the mother violence and father violence. The minimum score for mother violence was 0 with a maximum of 33 . The mean score for mother violence was 1.48 with a standard deviation of 4.43 and both a median and mode of 0 . For father violence, the minimum was 0 with a maximum of 43. The mean score for father violence was 1.48 with a standard deviation of 6.07 and, again, both a median and mode of 0 . As stated before, all of the distributions for the violence scales are positively skewed indicating that the majority of participants had not had experience with violence in the past year. Again, this is expected due to the low baseline of violence in society. 
Table 2

Descriptive Statistics

\begin{tabular}{|c|c|c|c|c|c|c|}
\hline Variable & Min & Max & Mean & Std. Deviation & Mode & Median \\
\hline Age & 17 & 58 & 22.31 & 5.068 & 21 & 21 \\
\hline Perpetration & 0 & 31 & 1.1904 & 3.943 & 0 & 0 \\
\hline Victimization & 0 & 53 & 1.5890 & 5.395 & 0 & 0 \\
\hline Interparental Violence & 0 & 68 & 2.4206 & 9.063 & 0 & 0 \\
\hline Mother Violence & 0 & 33 & 1.1088 & 4.431 & 0 & 0 \\
\hline Father Violence & 0 & 43 & 1.4753 & 6.072 & 0 & 0 \\
\hline Ego Threat & 144 & 1000 & 585.4962 & 149.077 & 540 & 570 \\
\hline Narcissism & 8 & 29 & 18.2882 & 3.505 & 19 & 18 \\
\hline Self-Esteem & 13 & 40 & 32.0099 & 5.425 & 40 & 32 \\
\hline
\end{tabular}

\section{$\underline{\text { Bivariate Statistics }}$}

\section{$\underline{\text { Chi-square }}$}

Several different bivariate analyses were run in order to determine if variables were significantly related to one another. Cross-tab tables were constructed and chi-square tests of independence were conducted for the categorical variables of perpetration with gender, race, interparental violence, and victimization (see Table 3). In addition, the same procedure was carried out for victimization with gender, race, and interparental violence (see Table 5). The purpose of this statistical test is to determine if the variables exist independent of each other. This is done by comparing the observed cell frequencies with those cell frequencies that would be expected if the two variables occurred independently of each other. Chi-square tests of independence are an appropriate test for variables measured at the nominal level. Upon discovery 
of a significant relationship, the cross-tab table can be consulted in order to determine where the difference lies.

Table 3

Perpetration Cross-Tabs

Perpetration

No $\quad$ Yes

\begin{tabular}{lll}
\hline Gender & $86.6 \%$ & $13.4 \%$ \\
Male & $76.9 \%$ & $23.1 \%$ \\
Female & & \\
\hline Race & $72.7 \%$ & $27.3 \%$ \\
Non-White & $80.5 \%$ & $19.5 \%$ \\
White & & \\
Victimization & $93.7 \%$ & $6.3 \%$ \\
No & $34.6 \%$ & $65.4 \%$ \\
Yes & & \\
Interparental Violence & $83.7 \%$ & $16.3 \%$ \\
No & $66.7 \%$ & $33.3 \%$ \\
Yes & & \\
\hline
\end{tabular}

For perpetration, the relationships between the variables of gender, race, victimization, and interparental violence were tested for significance (see Table 4). For perpetration and gender, the chi-square was significant indicating that the variables are related $\left(\chi^{2}=5.180 ; p<.05\right)$. For perpetration, $23 \%$ of the females in the study indicated that they had perpetrated at least one act of intimate violence against a partner while only $13 \%$ of the males indicated the same (see Table 3). Based on these findings, females are more likely to be identified as perpetrating intimate violence than are males. Next, race and perpetration are examined. As mentioned 
before, race was categorized into White and non-White. For this pair of variables, the chi-square statistic was not significant indicating that there is no relationship between a participant's race and perpetration of intimate violence $\left(\chi^{2}=.795 ; p=.372\right)$. Perpetration and victimization were examined next. For these two variables, the chi-square statistic was significant indicating that they are related to each other $\left(\chi^{2}=145.344 ; p<.01\right)$. Of those who reported no victimization, only $6 \%$ had perpetrated intimate violence while $65 \%$ of those who had been victimized were also perpetrator (see Table 3). This distribution indicates that those who perpetrate intimate violence are more likely to also be victimized by intimate violence. Finally, perpetration and interparental violence are tested for independence. The chi-square statistic indicates that these variables are related to each other $\left(\chi^{2}=9.059 ; p<.05\right)$. Of those who did not witness interparental violence, $16 \%$ reported perpetrating intimate violence while $33 \%$ of those who did witness interparental violence also reported perpetrating intimate violence (see Table 3). These frequencies indicate that those participants who witnessed interparental violence are more likely to perpetrate intimate violence.

Table 4

Perpetration Chi-Square Tests for Independence

\begin{tabular}{lccc}
\hline Variables & $\chi^{2}$ value & df & sig. \\
\hline Perpetration*Gender & $5.180^{*}$ & 1 & .023 \\
Perpetration*Race & .795 & 1 & .372 \\
Perpetration*Victimization & $145.344^{* *}$ & 1 & .000 \\
Perpetration*Interparental Violence & $9.059^{* *}$ & 1 & .003 \\
${ }^{*} \mathrm{p}<.05$ & & & \\
${ }^{* *} \mathrm{p}<.01$ & &
\end{tabular}

Cross-tabs and chi-squares were also undertaken for victimization using all of the same variables with the exception of perpetration as that combination has already been examined (see 
Table 6). For victimization and gender, no significant relationship emerged $\left(\chi^{2}=.001 ; p=.980\right)$. In fact, the percentage of males reporting victimization was $21.5 \%$ while $21.4 \%$ of females reported being victimized (see Table 5). These percentages are almost identical indicating that males and females are equally victimized. For race and victimization, as with perpetration, no significant relationship emerged indicating that Whites and non-Whites experience similar levels of victimization $\left(\chi^{2}=.146 ; p=.702\right)$. Finally, interparental violence and victimization were examined. The chi-square statistic for these two variables indicates that they are significantly related $\left(\chi^{2}=4.260 ; p<.05\right)$. Of those who did not witness interparental violence, almost $20 \%$ reported victimization while $32 \%$ of those who did witness interparental violence also reported being victimized. These percentages indicate that those participants who witnessed interparental violence are more likely to report victimization from an intimate partner.

Table 5

Victimization Cross-Tabs

\section{$\underline{\text { Victimization }}$}

No Yes

\begin{tabular}{|c|c|c|}
\hline \multicolumn{3}{|l|}{ Gender } \\
\hline Male & $78.5 \%$ & $21.5 \%$ \\
\hline Female & $78.6 \%$ & $21.4 \%$ \\
\hline \multicolumn{3}{|l|}{ Race } \\
\hline Non-White & $75.0 \%$ & $25.0 \%$ \\
\hline White & $78.6 \%$ & $21.4 \%$ \\
\hline \multicolumn{3}{|c|}{ Interparental Violence } \\
\hline No & $80.5 \%$ & $19.5 \%$ \\
\hline Yes & $67.9 \%$ & $32.1 \%$ \\
\hline
\end{tabular}


Table 6

Victimization Chi-Square Tests for Independence

\begin{tabular}{lccc}
\hline Variables & $\chi^{2}$ value & df & sig. \\
\hline Victimization*Gender & .001 & 1 & .980 \\
Victimization*Race & .146 & 1 & .702 \\
Victimization*Interparental Violence & $4.260^{*}$ & 1 & .039 \\
${ }^{*} \mathrm{p}<.05$ & & & \\
${ }^{* *} \mathrm{p}<.01$ & &
\end{tabular}

\section{$\underline{\text { Correlations }}$}

A correlation matrix was constructed with all interval level variables in order to determine if variables were significantly correlated and whether that relationship was positive or negative based on the Pearson $r$ coefficient (see Table 7). Correlation is a statistical test that is appropriate for use with variables measured at the interval/ratio level that measures the linear relationship between two variables. The possible values range from negative one to positive one. A score with an absolute value of one would indicate a perfect linear relationship, while a score of zero would indicate no relationship. The sign of the score indicates whether the relationship is positive or negative. If the relationship is positive, as one variable increases, so does the other and vice versa. If the relationship is negative, as one variable increases, the other decreases and vice versa. When the $r$ value is squared, the resulting $r$-squared indicates the amount of variance in one variable that is explained by the other. 
Table 7

Pearson Correlation Matrix

\begin{tabular}{|c|c|c|c|c|c|c|c|c|}
\hline$\underset{0}{D}$ & 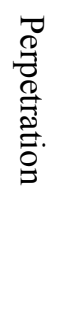 & 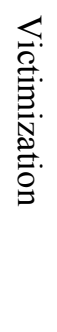 & 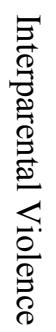 & 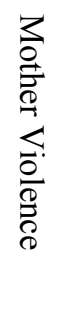 & 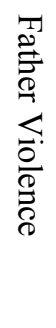 & 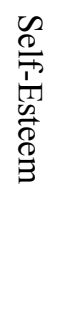 & 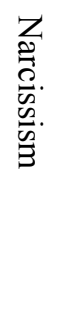 & 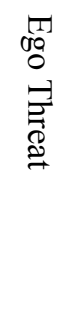 \\
\hline
\end{tabular}

\begin{tabular}{|c|c|c|c|c|c|c|c|c|c|}
\hline Age & --- & & & & & & & & \\
\hline Perpetration & -.076 & --- & & & & & & & \\
\hline Victimization & -.038 & $.561^{* *}$ & --- & & & & & & \\
\hline Interparental Violence & .100 & $.305^{* *}$ & $.178^{* *}$ & --- & & & & & \\
\hline Mother Violence & $.115^{*}$ & $.372^{* *}$ & $.148^{* *}$ & $.849^{* *}$ & --- & & & & \\
\hline Father Violence & .064 & $.211^{* *}$ & $.164^{* *}$ & $.920^{* *}$ & $.573^{* *}$ & --- & & & \\
\hline Self-Esteem & .016 & $-.176^{* *}$ & $-.161^{* *}$ & -.068 & -.025 & $-.107^{*}$ & --- & & \\
\hline Narcissism & $-.139^{* *}$ & .051 & .031 & -.047 & -.035 & -.027 & -.020 & --- & \\
\hline Ego Threat & -.064 & -.093 & -.094 & -.092 & -.058 & -.099 & $.639^{* *}$ & $.739^{* *}$ & --- \\
\hline
\end{tabular}

In the current study, the variables included in the correlation matrix are: age, perpetration, victimization, interparental violence, mother violence, father violence, self-esteem, narcissism, and ego threat. Age had a weak positive correlation with mother violence $(r=.115$; $p<.05)$. This indicates that older participants reported witnessing more mother to father violence. Age also had a negative correlation with narcissism $(r=-.139 ; p<.01)$. This negative relationship indicates that younger participants reported higher narcissism than older participants.

For perpetration, several significant relationships emerge. Perpetration has a strong, positive relationship with victimization $(r=.561 ; p<.01)$. This indicates that participants reporting 
more perpetration also reported more victimization. A significant positive relationship was also found for perpetration and interparental violence $(r=.305 ; p<.01)$. This indicates that those participants reporting higher levels of perpetration also reported witnessing more interparental violence. For mother violence $(r=.372 ; p<.01)$ and father violence $(r=.211 ; p<.01)$, the two components of interparental violence, positive significant relationships also emerged. This indicates that those who witnessed higher levels of mother and father violence also reported higher levels of perpetration. A significant negative relationship emerged for perpetration and self-esteem, indicating that higher levels of perpetration correspond to lower self-esteem ( $r=-$ $.176 ; p<.01)$.

Several significant relationships emerged for victimization as well. Victimization had a significant positive relationship with interparental violence $(r=.178 ; p<.01)$. This indicates that participants who reported more victimization also reported witnessing more interparental violence. Again, significant positive relationships emerged for the mother violence ( $r=.148$; $p<.01)$ and father violence $(r=.164, p<.01)$ with victimization. This means that those participants who reported more victimization also reported witnessing both their mothers and fathers engaging in more violence. Finally, victimization also had a significant negative relationship with self-esteem, indicating that those reporting more victimization also reported lower selfesteem $(r=-.161 ; p<.01)$.

In addition to the aforementioned relationships, interparental violence was also found to be positively significantly related to mother violence $(r=.849 ; p<.01)$ and father violence $(r=.920$, $p<.01$ ), which is logical as the variable is a computation of these two components. Mother violence was also found to be significantly positively related to father violence, meaning that reciprocity also appears to be a factor in interparental violence $(r=.573 ; p<.01)$. In addition, 
father violence has a significant negative relationship with self-esteem $(r=-.107 ; p<.05)$. This indicates that those participants reporting higher levels of violence by their fathers also reported lower self-esteem.

For the variable of ego threat, the only significant relationships that emerged were for those variables that were its components. As expected, self-esteem was significantly positively related to ego threat, meaning that higher self-esteem corresponded to higher scores on ego threat $(r=.639 ; p<.01)$. In addition, narcissism had a significant positive relationship with ego threat $(r=.739 ; p<.01)$. This indicates, as would logic, that higher self-esteem corresponded to higher scores on ego threat.

Mean Comparisons

Independent samples $t$-tests were conducted in order to determine if different groups had significantly different mean scores on various interval variables of interest. A $t$-test is a statistical test that is appropriate for use with a dichotomous nominal level independent variable and interval/ratio level dependent variable. A t-test groups the data according to the dichotomous independent variable and compares the calculated mean scores of the dependent variable for the two groups. The purpose is to determine whether significantly different mean scores occur based on group membership. In the current study, the dependent variables of interest were perpetration, victimization, self-esteem, and narcissism. The independent variables were gender, race, interparental violence, perpetration, and victimization. As dependent variables, the scales of perpetration, victimization, and interparental violence are all incidence measures, meaning that higher scores indicate more incidences in which the variable of interest occurred.

The first dependent variable under examination is perpetration (see Table 8). For perpetration and gender, initially looking at only those who reported that they had perpetrated 
violence, the mean for males was 6.44 while the mean for females was 5.88 . These means were not significantly different from each other $(t=.294 ; p=.770)$. Next, perpetration was examined for all participants, not just those who indicated that they had perpetrated violence. Again, no differences emerged in the mean for perpetration based on gender $(t=1.174 ; p=.241)$. This indicates that males and females reported relatively equal levels of perpetration. Perpetration and race were also examined, and, again the means for perpetration of Whites and non-Whites were not significantly different $(t=.906 ; p=.365)$. Finally, perpetration and interparental violence were examined by comparing the means of those who had and had not witnessed interparental violence. The mean scores for perpetration of those who had witnessed interparental violence were significantly higher than the mean score for those who had not witnessed interparental violence $(t=2.423 ; p<.05)$.

Table 8

Perpetration t-tests

\begin{tabular}{|c|c|c|c|c|}
\hline & erpetratic & & & \\
\hline Variable & Mean & $t$ & df. & sig. \\
\hline Gender & & 1.174 & 392 & .241 \\
\hline Male & .8657 & & & \\
\hline Female & 1.3577 & & & \\
\hline Gender (Perp. only) & & .294 & 76 & .770 \\
\hline Male & 6.4444 & & & \\
\hline Female & 5.8833 & & & \\
\hline Race & & .906 & 390 & .365 \\
\hline Non-White & .4545 & & & \\
\hline White & 1.2405 & & & \\
\hline
\end{tabular}


Table 8 (continued)

\begin{tabular}{ccccc}
\hline & Perpetration & & & \\
\hline Variable & Mean & $t$ & df. & sig. \\
\hline Interparental Violence & & $2.423^{*}$ & 60.498 & .018 \\
No & .7375 & & \\
Yes & 2.7895 & & \\
& & & \\
${ }^{*} \mathrm{p}<.05$ & & & \\
${ }^{* *} \mathrm{p}<.01$ & & &
\end{tabular}

In addition to perpetration, mean scores on the victimization scale were also examined for differences (see Table 9). Initially, mean scores for only those who were victimized were compared based on gender. For those who reported being victimized, no significant differences emerged for victimization based on gender $(t=.666 ; p=.507)$. For all participants, victimization scores again did not differ significantly based on gender $(t=.568 ; p=.570)$. Next, mean scores of victimization were compared based on race. As in perpetration, the mean victimization scores of Whites did not significantly differ from those of non-Whites $(t=.592 ; p=.554)$. Finally, mean victimization scores were compared for those who had and had not witnessed interparental violence. For victimization, no significant differences based on witnessing interparental violence $(t=1.347 ; p=.183)$.

Table 9

Victimization t-tests

$\underline{\text { Victimization }}$

\begin{tabular}{lcccc}
\hline Variable & Mean & $t$ & df. & sig. \\
\hline Gender & & .568 & 380 & .570 \\
Male & 1.8077 & & & \\
Female & 1.4762 & & & \\
& & & & \\
\hline
\end{tabular}


Table 9 (continued)

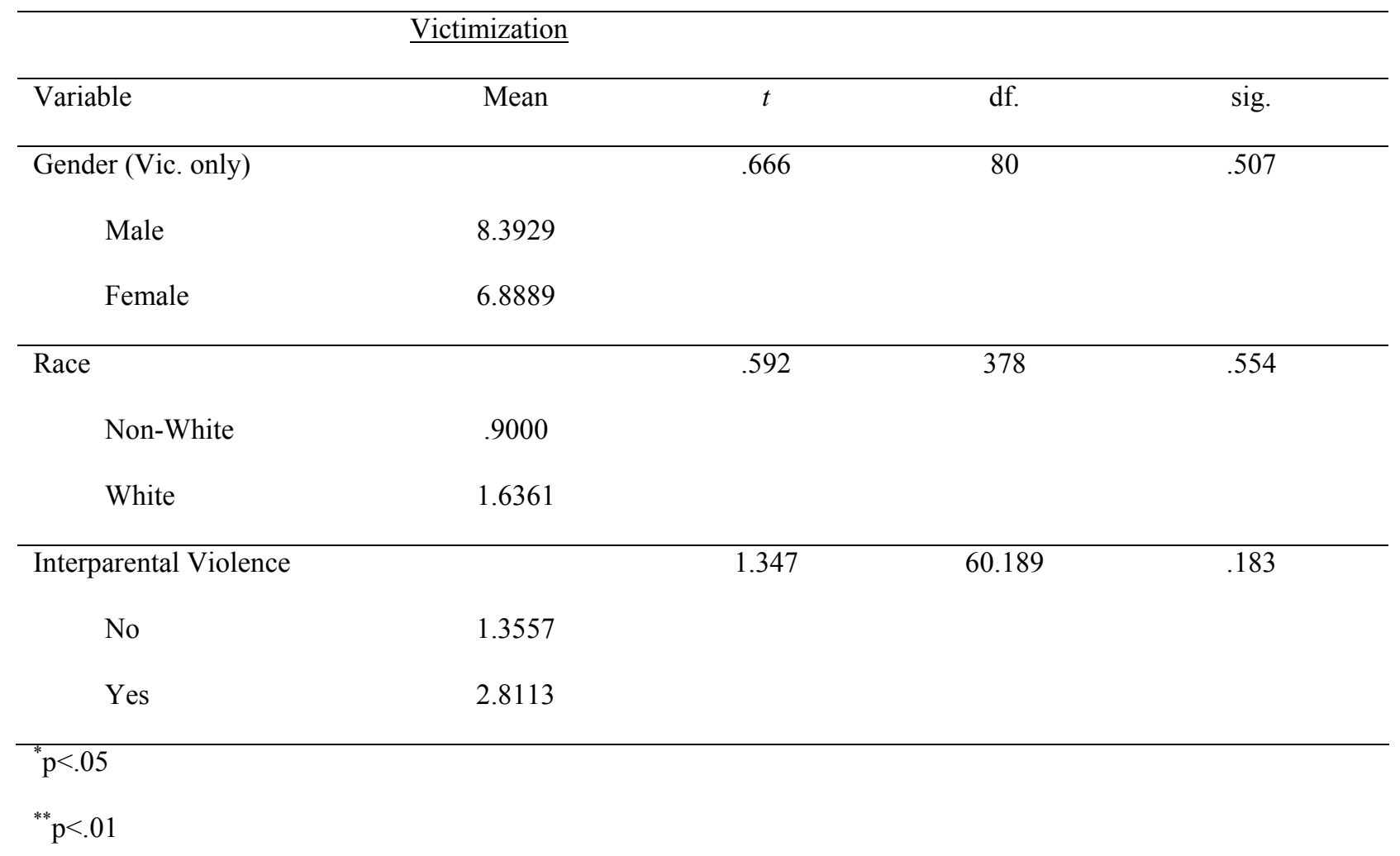

The next dependent variable of interest was self-esteem. The mean scores on the selfesteem scale were compared based on gender, race, perpetration, and victimization (see Table 10). For gender, significant differences emerged indicating that males, on average, had higher self-esteem than did females $(t=2.828 ; p<.01)$. For race, however, there was no significant difference in self-esteem for White or non-White participants $(t=.227 ; p=.820)$. When comparing the self-esteem of those participants who had and had not perpetrated intimate violence, significant differences were found indicating that those who had perpetrated violence had lower self-esteem than those who had not $(t=3.440 ; p<.01)$. Finally, the self-esteem of those who had and had not been the victim of intimate violence was compared. The mean scores on this index were found to be significantly different with those who had been victimized reporting lower levels of self-esteem than those who had not $(t=3.437 ; p<.01)$. 
Table 10

Self-Esteem t-tests

\begin{tabular}{|c|c|c|c|c|}
\hline & Self-Esteem & & & \\
\hline Variable & Mean & $t$ & df. & sig. \\
\hline Gender & & $2.828^{* *}$ & 329.019 & .005 \\
\hline Male & 32.9930 & & & \\
\hline Female & 31.4791 & & & \\
\hline Race & & .227 & 400 & .820 \\
\hline Non-White & 32.2500 & & & \\
\hline White & 31.9894 & & & \\
\hline Perpetration & & $3.440^{* *}$ & 378 & .001 \\
\hline No & 32.4243 & & & \\
\hline Yes & 30.0395 & & & \\
\hline Victimization & & $3.437^{* *}$ & 366 & .001 \\
\hline No & 32.5451 & & & \\
\hline Yes & 30.2375 & & & \\
\hline \multicolumn{5}{|l|}{$\mathrm{p}<.05$} \\
\hline${ }^{* *} \mathrm{p}<.01$ & & & & \\
\hline
\end{tabular}

Finally, mean scores on the narcissism scale were compared based on gender, race, perpetration, and victimization (see Table 11). As with self-esteem, significant differences were found indicating that males had higher narcissism than females $(t=2.508 ; p<.05)$. Again, race was not a significant factor $(t=.129 ; p=.898)$. Mean scores for narcissism were not significantly different for White versus non-White participants $(t=.129 ; p=.898)$. When comparing those who had and had not perpetrated intimate violence, no significant differences emerged for mean scores of narcissism $(t=1.323 ; p=.187)$. And, finally, for those who had and had not been 
victimized by intimate violence, the mean scores of narcissism did not differ significantly

$(t=.315 ; p=.753)$.

Table 11

Narcissism t-tests

\begin{tabular}{|c|c|c|c|c|}
\hline & Narcissism & & & \\
\hline Variable & Mean & $t$ & df. & sig. \\
\hline Gender & & $2.508^{*}$ & 403 & .013 \\
\hline Male & 18.8857 & & & \\
\hline Female & 17.9737 & & & \\
\hline Race & & .129 & 401 & .898 \\
\hline Non-White & 18.1818 & & & \\
\hline White & 18.2808 & & & \\
\hline Perpetration & & 1.323 & 381 & .187 \\
\hline No & 18.1759 & & & \\
\hline Yes & 18.7763 & & & \\
\hline Victimization & & .315 & 371 & .753 \\
\hline No & 18.2218 & & & \\
\hline Yes & 18.3625 & & & \\
\hline \multicolumn{5}{|l|}{${ }^{*} \mathrm{p}<.05$} \\
\hline
\end{tabular}

\section{$\underline{\text { Multivariate Statistics }}$}

Finally, ordinary least squares regression was undertaken in order to determine whether the dependent variable can be predicted by the independent variables. Regression calculates a formula based on independent variables to produce a linear equation to aid in prediction. Regression can also be undertaken as a causal analysis. Several different independent variables are viewed simultaneously to determine whether an observed relationship really exists with the 
dependent variable or whether the relationship can be explained by other variables. Ordinary least squares regression is a statistical test appropriate for use with interval/ratio level data. Dichotomous variables can be included as independent variables if they are dummy-coded into values of one and zero. In ordinary least squares regression, the overall equation is tested for significance and each independent variable is subsequently tested for significance. For the overall equation, an adjusted r-squared is calculated which indicates the amount of variance in the dependent variable that is explained by the equation. For each independent variable, a standardized regression coefficient, or beta, is calculated. The absolute values of these coefficients can be compared to each other with greater values indicating more impact on the dependent variable. The signs of the coefficient can be interpreted in the same way as correlation with positive values indicating a positive relationship and negative values indicating a negative relationship.

In the current study, the independent variables included in the regression equations are: age, gender, race, perpetration, victimization, interparental violence, mother violence, father violence, ego threat, self-esteem, and narcissism. The first dependent variable of interest is perpetration. Regression equations were calculated for perpetration for all participants, females only, and males only. In addition, the equation was ran twice for each dependent variable, once with the composite scores for interparental violence and threatened egotism, and again for the components of each of these (i.e. mother violence, father violence, self-esteem, and narcissism) in order to determine the relationship more accurately. The second dependent variable of interest is victimization. Again, equations were calculated for all participants, females only, and males only. 


\section{$\underline{\text { Perpetration }}$}

The first regression equation was calculated for all participants with the dependent variable of perpetration of intimate violence and independent variables of gender, age, race, victimization, interparental violence, and ego threat (see Table 12). Based on an alpha level of .05 , the equation was found to be statistically significant $(F(6,319)=24.045, p<.01)$. The adjusted $R$-squared for the equation was .298, indicating that approximately $30 \%$ of the variance in perpetration was explained by the variables in the equation. Still observing an alpha level of .05 , only two of the independent variables included were significant. The most powerful predictor was victimization $(\beta=.514, p<.01)$ followed by interparental violence $(\beta=.096 ; p<.05)$. Both of these regression coefficients are positive indicating that higher levels of both victimization and witnessing interparental violence predict higher levels of perpetration. While gender approached significance $(\beta=.091 ; p=.059)$, it was not significant at the aforementioned alpha level of .05 which is the standard for the current study.

Table 12

Summary of Regression Analysis for Variables Predicting Perpetration of Intimate Violence

\begin{tabular}{lccc}
\hline \multicolumn{1}{c}{ Variable } & B & SE B & $\beta$ \\
\hline Equation 1 & 1.212 & 1.317 & \\
Constant & .313 & .029 & $.514^{* *}$ \\
Victimization & .038 & .019 & $.096^{*}$ \\
Interparental Violence & -.001 & .001 & -.045 \\
Ego Threat & -.047 & .037 & -.061 \\
Age & .442 & .764 & .027 \\
White & .647 & .341 & .091 \\
Gender & & & \\
\hline
\end{tabular}


Table 12 (continued)

\begin{tabular}{lccc}
\hline \multicolumn{1}{c}{ Variable } & B & SE B & $\beta$ \\
\hline Equation 2 & 2.062 & & \\
Constant & .306 & 1.739 & $.504^{* *}$ \\
Victimization & .197 & .029 & $.246^{* *}$ \\
Mother Violence & -.075 & .045 & $-.121^{*}$ \\
Father Violence & -.060 & .035 & -.092 \\
Self-Esteem & .019 & .031 & .020 \\
Narcissism & -.045 & .045 & -.058 \\
Age & .452 & .036 & .028 \\
White & .712 & .746 & $.100^{*}$ \\
Gender & Note. $R^{2}=.30$ for equation $1(\mathrm{p}<.01) . R^{2}=.33$ for equation $2(\mathrm{p}<.01)$. & \\
${ }^{*} \mathrm{p}<.05$ & & & \\
${ }^{* *} \mathrm{p}<.01$ & &
\end{tabular}

Next, interparental violence and ego threat were removed and mother violence, father violence, self-esteem, and narcissism were added (see Table 12). Again, the equation was found to be statistically significant $(F(8,317)=20.977 ; p<.01)$. With the addition of these variables, the adjusted $R$-squared increased to .330 , indicating that the included variables account for $33 \%$ of the variance. In this equation, four variables were found to be significant at the .05 level. In order of importance, these included: victimization $(\beta=.504 ; p<.01)$; mother violence $(\beta=.246$; $p<.01)$; father violence $(\beta=-.121 ; p<.05)$; and gender $(\beta=.100 ; p<.05)$. Self-esteem approached significance $(\beta=-.092 ; p<.052)$ but was not significant at the selected alpha level. Of the significant variables, the regression coefficients for victimization, mother violence, and gender were all positive. This indicates that higher levels of victimization and mother to father violence predicted more perpetration, and, because gender was coded 0 for males and 1 for females, that the constant level of perpetration was higher for females than for males when all the other 
variables were controlled. The regression coefficient for father violence was negative indicating that those participants who witnessed more father to mother violence reported less perpetration. In addition, while self-esteem was not statistically significant, it is worth noting that the regression coefficient was negative indicating that if a relationship had been found, it would have probably been negative in nature.

Next, a regression equation was calculated for female only perpetration as the dependent variable with victimization, interparental violence, ego threat, age, and race as the independent variables (see Table 13). The equation was found to be significant $(F(5,202)=20.113 ; p<.01)$. The adjusted $R$-squared was .316 indicating that the equation accounted for approximately $32 \%$ of the variance in females' perpetration. However, there was only one variable that was found to be significant at the .05 alpha level. Victimization was found to be a significant predictor of female perpetration $(\beta=.570 ; p<.01)$. The regression coefficient was positive indicating that females who experienced more victimization reported more perpetration.

Table 13

Summary of Regression Analysis for Variables Predicting Female Perpetration of Intimate Violence

\begin{tabular}{lccc}
\hline \multicolumn{1}{c}{ Variable } & B & SE B & $\beta$ \\
\hline Equation 1 & 1.492 & 1.576 & \\
Constant & .402 & .042 & $.570^{* *}$ \\
Victimization & -.017 & .029 & -.035 \\
Interparental Violence & -.001 & .002 & -.019 \\
Ego Threat & -.055 & .048 & -.065 \\
Age & .660 & .899 & .042 \\
White & & & \\
\hline
\end{tabular}


Table 13 (continued)

\begin{tabular}{lccc}
\hline \multicolumn{1}{c}{ Variable } & B & SE B & $\beta$ \\
\hline Equation 2 & 2.184 & & \\
Constant & .389 & 2.136 & $.552^{* *}$ \\
Victimization & .130 & .042 & .118 \\
Mother Violence & -.087 & .067 & $-.132^{*}$ \\
Father Violence & -.085 & .040 & $-.125^{*}$ \\
Self-Esteem & .066 & .040 & .065 \\
Narcissism & .779 & .059 & .050 \\
White & -.037 & .880 & -.045 \\
Age & Note. $R^{2}=.32$ for equation $1(\mathrm{p}<.01) . R^{2}=.35$ for equation $2(\mathrm{p}<.01)$. & \\
\hline${ }^{*} \mathrm{p}<.05$ & & .047 & \\
${ }^{* *} \mathrm{p}<.01$ &
\end{tabular}

Again, interparental violence and ego threat were removed and their components were added into the equation (see Table 13). Again, this equation was significant $(F(7,200)=16.683$; $p<.01)$. The adjusted $R$-squared increased to .347 , indicating that the equation explained approximately $35 \%$ of the variance. In this equation, there were three variables that reached significance and one that approached significance. In order of importance, these variables were: victimization $(\beta=.552 ; p<.01)$; father violence $(\beta=-.132 ; p<.05)$; and self-esteem $(\beta=-.125$; $p<.05)$. The variable of mother violence $(\beta=.118 ; p=.054)$ approached significance but did not quite make the .05 level. The regression coefficient for victimization was, again, positive indicating that more victimization predicted more perpetration. However, the coefficients for father violence and self-esteem were both negative indicating that females who witnessed more violence from their father towards their mother reported perpetrating less violence towards their intimate partners, and females with lower self-esteem reported perpetrating more violence. While 
the variable of mother violence was not significant, the coefficient was positive indicating that if a relationship had existed, it would most likely have indicated that females witnessing their mothers be violent towards their fathers would have perpetrated more violence towards their partners.

Finally, a regression equation was calculated for male perpetration only as the dependent variable with victimization, interparental violence, ego threat, age, and race as the independent variables (see Table 14). The equation was found to be significant $(F(5,112)=12.558 ; p<.01)$, with an adjusted $R$-squared of .331 indicating that approximately $33 \%$ of the variance was explained by the equation. Two variables were found to be significant at the .05 level of significance. In order of importance, these two variables were: victimization $(\beta=.460 ; p<.01)$ and interparental violence $(\beta=.293 ; p<.01)$. Both of the regression coefficients were positive indicating that males who experienced more victimization and witnessed more interparental violence also reported more perpetration.

Table 14

Summary of Regression Analysis for Variables Predicting Male Perpetration of Intimate Violence

\begin{tabular}{lccc}
\hline \multicolumn{1}{c}{ Variable } & B & SE B & $\beta$ \\
\hline Equation 1 & 2.053 & & \\
Constant & .214 & .036 & $.460^{* *}$ \\
Victimization & .082 & .022 & $.293^{* *}$ \\
Interparental Violence & -.002 & .001 & -.090 \\
Ego Threat & -.045 & .053 & -.067 \\
Age & .006 & 1.444 & .000 \\
White & & & \\
\hline
\end{tabular}


Table 14 (continued)

\begin{tabular}{lccc}
\hline \multicolumn{1}{c}{ Variable } & B & SE B & $\beta$ \\
\hline Equation 2 & 2.053 & & \\
Constant & .197 & 2.539 & $.422^{* *}$ \\
Victimization & .351 & .035 & $.656^{* *}$ \\
Mother Violence & -.186 & .080 & $-.340^{*}$ \\
Father Violence & .031 & .079 & .051 \\
Self-Esteem & -.094 & .044 & -.109 \\
Narcissism & -.068 & .065 & -.101 \\
Age & .242 & .051 & .013 \\
White & Note. $R^{2}=.33$ for equation $1(\mathrm{p}<.01) . R^{2}=.40$ for equation $2(\mathrm{p}<.01)$. & \\
\hline $\mathrm{p}<.05$ & & & \\
${ }^{* *} \mathrm{p}<.01$ &
\end{tabular}

As before, interparental violence and ego threat were removed and their components were added (see Table 14). This equation was also significant $(F(7,110)=12.210 ; p<.01)$. The adjusted $R$-squared increased to .401 indicating that approximately $40 \%$ of the variance was explained. Three variables were found to be significant at the .05 level. In order of importance, these variables were: mother violence $(\beta=.656 ; p<.01)$; victimization $(\beta=.422 ; p<.01)$; and father violence $(\beta=-.340 ; p<.05)$. Regression coefficients for mother violence and victimization were both positive indicating that more mother to father violence and more victimization were related to more perpetration by males. The coefficient for father violence was negative indicating that higher levels of father-to-mother violence corresponded to less perpetration by males.

\section{$\underline{\text { Victimization }}$}

In addition to computing various regression equations in an attempt to explain perpetration, equations were also computed for victimization. The first such equation examines 
victimization for all participants as the dependent variable with perpetration, interparental violence, ego threat, age, race, and gender as independent variables (see Table 15). The equation was significant $(F(6,319)=23.061 ; p<.01)$, with an adjusted $R$-squared of .289 indicating that the equation explained about $29 \%$ of the variance in victimization. However, only one of the variables in the equation was significant at an alpha of .05 . This one variable was perpetration $(\beta=.521 ; p<.01)$. Because the regression coefficient is positive, this indicates that those participants reporting more victimization also reported more perpetration.

\section{Table 15}

Summary of Regression Analysis for Variables Predicting Victimization of Intimate Violence

\begin{tabular}{|c|c|c|c|}
\hline Variable & B & SE B & $\beta$ \\
\hline \multicolumn{4}{|l|}{ Equation 1} \\
\hline Constant & 2.824 & 2.179 & \\
\hline Perpetration & .857 & .079 & $.521^{* *}$ \\
\hline Interparental Violence & .054 & .031 & .084 \\
\hline Ego Threat & -.002 & .002 & -.052 \\
\hline Age & -.014 & .061 & -.011 \\
\hline Gender & -.906 & .566 & -.077 \\
\hline White & -.134 & 1.265 & -.055 \\
\hline \multicolumn{4}{|l|}{ Equation 2} \\
\hline Constant & 4.070 & 2.928 & \\
\hline Perpetration & .869 & .081 & $.528^{* *}$ \\
\hline Mother Violence & -.077 & .078 & -.058 \\
\hline Father Violence & .147 & .059 & $.144^{*}$ \\
\hline Self-Esteem & -.083 & .052 & -.078 \\
\hline Narcissism & -.003 & .075 & -.002 \\
\hline Age & .003 & .061 & .002 \\
\hline
\end{tabular}


Table 15 (continued)

\begin{tabular}{|c|c|c|c|}
\hline Variable & B & SE B & $\beta$ \\
\hline Gender & -.961 & .562 & -.082 \\
\hline White & -.151 & 1.258 & -.006 \\
\hline${ }^{*} \mathrm{p}<.05$ & $\overline{p<.01}$ & on 2( & \\
\hline
\end{tabular}

As for perpetration, interparental violence and ego threat were removed and their components were added to the equation (see Table 15). With these modifications, the equation was significant $(F(8,317)=18.185 ; p<.01)$, and the adjusted $R$-squared increased slightly to .297 , explaining about $30 \%$ of the variance in victimization. Two variables emerged as significant at the .05 level. These two variables, in order of predictive power, were: perpetration $(\beta=.528 ; p<.01)$; and father violence $(\beta=.144 ; p<.05)$. Both of these regression coefficients were positive. The variable of perpetration acted in the same way as was seen in the earlier equation. In addition, these findings suggest that participants who witnessed increased levels of father to mother violence also reported increased victimization.

In addition, regression equations were calculated for female victimization with all of the aforementioned independent variables, first with interparental violence and ego threat (see Table 16). The equation was significant $(F(5,202)=21.916 ; p<.01)$, with an adjusted $R$-squared of .336 indicating that the equation explains approximately $34 \%$ of the variance in females' victimization. Two variables emerged as being significant at the .05 level. These two were perpetration $(\beta=.081 ; p<.01)$ and interparental violence $(\beta=.158 ; p<.01)$. Both of the coefficients were positive, indicating positive relationships with the dependent variable. Female victims of intimate violence were more likely to have perpetrated violence and witnessed more interparental violence. 
Table 16

Summary of Regression Analysis for Variables Predicting Female Victimization of Intimate Violence

\begin{tabular}{|c|c|c|c|}
\hline Variable & B & SE B & $\beta$ \\
\hline \multicolumn{4}{|l|}{ Equation 1} \\
\hline Constant & 2.100 & 2.202 & \\
\hline Perpetration & .785 & .081 & $.553^{* *}$ \\
\hline Interparental Violence & .110 & .040 & $.158^{* *}$ \\
\hline Ego Threat & -.001 & .002 & -.034 \\
\hline Age & -.025 & .067 & -.021 \\
\hline White & -.509 & 1.257 & -.023 \\
\hline \multicolumn{4}{|l|}{ Equation 2} \\
\hline Constant & 2.300 & 3.034 & \\
\hline Perpetration & .783 & .084 & $.552^{* *}$ \\
\hline Mother Violence & -.068 & .096 & -.043 \\
\hline Father Violence & .191 & .056 & $.206^{* *}$ \\
\hline Self-Esteem & -.047 & .057 & -.049 \\
\hline Narcissism & .025 & .084 & .017 \\
\hline Age & -.021 & .067 & -.018 \\
\hline White & -.413 & 1.251 & -.019 \\
\hline
\end{tabular}

When interparental violence and ego threat were taken out and their components added, the equation remained significant $(F(7,200)=16.665 ; p<.01)$, and the explained variance increased slightly to $35 \%$ (adjusted $R^{2}=.346$ ) (see Table 16). Two variables, perpetration $(\beta=.552 ; p<.01)$ and father violence $(\beta=.206 ; p<.01)$, were significant predictors of female 
victimization. The relationship with perpetration was the same as before. For father violence, this suggested that female victims reported witnessing increased levels of father to mother violence.

Regression equations were also calculated for male victims of intimate violence (see

Table 17). The equation was significant $(F(5,112)=8.534 ; p<.01)$ with approximately $24 \%$ of explained variance in male victimization (adjusted $R^{2}=.244$ ). The only variable with any explanatory power was perpetration $(\beta=.520 ; p<.01)$, again indicating that male victims of intimate violence were more likely to also perpetrate more intimate violence. When mother violence, father violence, self-esteem, and narcissism were added to the equation, there was no change in the explanatory power of the equation, and no other variables emerged as having significant predictive power.

Table 17

Summary of Regression Analysis for Variables Predicting Male Victimization of Intimate Violence

\begin{tabular}{lccc}
\hline \multicolumn{1}{c}{ Variable } & B & SE B & $\beta$ \\
\hline Equation 1 & .973 & & \\
Constant & 1.115 & .656 & $.520^{* *}$ \\
Perpetration & -.024 & .054 & -.040 \\
Interparental Violence & -.003 & .003 & -.066 \\
Ego Threat & .031 & .122 & .022 \\
Age & 1.255 & 3.291 & .031 \\
White & & & $.535^{* *}$ \\
\hline Equation 2 & 3.961 & 6.140 & -.046 \\
Constant & 1.148 & .203 & .209 \\
Perpetration & -.052 & & \\
Mother Violence & & & \\
\hline
\end{tabular}


Table 17 (continued)

\begin{tabular}{lccc}
\hline \multicolumn{1}{c}{ Variable } & B & SE B & $\beta$ \\
\hline Father Violence & .006 & .195 & .005 \\
Self-Esteem & -.157 & .106 & -.120 \\
Narcissism & .039 & .158 & .021 \\
Age & .052 & .123 & .036 \\
White & .511 & 3.331 & .013 \\
${ }^{*} \mathrm{p}<.05$ & & \\
${ }^{* *} \mathrm{p}<.01$ & Note. $R^{2}=.24$ for equation $1(\mathrm{p}<.01) . R^{2}=.24$ for equation $2(\mathrm{p}<.01)$. &
\end{tabular}

$\underline{\text { Summary }}$

Some of the statistics set forth in this chapter lend support to the hypotheses under investigation while others do not. In short, there appears to be support for roughly equal expression and receipt of violence for males and females. Reciprocity seems to be very influential in both perpetration and victimization of intimate violence. Also, there does appear to be support for an intergenerational transmission of violence, especially for perpetration. However, threatened egotism does not appear to be supported in this study. The regression equations for perpetration appear to be more powerful than the ones for victimization. This is expected as the main focus of the study was on perpetration, not victimization. The interpretation of these results will be more fully explored in the following chapter. 


\section{CHAPTER 5}

\section{DISCUSSION}

The purpose of the current study was to investigate personal characteristics that are purported to affect an individual's propensity to use violence in intimate relationships. Specifically, the factors under consideration included: family of origin violence, threatened egotism, and reciprocity. A review of existing literature on the importance of witnessing violence in the family of origin on a person's later use of violence in intimate relationships gives substantial support to the concept of an intergenerational transmission of violence (e.g. see Carlson, 1987; Carlson, 2002; Carr \& VanDeusen, 2002; Flynn, 1990; Foshee et al., 1999;

Gwartney-Gibbs et al., 1987; Hendy et al., 2003; Lavoie et al., 2002; Lewis et al., 2002; Marshall \& Rose, 1990). This suggests that those individuals who witness interparental violence will be at an increased risk of engaging in violence in later intimate relationships.

In addition to this theory of intergenerational transmission of violence, threatened egotism was also examined as a factor influencing a person's use of intimate violence. Threatened egotism is the concept that suggests aggression results from high, but unstable selfesteem, which is conceptualized as high self-esteem coupled with high narcissism. Research indicates that high self-esteem and high narcissism coupled together can be related to a person's use of aggression and experience of anger (e.g. see Baumeister et al., 1996; Baumeister et al., 2000; Bushman \& Baumeister, 1998; Papps \& O’Carroll, 1998; Salmivalli, 2001; Washburn et al., 2004). This theory goes against the conventional notion that those who have low self-esteem will be more likely to use aggression than those with high self-esteem. The idea is that when those with high, unstable self esteem are presented with an ego threat, they will react more 
aggressively against the source of that threat in an attempt to maintain their fragile positive sense of self worth.

Finally, reciprocity was examined for its role in intimate violence. Reciprocity is simply that when something is done to them, people will respond in kind. If reciprocity is at work in intimate violence, then a person's perpetration should be closely related to that person's victimization. This idea is more grounded in common sense because it is logical to assume that if someone is violent towards another, that other person is likely to respond with violence. Not only is this concept grounded in common sense, it also has substantial empirical support (e.g. see Harned, 2002; Jenkins \& Aube, 2002; Lewis \& Fremouw, 2001; Marshall \& Rose, 1990; Straus, 1980).

\section{Methodology}

The current study used self-report survey questionnaires distributed to a sample of randomly selected clusters of college students on the campus of East Tennessee State University. The surveys included several scales intended to measure the latent variables of interest. The Conflict Tactics Scale (Straus, 1979) was used to measure physical aggression, both for the participants' intimate relationships and those of their parents. The CTS is a widely used scale and has been found to be valid and reliable (Archer, 1999; Archer, 2000b; Straus; Straus \& Gelles, 1990). In addition, the Rosenberg (1965) Self-Esteem Scale was included to measure the participant's self-esteem. This measure of self-esteem is the most widely used and has also been found to have high reliability (Whiteside-Mansell \& Corwyn, 2003). The final scale included in the survey was a section of the Narcissistic Personality Inventory (Raskin \& Hall, 1979). The NPI has been found to contain several factors, one of which has been identified as Exploitativeness/Entitlement (Emmons, 1987; Raskin \& Terry, 1988; Watson \& Biderman, 
1993).This factor was the one that was included in the current study as it has been found to be associated with the more maladaptive and pathological aspects of narcissism (Emmons; Raskin \& Terry; Watson \& Biderman).

\section{$\underline{\text { Findings }}$}

\section{Prevalence of Intimate Violence}

In the current study, $24 \%$ of participants reported being involved in intimate violence, either as perpetrator or victim, in the past year. This is higher than that found by some researchers (Makepeace, 1986) and lower than that found by others (Lewis et al., 2002). In a literature review of studies focusing on dating violence, Lewis and Fremouw (2001) found prevalence rates ranging from $21 \%$ to $45 \%$ with an average of about $30 \%$. The prevalence rate found in the current study would fall on the lower side of this range and below the average. When looking at perpetration and victimization, $20 \%$ of the participants reported perpetrating intimate violence in the past year while $22 \%$ report being the victim of intimate violence in the past year.

\section{Gendered Nature of Intimate Violence}

When comparing the percentage of participants who reported perpetration and victimization based on gender, some interesting findings appear. For perpetration, 13\% of males reported perpetrating at least one act of physical aggression against their partner in the past year while $23 \%$ of females reported doing the same. This difference is significant and indicates that in this study more females, on average, perpetrate violence than do males. These findings are similar to those of Hendy et al. (2003). Using a sample of over 1,000 undergraduate college students, Hendy et al. reported that $16 \%$ of males and $26 \%$ of females reported inflicting violence on their present romantic partner. For victimization, there are virtually no differences 
based on gender. In the current study, $21.5 \%$ of males reported being victimized and $21.4 \%$ of females reported the same. Again, these results are similar to those of Hendy et al. who found $22 \%$ of males and $23 \%$ of females reported being the victim of intimate violence.

In addition, the scores on the scales for perpetration and victimization were compared based on gender. The scales provide more of an incidence rate as they are based on the participants' response to how often each act occurred. When the mean scores of physical aggression were compared based on gender, no significant differences emerged for either perpetration or victimization. The means were compared for the complete sample and also only for those who reported either perpetration or victimization. Still, there were no differences for the mean scores of either victimization or perpetration. This indicates that while more females in the sample indicated that they had perpetrated intimate violence, the incidence of intimate violence both expressed and received is similar for males and females. These findings show support for both hypotheses one and two, and are consistent with findings of other researchers (e.g. Jenkins \& Aube, 2002; White \& Koss, 1991). Hypothesis one stated that females would report as much or more perpetration than males, and, based on these findings, the females in the current study did use violence at least as often as males. Hypothesis two suggested that males would report rates of victimization similar to that of females, and, based on these findings, males in the current study reported rates of victimization that were inappreciably different from those reported by females.

\section{$\underline{\text { Reciprocity }}$}

In order to look at the reciprocity of intimate violence, perpetration and victimization were compared. While only about $6 \%$ of those who were not victimized reported that they perpetrated intimate violence, $65 \%$ of those who reported being victimized also reported 
perpetrating intimate violence. The difference in these two percentages is quite obvious and significant. In addition, the scales of perpetration and victimization were found to be significantly correlated. The relationship is fairly strong and is positive in nature, indicating that as scores become higher on the perpetration scale, they also become higher on the victimization scale. These findings are also consistent with those of previous research conducted by Marshall and Rose (1990) and Lewis et al. (2002) into the reciprocal nature of intimate violence. The findings also lend support to hypothesis three which suggested that participants' perpetration would be significantly related to their partners' use of violence, in other words, their victimization.

Interparental Violence

For both perpetration and victimization, witnessing interparental violence appears to have an effect. Initially, looking at percentages of participants reporting on perpetration and interparental violence, $16 \%$ of those who did not witness interparental violence reported perpetrating violence while $33 \%$ of those who did witness interparental violence also perpetrated violence against their partner. This difference is statistically significant and indicates that those who witness interparental violence are more likely to perpetrate intimate violence. The same is true of victimization, although the difference is not as significant. For victimization, comparing the victimization of those who did and did not witness interparental violence, almost $20 \%$ of those who did not witness interparental violence were victimized by intimate violence; however, $32 \%$ of those who did witness interparental violence were victimized by their partner.

In addition, the relationship of the scales of interparental violence, mother violence, and father violence were examined in regard to both perpetration and victimization. Interparental violence, mother violence, and father violence were all found to have moderately strong positive 
statistical relationships with perpetration, indicating that as scores on all of these scales increase, so too does the score on the perpetration scale. Similar but, again, weaker relationships emerged for interparental violence, mother violence, and father violence with victimization. Again, the relationships are positive but fairly weak, indicating that as scores on each of the scales increase, the score on the victimization scale also increases. These findings are consistent with those of previous research indicating that there is a relationship between witnessing interparental violence and engaging in intimate violence (Carr \& VanDeusen, 2002; Gwartney-Gibbs et al., 1987; Hendy et al., 2003). These findings show support for the fourth and fifth hypotheses that proposed an individual's use of intimate violence and their receipt of intimate violence, respectively, would be significantly related to witnessing interparental violence.

In addition, the mean scores on the perpetration and victimization scales were compared based on whether or not the participant had witnessed interparental violence. For perpetration, there was a difference in the incidence of perpetration for those who had and had not witnessed interparental violence. Those who did witness interparental violence on average scored about two points higher on the perpetration scale than did those who did not witness interparental violence. However, no difference emerged for the victimization scale. This indicates that those who reported witnessing interparental violence experience intimate violence from their partners at a rate similar to those who did not witness interparental violence.

\section{Threatened Egotism}

Self-esteem was included as a component of threatened egotism and was multiplied with narcissism in order to obtain an interaction term for ego threat. In addition, self-esteem was also looked at alone. When comparing the mean scores on the self-esteem scale, males were found to have significantly higher self-esteem on average than females. In addition, mean differences 
emerged for both victimization and perpetration. However, for perpetration at least, the relationship was not as expected. Those who reported no perpetration of intimate violence scored significantly higher on self-esteem than did those who did perpetrate intimate violence. The same was observed for victimization in that those who were victimized reported lower self-esteem than those who were not. For the correlation, self-esteem was found to have a weak negative correlation with both perpetration and victimization, indicating that as scores on self-esteem increase, scores on both perpetration and victimization decrease.

As with the other component of threatened egotism, narcissism was also examined alone. In terms of mean differences, the only significant difference that emerged was that males scored higher on the narcissism scale than did females. In addition, the only significant correlation that was found was a weak, negative correlation with age meaning that as participants got older, their scores on the narcissism scale decreased.

The self-esteem and narcissism scales were multiplied in order to obtain an interaction term to represent ego threat. No significant relationships emerged for ego threat. This goes against hypothesis six which suggested that those scoring high on self-esteem and narcissism would report perpetrating more intimate violence.

\section{Predicting Perpetration and Victimization}

All of the aforementioned variables were examined together as possible explanations of both perpetration and victimization for all participants as well as for females and males separately. This was done in an attempt to gain a better understanding of how the variables operate and to introduce a type of statistical control by examining the effect of one independent variable while holding others constant. The variables were examined separately for males and females in an attempt to determine if they operate differently for males and females. If this is the 
case, treating aggression by males and females as the same would be counterproductive because different factors may be influencing their behavior. What might be important for males may not be for females.

\section{Predicting Perpetration}

Initially the sample was analyzed as a whole in order to look at the big picture. Victimization and witnessing interparental violence were found to be significant predictors of perpetrating intimate violence. When interparental violence was substituted with the variables of mother violence and father violence, more differences emerge. In addition to these differences, the explained variance increased from $30 \%$ to $33 \%$ with the addition of mother violence and father violence. While victimization retained its predictive power, gender also became significant. In addition, witnessing mother-to-father violence predicted more perpetration while witnessing father-to-mother violence predicted less perpetration. This last finding is contradictory to the intergenerational transmission of violence. According to this theory, the relationship for witnessing any form of interparental violence would be positive. This found partial support for hypothesis seven which stated that those participants who witnessed more interparental violence, scored higher on ego threat, and reported more victimization would perpetrate more intimate violence. While victimization and interparental violence were found to be significant predictors, ego threat had no significant impact on a person's perpetration of intimate violence.

\section{Predicting Female Perpetration}

A different picture emerges for females' perpetration of intimate violence. While the explained variance is similar to that for all perpetration (i.e. $32 \%$ ), the only significant predictor of female perpetration was victimization when interparental violence and ego threat were 
examined. When mother violence, father violence, self-esteem, and narcissism were added, the explained variance increased to $35 \%$. In addition to victimization, which remained the most powerful predictor, father-to-mother violence and self-esteem also emerged as significant predictors with a negative association. This means that those females who are victimized, witness lower levels of father-to-mother violence, and have lower self-esteem will perpetrate more intimate violence. Both of these findings go against the theories that are the focus of this study. Intergenerational transmission of violence would suggest that females who witness more father-to-mother violence and mother-to-father violence would perpetrate more intimate violence. The negative relationship with father-to-mother violence may have to do with the potential impact of male violence in terms of injury inflicted. It has been widely noted that females sustain more injuries at the hands of males than vice versa. Due to this, females who witnessed increased father-to-mother violence may refrain from using intimate violence out of fear of retaliation. The finding that mother-to-father violence is not significant is surprising as social learning theory postulates that children will more closely associate with their same gender parent and imitate their behavior. If this were the case, mother-to-father violence should have been a significant positive predictor of female perpetration. Also, the finding that lower selfesteem is associated with higher female perpetration goes against threatened egotism that suggests aggression results from high, unstable self-esteem. Females with lower self-esteem may feel more dependent upon their relationships. They may not feel secure in the relationship and may resort to violence in an attempt to force their partner to remain in the relationship. Also, females with lower self-esteem may have weaker communication skills and feel unable to verbally communicate their frustrations or anger. Violence may be the result of this inability to vocalize how they feel. 


\section{$\underline{\text { Predicting Male Perpetration }}$}

Males who were victimized and witnessed interparental violence are predicted to perpetrate more intimate violence with $33 \%$ of the variance explained. However, this explained variance increases to $40 \%$ with the addition of mother violence and father violence. When these two variables were substituted for interparental violence, mother-to-father violence surpasses victimization in predictability power for the first, and only, time. Mother violence is followed by victimization and witnessing father-to-mother violence. Both mother violence and victimization are positively associated with perpetration indicating that males who witness higher levels of mother-to-father violence and experience more victimization perpetrate more intimate violence. On the contrary, father violence is again negative as seen previously with overall perpetration and female perpetration. These findings lend partial support to the theory of an intergenerational transmission of violence with the finding that witnessing mother-to-father violence is positively associated with male perpetration. However, the finding that father violence is negatively associated goes against both the intergenerational transmission of violence and social learning theory. As stated before, social learning theory posits that males who witnessed their fathers being violent would more closely associate with them and imitate their behavior.

\section{Predicting Victimization}

For overall victimization, only $29 \%$ of the variance was explained by the variables included. The only variable that was found to be a significant predictor of victimization was perpetration. When mother violence and father violence were added, the explained variance increased slightly to $30 \%$, and father violence also emerged as a significant predictor. The direction of both of these relationships is positive indicating that more perpetration and 
witnessing more father-to-mother violence are associated with increased levels of intimate victimization.

\section{Predicting Female Victimization}

For females, perpetration and witnessing interparental violence were found to be significant predictors of victimization with $34 \%$ of the variance explained. When mother violence and father violence were added, the explained variance increased slightly to $35 \%$ and father violence also emerged as significant. Again, both associations are positive indicating that perpetrating intimate violence and witnessing father-to-mother violence increases a female's risk of intimate violence victimization.

Predicting Male Victimization

Of all of the predictor relationships examined, the one for male victimization is the weakest. The only significant predictor that emerged was perpetration with $24 \%$ of the variance explained. Even when father violence and mother violence were added to the equation, the explained variance remained at $24 \%$ and perpetration was still the only significant predictor.

\section{$\underline{\text { Implications }}$}

\section{$\underline{\text { Victimization vs. Perpetration }}$}

Based on the focus of the current study being on perpetration, it is not surprising to find that perpetration was explained more than victimization by the variables under consideration. Specifically, more male perpetration was explained than any other perpetration or victimization. Next, female perpetration and female victimization were explained to the same degree. Male victimization had the least support. Based on these findings, it becomes apparent that different factors predict victimization and perpetration, and especially victimization and perpetration for females and males. 


\section{$\underline{\text { Male vs. Female }}$}

From the findings for male and female perpetration, it appears that males and females are different and the factors that influence their behavior are different. Male perpetration was better explained than female perpetration; but female victimization was better explained than male victimization. While there are many differences, there are some commonalities in male and female perpetration and victimization. Both male and female perpetration is significantly influenced by their reported victimization and witnessing father-to-mother violence. In both instances, more victimization and less father violence are associated with increased perpetration of intimate violence. However, lower self-esteem is associated with female perpetration while self-esteem is not significant for male perpetration. Also, witnessing mother-to-father violence is positively associated with male perpetration while it is not significant for females. In terms of victimization, the only commonality for males and females is the reciprocity factor as perpetration is a significant positive predictor for both male and female victimization.

\section{Factors Affecting Intimate Violence}

While reciprocity received substantial support in both perpetration and victimization, intergenerational transmission of violence and threatened egotism did not receive as much support. Across all analyses of perpetration and victimization, reciprocity was the only factor that was consistently found to have a significant impact. In every case with the exception of one, reciprocity was the strongest predictor of both perpetration and victimization.

There was some support for the intergenerational transmission of violence. However, based on the findings of this study, the relationship does not appear to be as clear cut as witnessing any and all forms of interparental violence increase a person's propensity to express 
violence in intimate relationships. The relationship appears to be more complex and, in some instances, more powerful for males while in others it appears to be more powerful for females.

The theory of threatened egotism did not receive any support in the current study. The only significant findings for either self-esteem or narcissism actually were contradictory to threatened egotism. This should not immediately nullify any significance of threatened egotism to the study of intimate violence. Limitations of the study and other factors that could have affected these findings will be discussed in the following section.

\section{$\underline{\text { Limitations }}$}

The current study does have some limitations that must be considered when examining the results. This study used the Conflict Tactics Scale in order to assess both intimate violence and interparental violence. While the CTS is the most widely used method of measurement for interpersonal violence, its use can be controversial because it is a strictly quantitative measure of violence. Based on the CTS, one cannot determine who the aggressor was or under what circumstances the incident occurred. While this study found that more females than males identified themselves as perpetrators, this cannot be interpreted to mean that females are more violent than males in intimate relationships. The violence that females used could have been defensive in nature, but, based on the CTS, this cannot be determined. The same is true of interparental violence. No information is available on the context of the situation in which the violence occurred. Due to this, no inferences can be drawn about males, females, mothers, or fathers and who is the most aggressive.

The Conflict Tactics Scale could also be subject to a participants' underreporting or overreporting of behavior. Some researchers have included a social desirability scale in studies assessing behavior that is deemed undesirable or aberrant. By doing so, researchers hope to 
determine if participants might be answering questions based on what they want people to think about them and not how they really behave or feel. The current study, however, did not include such a scale. Therefore, no suppositions can be made about over or underreporting based on participants' social desirability.

In terms of the actual questionnaire that was used, some participants may have experienced test fatigue. The questionnaire was fairly lengthy and took, on average, 20 minutes to complete, sometimes more and sometimes less. In hindsight, there are several things that could have been taken out of the questionnaire that would have shortened the time it took to complete. For example, the entire Conflict Tactics Scale was presented twice in the questionnaire, once for the participants' own relationship and once for the relationship of their parents. Each scale consists of 19 items that were responded to twice each. For analyses, only the physical violence subsection was used which consisted of nine items, twice for each scale. In hindsight, it may have been beneficial to only include those items in the physical violence subscale. This change alone would have cut down the CTS dramatically. The first part of the CTS consists of items related to reasoning and verbal aggression which are more common than physical aggression. When participants were responding to those items and trying to remember how often they and their partner had used them in the past year, they may have grown frustrated and this could affect the quality of their responses to later items.

For interparental violence, participants were instructed to think back to the past year if they lived at home, or, if they did not live at home, the last year that they did live at home and respond to the items of the Conflict Tactics Scale based on this referent time period. This could produce results that are inconsistent with the environment in which the participant grew up. First off, the participant may have been living away from home for many years and may not be able to 
remember clearly things that happened in a one year time period. Also, the responsibilities and stresses that are related to raising children may have led to more conflict during earlier years when participants were younger. As most participants were responding to the scale based on a time when they were probably at least in their late teens, parents are more likely experiencing a reprieve from some of the stresses and responsibilities of childcare as the children become more independent and self-sufficient. Results may have been more accurate if participants were asked about their parents' interactions simply during their childhood. The response categories could have been changed to more subjective measures such as often, sometimes, never, etc. This may give a more accurate example of the environment that the participant was subjected to as a child during their formative years.

In terms of the theory of threatened egotism, the findings of this study may not be representative of its impact on intimate violence. For narcissism, the current study used only one section of the Narcissistic Personality Inventory. Several things could have happened to impact the results. The one factor that was selected may not have an impact on a person's propensity to engage in intimate violence. This factor was selected based on research indicating that it is most related to the pathological and maladaptive aspects of narcissism. The aspects of narcissism that are operating in threatened egotism may not be those that are most pathological or maladaptive. In addition, the presentation of the items for the NPI deviated from that which is normal for this scale. The NPI typically consists of forced choice statements based on true/false response options. Instead, the current study presented a statement that was narcissistic in nature and the participants were instructed to respond on a Likert-type scale from one (strongly agree) to four (strongly disagree). While the reliability coefficient of the current scale was found to be the exact 
same as that calculated by previous researchers, the results may be affected by the deviation from the original design.

A final limitation is based on the conceptualization of self-esteem. The current study conceptualized self-esteem as being a relatively stable trait of a person's personality. While some researchers agree with this view, others have conceptualized self-esteem as being more of a state and fluctuating over time. The finding that lower self-esteem was correlated with perpetration and victimization could be explained by this view. Instead of lower self-esteem predicting perpetration or victimization, perpetration or victimization may predict lower self-esteem. In other words, a person's self-esteem may be influenced by their receipt or expression of intimate violence instead of the other way around. Along these same lines, self-esteem was measured at the present time, while perpetration and victimization were assessed for the previous year. Therefore, conclusions made about self-esteem and perpetration or victimization may be erroneous due to one reflecting past behavior and the other being a measure based on the present time.

\section{$\underline{\text { Conclusions }}$}

In conclusion, the current study found substantial support for the reciprocal nature of intimate violence. While this may be common sense to some, this finding is important for people involved in relationships. In short, people often do to others what has been done to them. It appears that the best way to keep from being involved in a violent relationship is to not be violent yourself. Reciprocity in the current study is inferred from the participants' reported receipt of violence from their partners. The expression and receipt may have involved different partners and the outcome of the relationship is not known based on the current study. However, a 
participant's reported victimization or perpetration is the overall most powerful and consistent predictor of their own behavior.

Support was also found for an intergenerational transmission of violence. However, this theory seems to be more applicable to male than female perpetration. For male perpetration, both mother and father violence were significant. Mother violence was strongest and positive in nature, while, unexpectedly, father violence was negative in nature. This could be explained by males who grew up witnessing their mothers be violent towards their fathers may hold a view of all females as violent. If all females are violent, they may think that they should be treated violently in order to preempt violence by the females. On the other hand, higher levels of fatherto-mother violence predict lower levels of perpetration for both males and females. This could be explained by the potential impact of father-to-mother violence. Not to trivialize violence by females, but violence by males has more potential to produce injuries and harm. Children who grew up witnessing their fathers being violent towards their mothers may refrain from the use of violence in intimate relationships because they have been exposed to more negative consequences of the behavior. Another factor that could be present for the negative association in females may be that they fear retaliation. Females who witnessed their father be violent towards their mother know that some males hit females. Therefore, they may refrain from violence out of fear of retaliation while females who did not witness father-to-mother violence may have the notion that males will never hit a female no matter what because they have been socialized to believe that violence towards females is unacceptable, regardless of the circumstances.

While support was not found for threatened egotism in relation to intimate violence, this does not mean that threatened egotism cannot be a factor. The deviations that the current study made from the standard form of the Narcissistic Personality Inventory and/or the selection of 
only one section of the scale may have compromised the results. On the other hand, most of the research on threatened egotism has been conducted in a lab setting with the participants being presented with an ego threat and given the option to aggress against the source of that threat in the form of a noxious taste or sound. The concept of threatened egotism may lack external validity meaning that what is true in the lab does not always hold true in application. Theory and reality sometimes do not mesh and this could be what happened here. While the theory of threatened egotism makes sense, it may not be operating in the use of intimate violence. The problem may be in the conceptualization of self-esteem. As in the current study, threatened egotism views self-esteem as being relatively stable over time. If, however, self-esteem fluctuates over time, the theory of threatened egotism may not be appropriate in the explanation of intimate violence.

One finding of interest was the significance of low self-esteem for females but not for males. As stated before, it is apparent from the findings of this study that factors operate differently for males and females. Not only were females in the study found to have lower selfesteem on average than males, but lower self-esteem in females was also found to be predictive of perpetrating intimate violence. This finding may be related to differences in self-esteem in general for males and females. Self-esteem may operate differently for males and females and could be more stable for one than the other. Due to the importance that relationships tend to have for females based on societal ideas that females should be involved in relationships and are often defined by those relationships, more of a female's self-esteem could be tied into her relationship and maintenance of such. If a female has low self-esteem, she may react more violently and extremely when she feels that the relationship is threatened. She may feel that her worth is so entwined in the relationship that she will resort to violence in an attempt to keep her partner in 
the relationship. She may feel that her partner may leave the relationship if she depends only on his desire to be with her. She could view violence as a means of keeping him with her.

While the current study assumes that self-esteem is relatively stable, it was previously noted that self-esteem could be more of a state and could, in fact, be influenced by perpetration and/or victimization instead of the other way around. Post-hoc analyses were conducted in an attempt to examine this by conducting multiple regression with self-esteem as the dependent variable and perpetration, victimization, mother violence, father violence, age, and gender as the independent variables. For the entire sample, the equation was significant but the explained variance was only $5 \%$. The only variables that were significant were perpetration, mother violence, and gender. Mother violence was positive while the other two were negative, indicating that witnessing mother-to-father violence is predictive of higher self-esteem while perpetrating intimate violence is predictive of lower self-esteem. The negative relationship with gender indicates that females on average have lower self-esteem when all the other variables are controlled.

The same was undertaken for both males only and females only. For males only, the equation was not significant indicating that those variables are not predictive of male's selfesteem. For females, the equation was significant, but, again, only a small percentage (i.e. $7 \%$ ) of the variance was explained. For females, only perpetration and mother violence were significant. Perpetration was negative meaning that those who perpetrate more intimate violence have lower self-esteem and mother violence was again positive meaning that witnessing more mother-tofather violence is predictive of higher self-esteem in females. These findings lend support to the current view of self-esteem being a trait, and violence resulting more from self-esteem than vice versa. 
Post-hoc analyses were also undertaken to further investigate the relationship of selfesteem and victimization for males and females. Based on correlation, a significant relationship between self-esteem and victimization emerged for females only. For males, there was no significant relationship with self-esteem and victimization. The relationship for females was negative indicating that females' with lower self-esteem also experience more violent victimization. Again, this cannot imply causality as females with lower self-esteem could be subjected to more victimization or females who experience more victimization could develop lower self-esteem. However, the finding that the relationship is significant for females and not for males suggests that there are differences that should be further explored.

\section{$\underline{\text { Future Research }}$}

Based on the findings of the current research, future research should be undertaken to more fully explore the link between self-esteem and intimate violence. As stated before, the findings of the current study could indicate that self-esteem is more of an effect than a cause. Path-analysis should be undertaken in order to determine if lower self-esteem could be the result of aggression instead of aggression resulting from low self-esteem. Separate analyses should be conducted for males and females based on the current study's finding that low self-esteem was significant for female perpetration but not for male perpetration.

Narcissism should be more fully explored in order to further examine the theory of threatened egotism. Possibly the full Narcissistic Personality Inventory should be used in order to determine whether there is, in fact, a link with threatened egotism and intimate violence. The scale should be implemented in its full original form to better control for any differences that may emerge. 
Studies should also be undertaken to examine more qualitative factors associated with intimate aggression. Such factors include: primary aggressor, context of incident, motivation of aggressor, and effects of aggression. While these factors were not under examination in the current study, they are still very important. Examination of these factors could shed more light on the phenomenon of intimate violence. If the factors leading to intimate violence and the context in which it occurs are better understood, intervention strategies could be developed or utilized that are more effective.

In addition, more studies need to be undertaken to explore the differences in self-esteem for males and females. Based on the findings of the current study, it appears that self-esteem is different for males and females. It would be interesting to conduct research on the stability of self-esteem based on gender. Males could have more stable self-esteem overall than do females. The conceptualization of self-esteem needs to be more fully explored and examined in order to determine if it is even appropriate to treat the concept of self-esteem as the same for males and females.

Finally, more analyses to develop a better understanding of the impact of witnessing interparental violence should be conducted. Findings in the current study were supportive of the detrimental impact of witnessing interparental violence but the directions of the relationships and significance based on gender were not as expected. Separate analyses should be conducted for males and females and violence perpetrated by the mother and by the father. From the findings of this study, it appears that not only is violence perpetrated by males and females different, but the effects of witnessing violence perpetrated by a mother and father may also be perceived differently and have differing impacts. As stated before, future studies should investigate the environment in which the participant grew up. Future research should focus more on the whole 
picture of witnessing interparental violence instead of being restricted to that violence which occurred in a restricted time period. 


\section{REFERENCES}

Akers, R. (1994). Criminological theories: Introduction and evaluation. Los Angeles: Roxbury. Archer, J. (1999). Assessment of the reliability of the conflict tactics scales: A meta-analytic review. Journal of Interpersonal Violence, 14, 1263-1289.

Archer, J. (2000a). Sex differences in aggression between heterosexual partners: A metaanalytic review. Psychological Bulletin, 126, 651-680.

Archer, J. (200b). Sex differences in physical aggression to partners: A response to Frieze (2000), O’Leary (2000), and White, Smith, Koss, and Figueredo (2000). Psychological Bulletin, 126, 697-702.

Babcock, J. C., Miller, S. A., \& Siard, C. (2003). Toward a typology of abusive women: Differences between partner-only and generally violent women in the use of violence. Psychology of Women Quarterly, 27, 153-161.

Bandura, A. (1973). Social learning theory of aggression. In J. F. Knutson (Ed.), The control of aggression. Chicago: Aldine.

Baumeister, R. F., Bushman, B. J., \& Campbell, W. K. (2000). Self-esteem, narcissism, and aggression: Does violence result from low self-esteem or from threatened egotism? Current Directions in Psychological Science, 9, 26-29.

Baumeister, R. F., Smart, L., \& Boden, J. M. (1996). Relation of threatened egotism to violence and aggression: The dark side of high self-esteem. Psychological Review, 103, 5-33.

Bethke, T. M., \& DeJoy, D. M. (1993). An experimental study of factors influencing the acceptability of dating violence. Journal of Interpersonal Violence, 8, 36-51. 
Bird, G. W., Stith, S. M., \& Schladale, J. (1991). Psychological resources, coping strategies, and negotiation styles as discriminators of violence in dating relationships. Family Relations, 40, 45-50.

Bushman, B. J., \& Baumeister, R. F. (1998). Threatened egotism, narcissism, self-esteem, and direct and displaced aggression: Does self-love or self-hate lead to violence? Journal of Personality and Social Psychology, 75, 219-229.

Carlson, B. E. (1987). Dating violence: A research review and comparison with spouse abuse. Social Casework, 68, 16-23.

Carlson, K. T. (2002). Understanding violence among female adolescents: Intervention and treatment. Journal of School Social Work, 13, 47-69

Carr, J. L., \& VanDeusen, K. M. (2002). The relationship between family of origin violence and dating violence in college men. Journal of Interpersonal Violence, 17, 630-646.

Dasgupta, S. D. (2002). A framework for understanding women's use of nonlethal violence in intimate heterosexual relationships. Violence Against Women, 8, 1364-1389.

Dworetzky, J. P. (2000). Psychology (6 ${ }^{\text {th }}$ ed.). Pacific Grove, CA: Thomson Learning.

Emmons, R. A. (1987). Narcissism: Theory and measurement. Journal of Personality and Social Psychology, 52, 11-17.

Fiebert, M. S. (1996). College students' perception of men as victims of women's assaultive behavior. Perceptual and Motor Skills, 82, 49-50.

Fiebert, M. S., \& Gonzalez, D. M. (1997). College women who initiate assaults on their male partners and the reasons offered for such behavior. Psychological Reports, 80, 583-590.

Flynn, C. P. (1990). Relationship violence by women: Issues and implications. Family Relations, 39, 194-198. 
Follingstad, D. R., Bradley, R. G., Laughlin, J. E., \& Burke, L. (1999). Risk factors and correlates of dating violence: The relevance of examining frequency and severity levels in a college sample. Violence and Victims, 14, 365-380.

Follingstad, D. R., Wright, S., Lloyd, S., \& Sebastian, J. A. (1991). Sex differences in motivations and effects in dating violence. Family Relations, 40, 51-57.

Foshee, V. A., Bauman, K. E., \& Linder, G. F. (1999). Family violence and the perpetration of adolescent dating violence: Examining social learning and social control processes. Journal of Marriage and the Family, 61, 331-342.

Frieze, I. H. (2000). Violence in close relationships-Development of a research area: Comment on Archer (2000). Psychological Bulletin, 126, 681-684.

Gwartney-Gibbs, P. A., Stockard, J., \& Bohmer, S. (1987). Learning courtship aggression: The influence of parents, peers, and personal experiences. Family Relations, 36, 276-282.

Harned, M. S. (2002). A multivariate analysis of risk markers for dating violence victimization. Journal of Interpersonal Violence, 17, 1179-1197.

Hart, P. L., \& Joubert, C. E. (1996). Narcissism and hostility. Psychological Reports, 79, 161162.

Hendy, H. M., Weiner, K., Bakerofskie, J., Eggen, D., Gustitus, C., \& McLeod, K. C. (2003). Comparison of six models for violent romantic relationships in college men and women. Journal of Interpersonal Violence, 18, 645-665.

Hirschi, T. (1969). Causes of delinquency. Berkley: University of California Press.

Jenkins, S. S., \& Aube, J. (2002). Gender differences and gender-related constructs in dating aggression. Personality and Social Psychology Bulletin, 28, 1106-1118. 
Kirkpatrick, L. A., Waugh, C. E., Valencia, A., \& Webster, G. D. (2002). The functional domain specificity of self-esteem and the differential prediction of aggression. Journal of Personality and Social Psychology, 82, 756-767.

Lavoie, F., Hebert, M., Tremblay, R., Vitaro, F., Vezina, L., \& McDuff, P. (2002). History of family dysfunction and perpetration of dating violence by adolescent boys: A longitudinal study. Journal of Adolescent Health, 30, 375-383.

Lewis, S. F., \& Fremouw, W. (2001). Dating violence: A critical review of the literature. Clinical Psychology Review, 21, 105-127.

Lewis, S. F., Travea, L., \& Fremouw, W. J. (2002). Characteristics of female perpetrators and victims of dating violence. Violence and Victims, 17, 593-606.

Makepeace, J. M. (1981). Courtship violence among college students. Family Relations, 30, 97102.

Makepeace, J. M. (1986). Gender differences in courtship violence victimization. Family Relations, 35, 383-388.

Marshall, L. L., \& Rose, P. (1990). Premarital violence: The impact of family of origin violence, stress, and reciprocity. Violence and Victims, 5, 51-64.

Murphy, B. S., Stevens, S. J., McGrath, R. A., Wexler, H. K., \& Reardon, D. (1998). Women and violence: A different look. Drugs and Society, 13, 131-144.

O’Keefe, M. (1998). Factors mediating the link between witnessing interparental violence and dating violence. Journal of Family Violence, 13, 39-57.

Papps, B. P., \& O’Carroll, R. E. (1998). Extremes of self-esteem and narcissism and the experience and expression of anger and aggression. Aggressive Behavior, 24, 421-438. 
Raskin, R. N., \& Hall, C. S. (1979). A narcissistic personality inventory. Psychological Reports, 45, 590.

Raskin, R., \& Terry, H. (1988). A principal-components analysis of the Narcissistic Personality Inventory and further evidence of its construct validity. Journal of Personality and Social Psychology, 54, 890-902.

Roark, M. L. (1987). Preventing violence on college campuses. Journal of Counseling and Development, 65, 367-371.

Rosenberg, M. (1965). Society and the adolescent self-image. Princeton, NJ: Princeton University Press.

Ruiz, J. M., Smith, T. W., \& Rhodewalt, F. (2001). Distinguishing narcissism and hostility: Similarities and differences in interpersonal circumplex and five-factor correlates. Journal of Personality Assessment, 76, 537-555.

Salmivalli, C. (2001). Feeling good about oneself, being bad to others? Remarks on self-esteem, hostility, and aggressive behavior. Aggression and Violent Behavior, 6, 375-393.

Sandstrom, K. L., Martin, D. D., \& Fine, G. A. (2003). Symbols, selves, and social reality: A symbolic interactionist approach to social psychology and sociology. Los Angeles: Roxbury.

Saunders, D. G. (2002). Are physical assaults by wives and girlfriends a major social problem? Violence Against Women, 8, 1424-1448.

Soyer, R. B., Rovenpor, J. L., Kopelman, R. E., Mullins, L. S., \& Watson, P. J. (2001). Further assessment of the construct validity of four measures of narcissism: Replication and extension. Journal of Psychology: Interdisciplinary and Applied, 135, 245-258. 
Stets, J. E., \& Henderson, D. A. (1991). Contextual factors surrounding conflict resolution while dating: Results from a national sample. Family Relations, 40, 29-36.

Straus, M. A. (1979). Measuring intrafamily conflict and violence: The Conflict Tactics (CT) Scales. Journal of Marriage and the Family, 41, 75-88.

Straus, M. (1980). Victims and aggressors in marital violence. American Behavioral Scientist, 23, 681-704.

Straus, M. A. (1999). The controversy over domestic violence by women: A methodological, theoretical, and sociology of science analysis. In X. B. Arriaga \& S. Oskamp (Eds.), Violence in intimate relationships (p. 17-44). Thousand Oaks, CA: Sage.

Straus, M. A., \& Gelles, R. J. (1990). Physical violence in American families: Risk factors and adaptations to violence in 8,145 families. In C. Smith (Ed.). New Brunswick, NJ: Transaction.

Swan, S. C., \& Snow, D. L. (2002). A typology of women's use of violence in intimate relationships. Violence Against Women, 8, 286-319.

Tennessee Code Annotated §36-3-601 (2004).

Washburn, J. J., McMahon, S. D., King, C. A., Reinecke, M. A., \& Silver, C. (2004). Narcissistic features in young adolescents: Relations to aggression and internalizing symptoms. Journal of Youth and Adolescence, 33, 247-261.

Watson, P. J., \& Biderman, M. D. (1993). Narcissistic personality inventory factors, splitting, and self-consciousness. Journal of Personality Assessment, 61, 41-57.

White, J. W., \& Koss, M. P. (1991). Courtship violence: Incidence in a national sample of higher education students. Violence and Victims, 6, 247-256. 
Whiteside-Mansell, L., \& Corwyn, R. F. (2003). Mean and covariance structure analyses: An examination of the Rosenberg self-esteem scale among adolescents and adults. Educational and Psychological Measurement, 63, 163-173.

Williams, J. G., \& Smith, J. P. (1994). Drinking patterns and dating violence among college students. Psychology of Addictive Behaviors, 8, 51-53.

Witte, T. H., Callahan, K. L., \& Perez- Lopez, M. (2002). Narcissism and anger: An exploration of underlying correlates. Psychological Reports, 90, 871-875.

Worcester, N. (2002). Women's use of force: Complexities and challenges of taking the issue seriously. Violence Against Women, 81, 1390-1415. 


\section{APPENDIX}

\section{Data Collection Instrument}

Thank you in advance for your help and participation in this study. The results of this study will be used for my thesis to fulfill the requirements for a master's degree in Criminal Justice/Criminology. Please answer the questions as honestly as you possibly can and as accurately as your memory will allow. You are under no obligation to complete this study. If you begin to feel uncomfortable at anytime during the questionnaire, you may choose to terminate your participation with no negative repercussions. Please do not put your name or any other identifying information on the questionnaire. All of your responses are strictly confidential. Again, thank you for all of your help. If you have any questions regarding the study or would like to discuss the study with me, you may contact me via email at zjlh3@imail.etsu.edu, or you may come to office 201F in the department of Criminal Justice/Criminology. Below you will find a list of resources available to individuals who are experiencing problems related to violence or alcohol/drug use. If you or someone you know could use these resources, please feel free to take this top sheet with you or copy down any numbers that would be of help.

Thank you,

Jessica Holt

Resources

Alcoholics’ Anonymous (423)928-0871

Watauga Mental Health (423)232-4300

Woodridge (800)316-8899

Safe Passage Crisis Line (423)926-7233

Salvation Army Domestic Violence (423)926-8901

Victim-Witness Services (423)279-3288

Sexual Assault Response Center (423)928-8522

Alcohol \& Drug Counseling \& Prevention Center (423)928-6581

Johnson City Bureau of Police Crisis Intervention Unit (423)975-2654

24 Hr. Crisis Intervention Hotline (423)926-0144 


\begin{tabular}{|c|c|}
\hline \multicolumn{2}{|c|}{$\begin{array}{l}\text { Section } 1 \\
\text { Please answer each question by marking the appropriate response or filling in the blank } \\
\text { provided. }\end{array}$} \\
\hline 1. What is your age: & \\
\hline $\begin{array}{l}\text { 2. What is your classification in } \\
\text { school: }\end{array}$ & $\begin{array}{l}\square \text { Freshman } \quad \square \text { Sophomore } \quad \square \text { Junior } \quad \square \text { Senior } \\
\square \text { Graduate } \quad \square^{\text {Other }} \quad-\end{array}$ \\
\hline $\begin{array}{l}\text { 3. Which best describes your } \\
\text { race: }\end{array}$ & $\begin{array}{l}\square \text { White } \square \text { Black } \square \text { Asian } \square \text { Hispanic } \\
\square \text { Other } \quad \square\end{array}$ \\
\hline 4. What is your gender: & $\square$ Female \\
\hline $\begin{array}{l}\text { 5a. What best describes your } \\
\text { relationship status: } \\
\text { b. How long have you been in } \\
\text { your current relationship: }\end{array}$ & $\begin{array}{l}\square \text { Single (not dating) } \quad \square \text { Casually dating } \\
\square \text { Seriously dating } \quad \square \text { Engaged } \quad \square \text { Married }\end{array}$ \\
\hline $\begin{array}{l}\text { 6. What best describes your } \\
\text { current living arrangement: }\end{array}$ & $\begin{array}{l}\square \text { On-campus } \quad \square \text { Off-campus (with parents) } \\
\square \text { Off-campus (not with parents) } \quad \square \text { Other }\end{array}$ \\
\hline 7. What is your marital status: & $\begin{array}{l}\square \text { Single (never married) } \quad \square \text { Married } \square \text { Divorced } \\
\square \text { Separated } \quad \square^{\text {Vidowed }}\end{array}$ \\
\hline $\begin{array}{l}\text { 8a. Are you religious: } \\
\text { b. What is your religious } \\
\text { affiliation (ex. Baptist): }\end{array}$ & $\square$ Yes $\quad \square$ No \\
\hline $\begin{array}{l}\text { 9. What is your approximate } \\
\text { income level: }\end{array}$ & $\begin{array}{ll}\square \text { Less than } \$ 10,000 & \square \$ 10,001-\$ 20,000 \\
\square \$ 20,001-\$ 30,000 & \square \$ 30,001-\$ 40,000 \\
\square \$ 40,001-\$ 50,000 & \square \text { Over } \$ 50,000\end{array}$ \\
\hline $\begin{array}{l}\text { 10a. Do you have any children: } \\
\text { b. If yes, are you a single } \\
\text { parent: }\end{array}$ & $\begin{array}{l}\square \text { Yes } \\
\square \text { Yes }\end{array}$ \\
\hline
\end{tabular}




\section{Section 2}

The next series of questions is regarding conflicts that may have taken place in your interpersonal relationships over the past year. Regardless of how well a couple gets along, there will always be disagreements, spats, and fights for many different reasons ranging from annoyance and bad moods to simply being tired. Different people also employ several different tactics in attempts to resolve the conflict. Following are a list of things that you or your partner may have done when you had an argument. The first column should be used to indicate how many times YOU employed the specified tactic toward a partner in the past year; while the second column should be used to indicate how many times a PARTNER employed the tactic toward you in the past year. The response options are $1=$ once, $2=$ twice, $3=3-5$ times, $4=6-10$ times, $5=11-20$ times, $6=$ more than 20 times, $0=$ never. Remember, these are how many times these things have happened in the past year. If you have not experienced/employed any of these in the past year, there will be third column in which to indicate if you have ever experienced/employed these tactics.

\begin{tabular}{|c|c|c|c|}
\hline & $\begin{array}{l}\text { Q11. YOU in } \\
\text { Past Year } \\
\text { 1-Once } \\
\text { 2-Twice } \\
\text { 3-3-5 Times } \\
\text { 4-6-10 Times } \\
\text { 5-11-20 Times } \\
\text { 6-More than } 20 \\
\text { 0-Never }\end{array}$ & $\begin{array}{l}\text { Q12. PARTNER } \\
\text { in Past Year } \\
\text { 1-Once } \\
\text { 2-Twice } \\
\text { 3-3-5 Times } \\
\text { 4-6-10 Times } \\
\text { 5-11-20 Times } \\
\text { 6-More than } 20 \\
\text { 0-Never }\end{array}$ & $\begin{array}{l}\text { Q13. For } \\
\text { items } \\
\frac{\text { marked }}{\text { never in }} \\
\begin{array}{l}\text { columns: } \\
\text { Has it ever } \\
\text { happened? }\end{array} \\
1-Y e s \\
0-N o\end{array}$ \\
\hline A. Discussed issue calmly & $\begin{array}{lllllll}1 & 2 & 3 & 4 & 5 & 6 & 0 \\
\end{array}$ & $\begin{array}{lllllll}1 & 2 & 3 & 4 & 5 & 6 & 0\end{array}$ & 10 \\
\hline $\begin{array}{l}\text { B. Got information to } \\
\text { back up your/his/her side } \\
\text { of things........................ }\end{array}$ & $\begin{array}{lllllll}1 & 2 & 3 & 4 & 5 & 6 & 0\end{array}$ & $\begin{array}{lllllll}1 & 2 & 3 & 4 & 5 & 6 & 0\end{array}$ & 10 \\
\hline $\begin{array}{l}\text { C. Brought in, or tried to } \\
\text { bring in, someone to help } \\
\text { settle things................ }\end{array}$ & $\begin{array}{lllllll}1 & 2 & 3 & 4 & 5 & 6 & 0\end{array}$ & $\begin{array}{lllllll}1 & 2 & 3 & 4 & 5 & 6 & 0\end{array}$ & 10 \\
\hline $\begin{array}{l}\text { D. Insulted or swore at } \\
\text { him/her/you.................. }\end{array}$ & $\begin{array}{lllllll}1 & 2 & 3 & 4 & 5 & 6 & 0 \\
\end{array}$ & $\begin{array}{lllllll}1 & 2 & 3 & 4 & 5 & 6 & 0 \\
\end{array}$ & 10 \\
\hline $\begin{array}{l}\text { E. Sulked or refused to } \\
\text { talk about an issue......... }\end{array}$ & $\begin{array}{lllllll}1 & 2 & 3 & 4 & 5 & 6 & 0\end{array}$ & $\begin{array}{lllllll}1 & 2 & 3 & 4 & 5 & 6 & 0\end{array}$ & 10 \\
\hline $\begin{array}{l}\text { F. Stomped out of the } \\
\text { room or house or yard..... }\end{array}$ & $\begin{array}{lllllll}1 & 2 & 3 & 4 & 5 & 6 & 0 \\
\end{array}$ & $\begin{array}{lllllll}1 & 2 & 3 & 4 & 5 & 6 & 0 \\
\end{array}$ & 10 \\
\hline G. Cried..................... & $\begin{array}{lllllll}1 & 2 & 3 & 4 & 5 & 6 & 0\end{array}$ & $\begin{array}{lllllll}1 & 2 & 3 & 4 & 5 & 6 & 0\end{array}$ & 10 \\
\hline $\begin{array}{l}\text { H. Did or said something } \\
\text { to spite him/her/you........ }\end{array}$ & $\begin{array}{lllllll}1 & 2 & 3 & 4 & 5 & 6 & 0 \\
\end{array}$ & $\begin{array}{lllllll}1 & 2 & 3 & 4 & 5 & 6 & 0 \\
\end{array}$ & 10 \\
\hline $\begin{array}{l}\text { I. Threatened to hit or } \\
\text { throw something at } \\
\text { him/her/you................ }\end{array}$ & $\begin{array}{lllllll}1 & 2 & 3 & 4 & 5 & 6 & 0\end{array}$ & $\begin{array}{lllllll}1 & 2 & 3 & 4 & 5 & 6 & 0\end{array}$ & 10 \\
\hline $\begin{array}{l}\text { J. Threw or smashed or } \\
\text { hit or kicked something... }\end{array}$ & $\begin{array}{lllllll}1 & 2 & 3 & 4 & 5 & 6 & 0 \\
\end{array}$ & $\begin{array}{lllllll}1 & 2 & 3 & 4 & 5 & 6 & 0 \\
\end{array}$ & 10 \\
\hline $\begin{array}{l}\text { K. Threw something at } \\
\text { him/her/you................. }\end{array}$ & $\begin{array}{lllllll}1 & 2 & 3 & 4 & 5 & 6 & 0 \\
\end{array}$ & $\begin{array}{lllllll}1 & 2 & 3 & 4 & 5 & 6 & 0 \\
\end{array}$ & 10 \\
\hline $\begin{array}{l}\text { L. Pushed, grabbed, or } \\
\text { shoved him/her/you........ }\end{array}$ & $\begin{array}{lllllll}1 & 2 & 3 & 4 & 5 & 6 & 0\end{array}$ & $\begin{array}{lllllll}1 & 2 & 3 & 4 & 5 & 6 & 0\end{array}$ & 10 \\
\hline M. Slapped him/her/you... & $\begin{array}{lllllll}1 & 2 & 3 & 4 & 5 & 6 & 0 \\
\end{array}$ & $\begin{array}{lllllll}1 & 2 & 3 & 4 & 5 & 6 & 0 \\
\end{array}$ & \\
\hline
\end{tabular}




\begin{tabular}{|c|c|c|c|}
\hline & $\begin{array}{l}\text { Q11. YOU in } \\
\text { Past Year } \\
\text { 1-Once } \\
\text { 2-Twice } \\
\text { 3-3-5 Times } \\
\text { 4-6-10 Times } \\
\text { 5-11-20 Times } \\
\text { 6-More than 20 } \\
\text { 0-Never }\end{array}$ & $\begin{array}{l}\text { Q12. PARTNER } \\
\text { in Past Year } \\
\text { 1-Once } \\
\text { 2-Twice } \\
\text { 3-3-5 Times } \\
\text { 4-6-10 Times } \\
\text { 5-11-20 Times } \\
\text { 6-More than 20 } \\
\text { 0-Never }\end{array}$ & $\begin{array}{l}\text { Q13. For } \\
\text { items } \\
\frac{\text { marked }}{\text { never in }} \\
\text { columns: } \\
\text { Has it ever } \\
\text { happened? } \\
\text { 1-Yes } \\
\text { 0-No }\end{array}$ \\
\hline $\begin{array}{l}\text { N. Kicked, bit, or hit him/ } \\
\text { her/you..................... }\end{array}$ & $\begin{array}{lllllll}1 & 2 & 3 & 4 & 5 & 6 & 0 \\
\end{array}$ & $\begin{array}{lllllll}1 & 2 & 3 & 4 & 5 & 6 & 0\end{array}$ & 10 \\
\hline $\begin{array}{l}\text { O. Hit or tried to hit } \\
\text { him/her/you with } \\
\text { something................ }\end{array}$ & $\begin{array}{lllllll}1 & 2 & 3 & 4 & 5 & 6 & 0\end{array}$ & $\begin{array}{lllllll}1 & 2 & 3 & 4 & 5 & 6 & 0\end{array}$ & 10 \\
\hline P. Beat him/her/you up... & $\begin{array}{lllllll}1 & 2 & 3 & 4 & 5 & 6 & 0 \\
\end{array}$ & $\begin{array}{lllllll}1 & 2 & 3 & 4 & 5 & 6 & 0 \\
\end{array}$ & 10 \\
\hline Q. Choked him/her/you... & $\begin{array}{lllllll}1 & 2 & 3 & 4 & 5 & 6 & 0\end{array}$ & $\begin{array}{lllllll}1 & 2 & 3 & 4 & 5 & 6 & 0\end{array}$ & 10 \\
\hline $\begin{array}{l}\text { R. Threatened him/her/ } \\
\text { you with a knife or gun }\end{array}$ & $\begin{array}{lllllll}1 & 2 & 3 & 4 & 5 & 6 & 0 \\
\end{array}$ & $\begin{array}{lllllll}1 & 2 & 3 & 4 & 5 & 6 & 0 \\
\end{array}$ & 10 \\
\hline $\begin{array}{l}\text { S. Used a knife or fired a } \\
\text { gun.......................... }\end{array}$ & $\begin{array}{lllllll}1 & 2 & 3 & 4 & 5 & 6 & 0\end{array}$ & $\begin{array}{lllllll}1 & 2 & 3 & 4 & 5 & 6 & 0\end{array}$ & \\
\hline
\end{tabular}

\section{Section 3}

Q14. If you answered indicating that you had employed any of the tactics listed in questions $11 \mathrm{~K}-11 \mathrm{~S}$, I would like to know what was your motivation, or reason, for engaging in these acts. If you did not, please skip to section 4 . Following will be a list of possible motivating factors. Please indicate, by placing a mark in the space provided, which one of the following is most like how you felt.

To show anger

Unable to express my feelings verbally

To feel powerful

In order to exert control over my partner

In retaliation for being hit first

To protect myself

In retaliation for being emotionally hurt

Anger that I took out on my partner

In order to punish my partner for doing something wrong

To show my partner that I loved them

Because it was sexually arousing to me

In order to get attention

Because I was jealous

Other 


\section{Section 4}

The following section regards the relationship that your parents had while you lived at home. Again, as with your interpersonal relationships, the relationship between parents is oftentimes stressful and will always have some conflicts regardless of how well the parents get along. Following, you will see the same questions which you just answered about yourself and your partner. However, this time, the questions will be asked with your mother (or mother-figure) and your father (or father-figure) in mind. If you currently live at home with your parents, answer the questions thinking back to the past year. If, however, you do not live at home, think back to the last year that you did live at home and answer the questions, as best you can, based on that year. Answer these questions about tactics that you saw your parents employ with each other, not with you or your siblings. For example, question 15 relates to how many times your mother acted in the listed ways towards your father, while question 16 relates to how many times your father acted in the listed ways towards your mother.

\begin{tabular}{|c|c|c|c|}
\hline & $\begin{array}{l}\text { Q15. Mother in } \\
\text { Past Year } \\
\text { 1-Once } \\
\text { 2-Twice } \\
\text { 3-3-5 Times } \\
\text { 4-6-10 Times } \\
\text { 5-11-20 Times } \\
\text { 6-More than } 20 \\
\text { 0-Never }\end{array}$ & $\begin{array}{l}\text { Q16. Father } \\
\text { in Past Year } \\
\text { 1-Once } \\
\text { 2-Twice } \\
\text { 3-3-5 Times } \\
\text { 4-6-10 Times } \\
\text { 5-11-20 Times } \\
\text { 6-More than } 20 \\
\text { 0-Never }\end{array}$ & 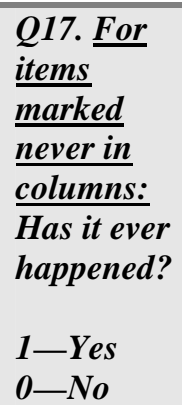 \\
\hline A. Discussed issue calmly & $\begin{array}{lllllll}1 & 2 & 3 & 4 & 5 & 6 & 0 \\
\end{array}$ & $\begin{array}{lllllll}1 & 2 & 3 & 4 & 5 & 6 & 0 \\
\end{array}$ & 10 \\
\hline $\begin{array}{l}\text { B. Got information to back } \\
\text { up his/her side of } \\
\text { things..................... }\end{array}$ & $\begin{array}{lllllll}1 & 2 & 3 & 4 & 5 & 6 & 0\end{array}$ & $\begin{array}{lllllll}1 & 2 & 3 & 4 & 5 & 6 & 0\end{array}$ & 10 \\
\hline $\begin{array}{l}\text { C. Brought in, or tried to } \\
\text { bring in, someone to help } \\
\text { settle things................. }\end{array}$ & $\begin{array}{lllllll}1 & 2 & 3 & 4 & 5 & 6 & 0\end{array}$ & $\begin{array}{lllllll}1 & 2 & 3 & 4 & 5 & 6 & 0\end{array}$ & 10 \\
\hline $\begin{array}{l}\text { D. Insulted or swore at } \\
\text { him/her...................... }\end{array}$ & $\begin{array}{lllllll}1 & 2 & 3 & 4 & 5 & 6 & 0 \\
\end{array}$ & $\begin{array}{lllllll}1 & 2 & 3 & 4 & 5 & 6 & 0 \\
\end{array}$ & 10 \\
\hline $\begin{array}{l}\text { E. Sulked or refused to talk } \\
\text { about an issue......... }\end{array}$ & $\begin{array}{lllllll}1 & 2 & 3 & 4 & 5 & 6 & 0 \\
\end{array}$ & $\begin{array}{lllllll}1 & 2 & 3 & 4 & 5 & 6 & 0 \\
\end{array}$ & 10 \\
\hline $\begin{array}{l}\text { F. Stomped out of the room } \\
\text { or house or yard..... }\end{array}$ & $\begin{array}{lllllll}1 & 2 & 3 & 4 & 5 & 6 & 0 \\
\end{array}$ & $\begin{array}{lllllll}1 & 2 & 3 & 4 & 5 & 6 & 0 \\
\end{array}$ & \\
\hline G. Cried...................... & $\begin{array}{lllllll}1 & 2 & 3 & 4 & 5 & 6 & 0 \\
\end{array}$ & $\begin{array}{lllllll}1 & 2 & 3 & 4 & 5 & 6 & 0 \\
\end{array}$ & 10 \\
\hline $\begin{array}{l}\text { H. Did or said something to } \\
\text { spite him/her............. }\end{array}$ & $\begin{array}{lllllll}1 & 2 & 3 & 4 & 5 & 6 & 0\end{array}$ & $\begin{array}{lllllll}1 & 2 & 3 & 4 & 5 & 6 & 0\end{array}$ & 10 \\
\hline $\begin{array}{l}\text { I. Threatened to hit or throw } \\
\text { something at } \\
\text { him/her..................... }\end{array}$ & $\begin{array}{lllllll}1 & 2 & 3 & 4 & 5 & 6 & 0\end{array}$ & $\begin{array}{lllllll}1 & 2 & 3 & 4 & 5 & 6 & 0\end{array}$ & 10 \\
\hline $\begin{array}{l}\text { J. Threw or smashed or hit } \\
\text { or kicked something... }\end{array}$ & $\begin{array}{lllllll}1 & 2 & 3 & 4 & 5 & 6 & 0 \\
\end{array}$ & $\begin{array}{lllllll}1 & 2 & 3 & 4 & 5 & 6 & 0 \\
\end{array}$ & 10 \\
\hline $\begin{array}{l}\text { K. Threw something at } \\
\text { him/her...................... }\end{array}$ & $\begin{array}{lllllll}1 & 2 & 3 & 4 & 5 & 6 & 0 \\
\end{array}$ & $\begin{array}{lllllll}1 & 2 & 3 & 4 & 5 & 6 & 0 \\
\end{array}$ & 10 \\
\hline $\begin{array}{l}\text { L. Pushed, grabbed, or } \\
\text { shoved him/her.............. }\end{array}$ & $\begin{array}{lllllll}1 & 2 & 3 & 4 & 5 & 6 & 0\end{array}$ & $\begin{array}{lllllll}1 & 2 & 3 & 4 & 5 & 6 & 0\end{array}$ & 10 \\
\hline M. Slapped him/her.......... & $\begin{array}{lllllll}1 & 2 & 3 & 4 & 5 & 6 & 0 \\
\end{array}$ & $\begin{array}{lllllll}1 & 2 & 3 & 4 & 5 & 6 & 0 \\
\end{array}$ & 10 \\
\hline $\begin{array}{l}\text { N. Kicked, bit, or hit } \\
\text { him/her........................ }\end{array}$ & $\begin{array}{lllllll} & 2 & 3 & 4 & 5 & 6 & 0 \\
\end{array}$ & $\begin{array}{lllllll}1 & 2 & 3 & 4 & 5 & 6 & 0 \\
\end{array}$ & 10 \\
\hline $\begin{array}{l}\text { O. Hit or tried to hit him/her } \\
\text { with } \\
\text { something................ }\end{array}$ & $\begin{array}{lllllll}1 & 2 & 3 & 4 & 5 & 6 & 0\end{array}$ & $\begin{array}{lllllll}1 & 2 & 3 & 4 & 5 & 6 & 0\end{array}$ & 10 \\
\hline P. Beat him/her up......... & $\begin{array}{lllllll}1 & 2 & 3 & 4 & 5 & 6 & 0 \\
\end{array}$ & $\begin{array}{lllllll}1 & 2 & 3 & 4 & 5 & 6 & 0 \\
\end{array}$ & $\begin{array}{ll}10 \\
\end{array}$ \\
\hline Q. Choked him/her......... & $\begin{array}{lllllll}1 & 2 & 3 & 4 & 5 & 6 & 0 \\
\end{array}$ & $\begin{array}{lllllll}1 & 2 & 3 & 4 & 5 & 6 & 0 \\
\end{array}$ & 10 \\
\hline
\end{tabular}




\begin{tabular}{|c|c|c|c|}
\hline & $\begin{array}{l}\text { Q15. Mother in } \\
\text { Past Year } \\
\text { 1- Once } \\
\text { 2-Twice } \\
\text { 3-3-5 Times } \\
\text { 4-6-10 Times } \\
\text { 5-11-20 Times } \\
\text { 6--More than 20 } \\
\text { 0-Never }\end{array}$ & $\begin{array}{l}\text { Q16. Father } \\
\text { in Past Year } \\
\text { 1- Once } \\
\text { 2-Twice } \\
\text { 3-3-5 Times } \\
\text { 4-6-10 Times } \\
\text { 5-11-20 Times } \\
\text { 6--More than 20 } \\
\text { 0-Never }\end{array}$ & $\begin{array}{l}\text { Q17. For } \\
\text { items } \\
\text { marked } \\
\text { never in } \\
\text { columns: } \\
\text { Has it ever } \\
\text { happened? } \\
\text { 1-Yes } \\
\text { 0-No }\end{array}$ \\
\hline $\begin{array}{l}\text { R. Threatened him/her/ with } \\
\text { a knife or gun........... }\end{array}$ & $\begin{array}{lllllll}1 & 2 & 3 & 4 & 5 & 6 & 0\end{array}$ & $\begin{array}{lllllll}1 & 2 & 3 & 4 & 5 & 6 & 0\end{array}$ & 10 \\
\hline $\begin{array}{l}\text { S. Used a knife or fired a } \\
\text { gun.......................... }\end{array}$ & $\begin{array}{lllllll}1 & 2 & 3 & 4 & 5 & 6 & 0\end{array}$ & $\begin{array}{lllllll}1 & 2 & 3 & 4 & 5 & 6 & 0\end{array}$ & 10 \\
\hline
\end{tabular}

\section{Section 5}

The following section will be regarding your alcohol and drug use. Please answer these questions as honestly as possible. There is no way for your answers to traced back to you. Your answers will be kept confidential.

\begin{tabular}{|c|c|c|}
\hline $\begin{array}{l}\text { 18. Have you used any of the } \\
\text { following substances during the } \\
\text { past } 30 \text { days? }\end{array}$ & $\begin{array}{l}\square \text { Tobacco } \square \text { Marijuana } \quad \square \text { Heroin } \\
\square \text { Ketamine (Special K) } \square \text { GHB }\end{array}$ & $\begin{array}{l}\square \text { Alcohol } \\
\square \text { Ecstasy }\end{array}$ \\
\hline & $\square$ Cocaine $\quad \square$ Rohypnol (Roofies) & $\square$ Crystal Meth \\
\hline $\begin{array}{l}\text { 19. Have you used any of the } \\
\text { following substances during the } \\
\text { nast vear? }\end{array}$ & $\begin{array}{l}\square \text { Tobacco } \square \text { Marijuana } \square \text { Heroin } \\
\square \text { Ketamine (Special K) } \square \text { GHB }\end{array}$ & $\square$ Alcohol \\
\hline & $\square$ Rohypnol (Roofies) & $\square$ Crystal Meth \\
\hline
\end{tabular}

If you checked any of the boxes in the previous two questions (with the exception of tobacco), please answer questions 20-34 indicating how strongly you agree or disagree with each statement using the following scale.

\begin{tabular}{|c|c|c|c|c|c|c|c|c|}
\hline 1=Strongly Agree & 2=Agree & $3=$ Neutral & 4=Disagree & \multicolumn{5}{|c|}{ 5=Strongly Disagree } \\
\hline \multicolumn{4}{|c|}{ 20. I am unhappy because of my drinking or drug use. } & 1 & 2 & 3 & 4 & 5 \\
\hline \multicolumn{4}{|c|}{ 21. I have lost weight or not eaten properly because of my drinking or drug use. } & 1 & 2 & 3 & 4 & 5 \\
\hline \multicolumn{4}{|c|}{ 22. I failed to do what was expected of me because of my drinking or drug use. } & 1 & 2 & 3 & 4 & 5 \\
\hline \multicolumn{4}{|c|}{ 23. When drinking or using drugs, my personality changes for the worse. } & 1 & 2 & 3 & 4 & 5 \\
\hline \multicolumn{4}{|c|}{ 24. I have taken foolish risks when drinking or using drugs. } & 1 & 2 & 3 & 4 & 5 \\
\hline \multicolumn{4}{|c|}{ 25. While drinking or using drugs, I said harsh or cruel things to someone. } & 1 & 2 & 3 & 4 & 5 \\
\hline \multicolumn{4}{|c|}{ 26. When drinking or using drugs, I did impulsive things I regretted. } & 1 & 2 & 3 & 4 & 5 \\
\hline
\end{tabular}


27. I have experienced money problems because of drinking or using drugs.

$\begin{array}{lllll}1 & 2 & 3 & 4 & 5\end{array}$

28. My physical appearance has been harmed by my drinking or drug use.

$\begin{array}{lllll}1 & 2 & 3 & 4 & 5\end{array}$

29. My family has been hurt by my drinking or drug use.

$\begin{array}{lllll}1 & 2 & 3 & 4 & 5\end{array}$

30. My friendships have been damaged by my drinking or drug use.

$\begin{array}{lllll}1 & 2 & 3 & 4 & 5\end{array}$

31. I have lost interest in activities because of my drinking or drug use.

$\begin{array}{lllll}1 & 2 & 3 & 4 & 5\end{array}$

32. Drinking or drug use has gotten in the way of my personal growth.

$\begin{array}{lllll}1 & 2 & 3 & 4 & 5\end{array}$

33. Drinking or drug use has damaged my social life, popularity, or reputation.

$\begin{array}{lllll}1 & 2 & 3 & 4 & 5\end{array}$

34. I have spent too much money or lost money because of drinking or drug use.

$\begin{array}{lllll}1 & 2 & 3 & 4 & 5\end{array}$

\begin{tabular}{|l|l|}
\hline 35. Do you drink alcohol? & $\square$ Yes $\square$ No (skip to end of section) \\
\hline $\begin{array}{l}\text { 36. How often, on average, do you drink } \\
\text { alcohol? }\end{array}$ & $\square$ Less than once a month $\square$ Once a month \\
& $\begin{array}{l}\square_{2-3} \text { times a month } \square_{\text {Once a week }} \square_{\text {2-3 times a week }} \\
\square_{\text {or more times a week }}\end{array}$ \\
\hline $\begin{array}{l}\text { 37. When you drink, what do you usually } \\
\text { drink? }\end{array}$ & $\square$ Beer $\square$ Wine $\square$ Mixed drinks $\square$ Straight liquor \\
\hline $\begin{array}{l}\text { 38. When you drink, how many drinks do } \\
\text { you typically consume per episode: }\end{array}$ & \\
\hline
\end{tabular}

\section{Section 6}

Please answer the following questions using the scale provided.

\begin{tabular}{|c|c|c|c|c|c|c|}
\hline $1=$ Strongly Agree & $2=$ Agree & \multicolumn{2}{|c|}{$3=$ Disagree } & \multicolumn{3}{|c|}{ 4=Strongly Disagree } \\
\hline \multicolumn{3}{|c|}{ 39. On the whole, I am satisfied with myself. } & 1 & 2 & 3 & 4 \\
\hline \multicolumn{3}{|c|}{ 40. At times, I think I am no good at all. } & 1 & 2 & 3 & 4 \\
\hline \multicolumn{3}{|c|}{ 41. I feel that I have a number of good qualities. } & 1 & 2 & 3 & 4 \\
\hline \multicolumn{3}{|c|}{ 42. I am able to do things as well as most other people. } & 1 & 2 & 3 & 4 \\
\hline \multicolumn{3}{|c|}{ 43. I feel I do not have much to be proud of. } & 1 & 2 & 3 & 4 \\
\hline \multicolumn{3}{|c|}{ 44. I certainly feel useless at times. } & 1 & 2 & 3 & 4 \\
\hline \multicolumn{3}{|c|}{$\begin{array}{l}\text { 45. I feel that I am a person of worth, at least on an equal } \\
\text { plane with others. }\end{array}$} & 1 & 2 & 3 & 4 \\
\hline \multicolumn{3}{|c|}{ 46. I wish that I could have more respect for myself. } & 1 & 2 & 3 & 4 \\
\hline \multicolumn{3}{|c|}{ 47. All in all, I am inclined to feel that I am a failure. } & 1 & 2 & 3 & 4 \\
\hline \multicolumn{3}{|c|}{ 48. I take a positive attitude toward myself. } & 1 & 2 & 3 & 4 \\
\hline
\end{tabular}




\begin{tabular}{|l|lllc|}
\hline 49. I expect a great deal from other people & 1 & 2 & 3 & 4 \\
\hline 50. I am envious of other people's good fortune. & 1 & 2 & 3 & 4 \\
\hline 51. I insist upon getting the respect that is due to me. & 1 & 2 & 3 & 4 \\
\hline 52. I will never be satisfied until I get all that I deserve. & 1 & 2 & 3 & 4 \\
\hline 53. I have a strong will to power. & 1 & 2 & 3 & 4 \\
\hline $\begin{array}{l}\text { 54. I get upset when people don't notice how I look when I go } \\
\text { out in public. }\end{array}$ & 1 & 2 & 3 & 4 \\
\hline 55. I find it easy to manipulate people & 1 & 2 & 3 & 4 \\
\hline 56. I am more capable than other people. & 1 & 2 & 3 & 4 \\
\hline
\end{tabular}

If you are a male, I would like to thank you very much for your participation. The survey for you ends at this point. If, however, you are a female, there is one additional section that I would like to ask you to complete. Please continue to section 7.

\section{Section 7}

Following is a list of things that you may do or have done when aggravated by or in a disagreement with female acquaintances (not a lover). Please circle a number which best corresponds with how you typically respond.

\begin{tabular}{|l|l|l|l|l|}
\hline 1=Always & $2=$ Most of the time & $3=$ Sometimes & $4=$ Rarely & $5=$ Never \\
\hline
\end{tabular}

\begin{tabular}{|l|lllll|}
\hline 57. I tried to resolve the conflict through a calm discussion & 1 & 2 & 3 & 4 & 5 \\
\hline 58. I reiterated my position and stuck to it & 1 & 2 & 3 & 4 & 5 \\
\hline 59. I gave the person an option, it is my way or no way & 1 & 2 & 3 & 4 & 5 \\
\hline 60. I discussed the issue calmly & 1 & 2 & 3 & 4 & 5 \\
\hline 61. Brought in documents and other information to support my position & 1 & 2 & 3 & 4 & 5 \\
\hline 62. Brought in someone else to aid in a peaceful resolution & 1 & 2 & 3 & 4 & 5 \\
\hline 63. Brought in someone else whom I knew would support my position & 1 & 2 & 3 & 4 & 5 \\
\hline $\begin{array}{l}\text { 64. Let the person know I had more seniority and therefore my decision was } \\
\text { final }\end{array}$ & & & & & \\
\hline 65. Argued heatedly but without yelling & 1 & 2 & 3 & 4 & 5 \\
\hline 66. Yelled and called the individual names & 1 & 2 & 3 & 4 & 5 \\
\hline 67. Pushed or shoved the individual & 1 & 2 & 3 & 4 & 5 \\
\hline 68. Threatened the individual with violence & 1 & 2 & 3 & 4 & 5 \\
\hline 69. Smacked or slapped the individual & 1 & 2 & 3 & 4 & 5 \\
\hline 70. Hit or tried to hit her & 1 & 2 & 3 & 4 & 5 \\
\hline
\end{tabular}




\begin{tabular}{|l|lllll|}
\hline 71. Threatened to ostracize or cause her to be isolated by her peers & 1 & 2 & 3 & 4 & 5 \\
\hline 72. Hit or tried to hit her with something hard & 1 & 2 & 3 & 4 & 5 \\
\hline
\end{tabular}

73. Over the past year, have you ever:

\begin{tabular}{|l|c|}
\hline A. Slapped or hit another woman of your age group & Yes No \\
\hline B. Verbally attacked another female & Yes No \\
\hline C. Had a female younger than you or in a lower position do long or hard calisthenics & Yes No \\
\hline D. Beat up another female younger than you or in a lower subordinate position & Yes No \\
\hline $\begin{array}{l}\text { E. Encouraged another female to beat up or hit a younger female or one in a subordinate } \\
\text { position }\end{array}$ & Yes No \\
\hline F. Used a knife or fired a gun & Yes No \\
\hline G. Intimidated another female to surrender her property to you or another person & Yes No \\
\hline H. Intimidated another female to do something she did not want to do & Yes No \\
\hline I. Verbally assaulted another female because she did not follow your directions & Yes No \\
\hline
\end{tabular}

74. Are there situations in which you can imagine you would approve of one female using violent behavior against another female?
$\square$ Yes
$\square$ No
Not Sure

75. If you indicated yes to the previous question, please indicate how you feel about the appropriateness of violent behavior in each of the following situations using the scale:

\begin{tabular}{|l|l|l|l|l|}
\hline 1=Strongly Agree & 2=Agree & 3=Neutral & 4=Disagree & 5=Strongly Disagree \\
\hline
\end{tabular}

\begin{tabular}{|c|c|}
\hline A. I was provoked by the other female & $\begin{array}{lllll}1 & 2 & 3 & 4 & 5\end{array}$ \\
\hline B. I was physically attacked by the other female & $\begin{array}{lllll}1 & 2 & 3 & 4 & 5\end{array}$ \\
\hline C. I was threatened by the other female & $\begin{array}{lllll}1 & 2 & 3 & 4 & 5\end{array}$ \\
\hline D. The other female wanted to be a member of the organization I was in & $\begin{array}{lllll}1 & 2 & 3 & 4 & 5\end{array}$ \\
\hline E. The female needed a wake up call; she was too timid & $\begin{array}{lllll}1 & 2 & 3 & 4 & 5\end{array}$ \\
\hline F. It was part of tradition & $\begin{array}{lllll}1 & 2 & 3 & 4 & 5\end{array}$ \\
\hline
\end{tabular}


VITA

JESSICA LYNNE HOLT

Personal Information

Date of Birth: May 4, 1976

Place of Birth: Morristown, Tennessee

Marital Status: Single

Educational Information

Public Schools, Morristown, Tennessee

East Tennessee State University, Johnson City, TN

B.S. Criminal Justice/Psychology May 2003

East Tennessee State University, Johnson City, TN

M.A. Criminal Justice/Criminology May 2005

Experience

Graduate Assistant

Department of Criminal Justice/Criminology, 2003-2005

Research Projects

"Growing Trends of Violence among Female College Students"

Paper presented at ASC conference in Nashville, TN, Nov. 2004;

Co-authored with Dr. Marian Whitson

"Gender Differences in Self-Esteem and Intimate Violence"

Paper in progress; Co-authored with Dr. Wayne Gillespie

Academic Awards/Recognition

Dean's List 